\title{
School-based education programmes for the prevention of unintentional injuries in children and young people (Review)
}

Orton E, Whitehead J, Mhizha-Murira J, Clarkson M, Watson MC, Mulvaney CA, Staniforth JUL, Bhuchar M, Kendrick D

Orton E, Whitehead J, Mhizha-Murira J, Clarkson M, Watson MC, Mulvaney CA, Staniforth JUL, Bhuchar M, Kendrick D. School-based education programmes for the prevention of unintentional injuries in children and young people. Cochrane Database of Systematic Reviews 2016, Issue 12. Art. No.: CD010246. DOI: 10.1002/14651858.CD010246.pub2.

www.cochranelibrary.com 
TABLE OF CONTENTS

ABSTRACT 1

PLAIN LANGUAGE SUMMARY

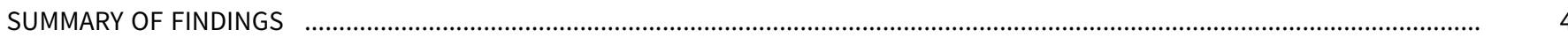

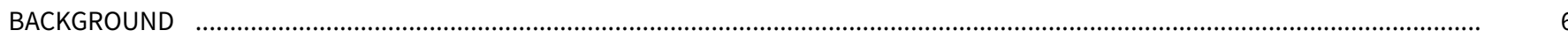

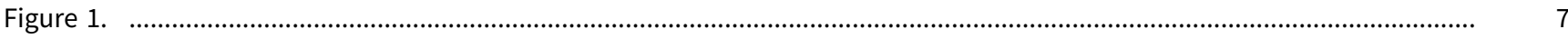

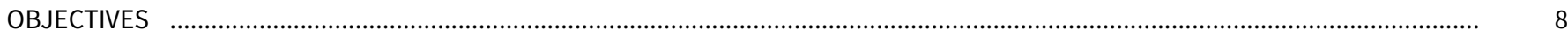

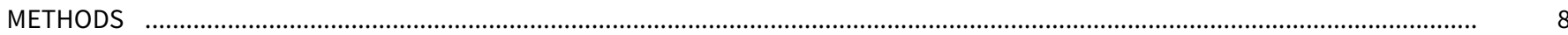

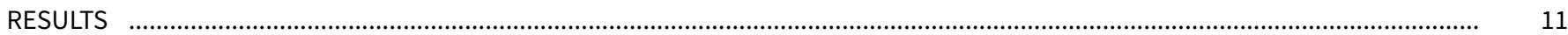

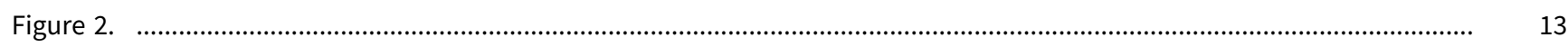

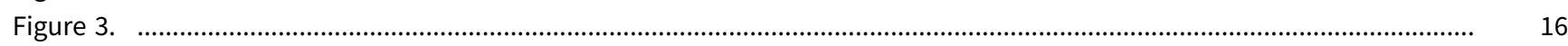

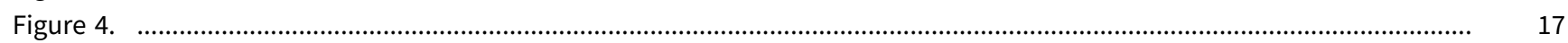

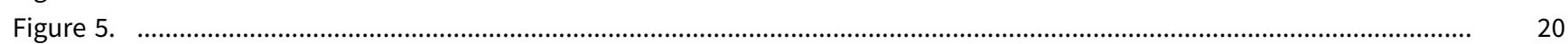

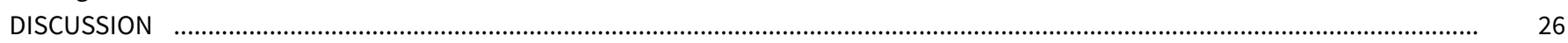

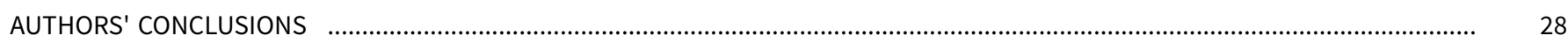

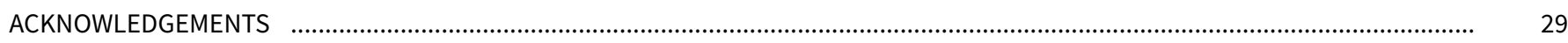

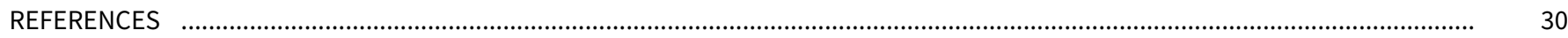

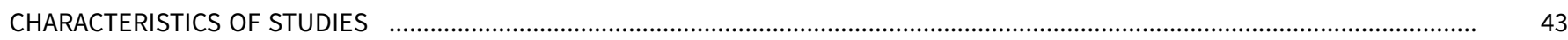

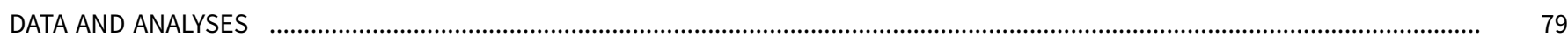

Analysis 1.1. Comparison 1 Medically attended or non-medically attended injury rates, Outcome 1 Injury rates at follow-up, 80 adjusted for baseline injury rates in non-randomised studies.

ADDITIONAL TABLES

APPENDICES

HISTORY

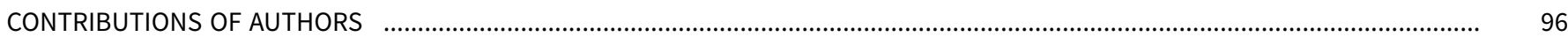

DECLARATIONS OF INTEREST

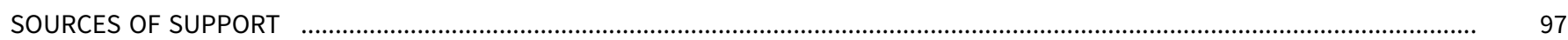

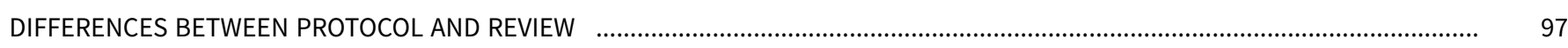

INDEX TERMS 
[Intervention Review]

\section{School-based education programmes for the prevention of unintentional injuries in children and young people}

Elizabeth Orton ${ }^{1}$, Jessica Whitehead ${ }^{1}$, Jacqueline Mhizha-Murira1 ${ }^{1}$, Mandy Clarkson ${ }^{1}$, Michael C Watson², Caroline A Mulvaney 3,4 , Joy UL Staniforth ${ }^{1}$, Munish Bhuchar ${ }^{1}$, Denise Kendrick ${ }^{5}$

1Division of Primary Care, University of Nottingham, Nottingham, UK. ${ }^{2}$ School of Health Sciences, The University of Nottingham, Nottingham, UK. ${ }^{3}$ Lancaster Health Hub, Lancaster University, Lancaster, UK. ${ }^{4}$ Faculty of Medicine \& Health Sciences, University of Nottingham, Nottingham, UK. ${ }^{5}$ Division of Primary Care, School of Medicine, The University of Nottingham, Nottingham, UK

Contact: Elizabeth Orton, Division of Primary Care, University of Nottingham, Room 1313, Tower Building, University Park, Nottingham, NG7 2RD, UK. elizabeth.orton@nottingham.ac.uk.

Editorial group: Cochrane Injuries Group.

Publication status and date: Edited (no change to conclusions), published in Issue 7, 2017.

Citation: Orton E, Whitehead J, Mhizha-Murira J, Clarkson M, Watson MC, Mulvaney CA, Staniforth JUL, Bhuchar M, Kendrick D. School-based education programmes for the prevention of unintentional injuries in children and young people. Cochrane Database of Systematic Reviews 2016, Issue 12. Art. No.: CD010246. DOI: 10.1002/14651858.CD010246.pub2.

Copyright ( 2017 The Cochrane Collaboration. Published by John Wiley \& Sons, Ltd.

\section{A B S T R A C T}

\section{Background}

Unintentional injuries are the leading cause of death in children aged four to 18 years and are a major cause of ill health. The school setting offers the opportunity to deliver preventive interventions to a large number of children and has been used to address a range of public health problems. However, the effectiveness of the school setting for the prevention of different injury mechanisms in school-aged children is not well understood.

\section{Objectives}

To assess the effects of school-based educational programmes for the prevention of injuries in children and evaluate their impact on improving children's safety skills, behaviour and practices, and knowledge, and assess their cost-effectiveness.

\section{Search methods}

We ran searches on the following electronic databases to 26 June 2015: PsycINFO, British Education Index (BEI), Education Resources Information Center (ERIC), Applied Social Sciences Index and Abstracts (ASSIA), International Bibliography of the Social Sciences (IBSS), Sociological Abstracts; Latin America and the Caribbean database (LILACS), together with several sources of grey literature. The Cochrane Injuries Information Specialist ran searches, to August 2013, on the Groups Specialised Register (SR-INJ), the Cochrane Central Register of Controlled Trials (CENTRAL) and other Cochrane Library databases, Ovid MEDLINE, Embase, CINAHL and the ISI Web of Science. In keeping with Cochrane standards, along with Cochrane Injuries' Information Specialist we ran an update search prior to publication (September and October 2016). We have screened the results and placed any relevant studies in the Characteristics of studies awaiting classification section of this review.These will be incorporated in the next version of this review, as appropriate.

\section{Selection criteria}

We included randomised controlled trials (RCTs), non-randomised controlled trials (non-RCTs), and controlled before-and-after (CBA) studies that evaluated school-based educational programmes aimed at preventing a range of injury mechanisms. The primary outcome was self-reported or medically attended unintentional (or unspecified intent) injuries and secondary outcomes were observed safety skills, observed behaviour, self-reported behaviour and safety practices, safety knowledge, and health economic outcomes. The control groups received no intervention, a delayed injury-prevention intervention or alternative school-based curricular activities. We included studies 
that aimed interventions at primary or secondary prevention of injuries from more than one injury mechanism and were delivered, in part or in full, in schools catering for children aged four to 18 years.

\section{Data collection and analysis}

We used standard methodological procedures expected by Cochrane. Two review authors identified relevant trials from title and abstracts of studies identified in searches and two review authors extracted data from the included studies and assessed risk of bias. We grouped different types of interventions according to the outcome assessed and the injury mechanism targeted. Where data permitted, we performed random-effects meta-analyses to provide a summary of results across studies.

\section{Main results}

The review included 27 studies reported in 30 articles. The studies had 73,557 participants with 12 studies from the US; four from China; two from each of Australia, Canada, the Netherlands and the UK; and one from each of Israel, Greece and Brazil. Thirteen studies were RCTs, six were non-RCTs and eight were CBAs. Of the included studies, 18 provided some element of the intervention in children aged four to 11 years, 17 studies included children aged 11 to 14 years and nine studies included children aged 14 to 18 years.

The overall quality of the results was poor, with the all studies assessed as being at high or unclear risks of bias across multiple domains, and varied interventions and data collection methods employed. Interventions comprised information-giving, peer education or were multi-component.

Seven studies reported the primary outcome of injury occurrence and only three of these were similar enough to combine in a metaanalysis, with a pooled incidence rate ratio of 0.73 (95\% confidence interval $(\mathrm{Cl}) 0.49$ to 1.08; 2073 children) and substantial statistical heterogeneity $(12=63 \%)$. However, this body of evidence was low certainty, due to concerns over this heterogeneity (inconsistency) and imprecision. This heterogeneity may be explained by the non-RCT study design of one of the studies, as a sensitivity analysis with this study removed found stronger evidence of an effect and no heterogeneity $(12=0 \%)$.

Two studies report an improvement in safety skills in the intervention group. Likewise, the four studies measuring observed safety behaviour reported an improvement in the intervention group relative to the control. Thirteen out of 19 studies describing self-reported behaviour and safety practices showed improvements, and of the 21 studies assessing changes in safety knowledge, 19 reported an improvement in at least one question domain in the intervention compared to the control group. However, we were unable to pool data for our secondary outcomes, so our conclusions were limited, as they were drawn from highly diverse single studies and the body of evidence was low (safety skills) or very low (behaviour, safety knowledge) certainty. Only one study reported intervention costs but did not undertake a full economic evaluation (very low certainty evidence).

\section{Authors' conclusions}

There is insufficient evidence to determine whether school-based educational programmes can prevent unintentional injuries. More highquality studies are needed to evaluate the impact of educational programmes on injury occurrence. There is some weak evidence that such programmes improve safety skills, behaviour/practices and knowledge, although the evidence was of low or very low quality certainty. We found insufficient economic studies to assess cost-effectiveness.

\section{PLAIN LANGUAGE SUMMARY}

\section{School-based education programmes for the prevention of unintentional injuries in children and young people}

\section{About the review question}

We looked at the evidence on the effects of programmes in schools that aimed to prevent accidental injuries in children and young people. Preventing injuries in children is important because injuries are common in this age group and the effects on the child and the family can be severe and long-lasting. Schools are potentially a good setting within which to provide education programmes aimed at preventing such injuries occurring. However, it has not been examined in detail whether this works or not. We found 27 studies to help us address this question.

\section{Background}

We wanted to discover whether teaching children in school education about injury prevention resulted in them having fewer injuries, improved their knowledge about injury prevention and improved their behaviours in relation to safety. We also wanted to assess whether this type of approach was good value for money.

\section{Study characteristics}

The evidence is current to June 2015. It includes the results from 27 studies of 73,557 children. It included boys and girls aged four to 18 . The studies compared injury prevention education with either the usual curriculum or an alternative programme unrelated to injuries. The studies we included were aimed at preventing a range of injuries. We excluded programmes that focused on just one cause of injury. The 
review measured the effects of the educational programmes on the occurrence of injuries in children, their safety skills, behaviour and knowledge. The review also looked at whether school-based approaches are good value for money.

\section{Key results}

Only a few studies reported the effect on injury occurrence in children and so these effects were inconclusive. This does not mean that school-based programmes are ineffective but rather that more evidence is needed. The review did find evidence that school-based injury prevention education programmes can improve children's safety skills, safety behaviours and safety knowledge. However, the evidence was inconsistent, with some studies showing a positive effect and others showing no effect. Only one study reported on how cost-effective school-based programmes were and so again it is difficult to draw conclusions from this evidence alone.

\section{Quality of the evidence}

The studies were generally of poor quality for all the measurements of effectiveness of the programmes but particularly for behaviour and knowledge. This is because information about how the study was conducted was not usually reported very clearly in the study reports or there were major flaws in the way that the studies were undertaken. More research is needed that is of higher quality. 
SUMMARY OF FINDINGS

Summary of findings for the main comparison. School injury prevention programmes compared to controls for the prevention of unintentional injuries in children and young people

School injury prevention programmes compared to controls for the prevention of unintentional injuries in children and young people

Patient or population: children and young people

Setting: schools

Intervention: school injury prevention programmes aimed at preventing multiple injury mechanisms

Comparison: control

\begin{tabular}{|c|c|c|c|c|c|c|}
\hline \multirow[t]{2}{*}{ Outcomes } & \multicolumn{2}{|c|}{ Anticipated absolute effects ${ }^{\star}(95 \% \mathrm{Cl})$} & \multirow{2}{*}{$\begin{array}{l}\text { Relative effect } \\
(95 \% \mathrm{CI})\end{array}$} & \multirow{2}{*}{$\begin{array}{l}\text { No of partici- } \\
\text { pants } \\
\text { (studies) }\end{array}$} & \multirow{2}{*}{$\begin{array}{l}\text { Quality of the } \\
\text { evidence } \\
\text { (GRADE) }\end{array}$} & \multirow[t]{2}{*}{ Comments } \\
\hline & $\begin{array}{l}\text { Injury rate, adjust- } \\
\text { ed for clustering, } \\
\text { with control }\end{array}$ & $\begin{array}{l}\text { Injury rate, adjusted } \\
\text { for clustering, with } \\
\text { School injury preven- } \\
\text { tion programmes }\end{array}$ & & & & \\
\hline $\begin{array}{l}\text { Self-reported medically or non- } \\
\text { medically attended uninten- } \\
\text { tional injuries or injuries with } \\
\text { an unspecified intent (injury } \\
\text { rates adjusted for clustering) } \\
\text { assessed with: self-report } \\
\text { follow-up: range } 12 \text { months to } \\
24 \text { months }\end{array}$ & $\begin{array}{l}367 \text { per } 1000 \text { per- } \\
\text { son-years }\end{array}$ & $\begin{array}{l}243 \text { per } 1000 \text { per- } \\
\text { son-years }\end{array}$ & $\begin{array}{l}\text { Rate ratio } 0.76 \\
(0.49 \text { to } 1.17)\end{array}$ & $\begin{array}{l}12,977 \\
\text { (2073 per- } \\
\text { son-years ad- } \\
\text { justed for clus- } \\
\text { tering) } \\
\text { (2 RCTs, } 1 \text { CBA) }\end{array}$ & $\begin{array}{l}\oplus \oplus \ominus \ominus \\
\text { Low } 1\end{array}$ & $\begin{array}{l}\text { We excluded } 4 \text { studies } \\
\text { from the meta-analysis } \\
\text { due to varied interven- } \\
\text { tions (e.g. sports, agricul- } \\
\text { ture or risk-taking injury } \\
\text { prevention). Their findings } \\
\text { were consistent with the } \\
\text { meta-analysis studies. }\end{array}$ \\
\hline $\begin{array}{l}\text { Safety skills } \\
\text { assessed with: observations } \\
\text { follow-up: range } 4 \text { months to } 5 \\
\text { months }\end{array}$ & \multicolumn{2}{|c|}{$\begin{array}{l}\text { Both studies found an improvement in observed } \\
\text { safety skills (Kendrick } 2007 \text { - fire and burn pre- } \\
\text { vention skills: odds ratio } 8.93 \text { ( } 95 \% \mathrm{Cl} 1.67 \text { to } \\
47.78, \mathrm{P}=0.01 \text { ); Frederick } 2000 \text { - basic life sup- } \\
\text { port skills, } \mathrm{P}<0.005 \text { for assessment of danger, re- } \\
\text { sponsiveness and circulation). }\end{array}$} & - & $\begin{array}{l}1751 \\
(1 \mathrm{RCT}, 1 \mathrm{CBA})\end{array}$ & $\begin{array}{l}\oplus \oplus \ominus \ominus \\
\text { Low } 2\end{array}$ & $\begin{array}{l}\text { Interventions and safety } \\
\text { skills observed were var- } \\
\text { ied in these } 2 \text { studies. }\end{array}$ \\
\hline $\begin{array}{l}\text { Behaviour } \\
\text { assessed with: observations } \\
\text { and self-reported } \\
\text { follow-up: range } 2 \text { weeks to } 36 \\
\text { months }\end{array}$ & \multicolumn{2}{|c|}{$\begin{array}{l}\text { All } 4 \text { studies ( } 5 \text { articles) reported that observed } \\
\text { safety behaviour showed evidence of improved } \\
\text { practices and } 13 / 19 \text { studies describing self-re- } \\
\text { ported behaviour reported improved practices. }\end{array}$} & - & $\begin{array}{l}52,950 \\
(9 \text { RCTs, } 4 \text { non- } \\
\text { RCTs, } 6 \text { CBA) }\end{array}$ & $\begin{array}{l}\oplus \ominus \ominus \odot \\
\text { Very low } 3\end{array}$ & $\begin{array}{l}\text { Behaviours included } \\
\text { safety equipment wear- } \\
\text { ing, road risk-taking be- } \\
\text { haviour, agriculture and } \\
\text { sports-related injury be- } \\
\text { haviours. }\end{array}$ \\
\hline $\begin{array}{l}\text { Safety knowledge } \\
\text { assessed with: surveys and }\end{array}$ & \multicolumn{2}{|c|}{$\begin{array}{l}\text { Of the } 21 \text { studies assessing changes in safety } \\
\text { knowledge, } 19 \text { reported an improvement in at }\end{array}$} & - & 55,732 & $\begin{array}{l}\oplus \ominus \ominus \ominus \\
\text { Very low } 4\end{array}$ & $\begin{array}{l}\text { Outcomes included a wide } \\
\text { range of knowledge test- }\end{array}$ \\
\hline
\end{tabular}

self-completion tests

knowledge, 19 reported an improvement in at

$\oplus \odot \Theta \odot$
Very low

range of knowledge test- 


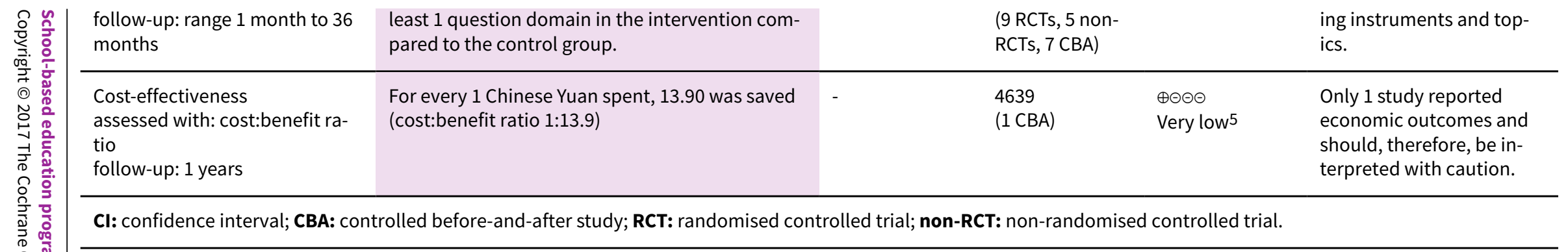

\section{GRADE Working Group grades of evidence}

High quality: We are very confident that the true effect lies close to that of the estimate of the effect

Moderate quality: We are moderately confident in the effect estimate: The true effect is likely to be close to the estimate of the effect, but there is a possibility that it is substantially different

Low quality: Our confidence in the effect estimate is limited: The true effect may be substantially different from the estimate of the effect

Very low quality: We have very little confidence in the effect estimate: The true effect is likely to be substantially different from the estimate of effect

1 Downgraded twice because of inconsistency as the $\mathrm{I}^{2}=63 \%$, indicating substantial heterogeneity and because there was imprecision in the results (the rate ratio was 0.76 but the confidence intervals spanned 1). Two of the studies were RCTs with a low risk of bias.

2 Downgraded twice because of a serious risk of bias (one of the two studies was a CBA resulting in selection biases relating to which schools participated in studies) and inconsistency, which was rated as serious because the two studies had different intervention types with different outcome measures. Imprecision was serious as there were wide confidence intervals in one of the two included studies, as well as a paucity of data. However, the effect sizes were classed as large as there was a nearly nine times greater odds of fire and burn prevention skills in the Risk Watch programme (Kendrick 2007), and 33\% greater skills assessment in the Injury Minimisation Programme for Schools (IMPS) relating to assessment of danger (Frederick 2000).

3 Downgraded three times because 10 studies were CBA or non-RCT design with high risk of selection bias of included schools, there was serious inconsistency in methods of collecting data and intervention types, and this may have contributed to the wide range of effect sizes and directions seen (no effect or some effect), There was often wide confidence intervals in results presented.

4 Downgraded three times because 11 studies were CBA or non-RCT design with high risk of selection bias of included schools; there was serious inconsistency in knowledge tested, questionnaire designs and methods of collecting data, a wide range of intervention types and pedagogical approaches and this may have contributed to the wide range of effect sizes and directions seen (no effect or some effect). Results were presented in a way that often made precision difficult to compare.

5 Downgraded three times because this was one study, limited in applicability with high or unclear risk of bias across multiple domains. 


\section{B A C K G R O U N D}

\section{Description of the condition}

Unintentional injuries are the leading cause of death in children aged four to 18 years in the European region (Sethi 2008), and are a major cause of ill health. In 2013, injuries accounted for $13 \%$ of all disability-adjusted life years globally and $4.9 \%$ in the UK among children aged four to 14 years (Haagsma 2016). The financial costs associated with treating injuries in children are also significant. Injuries from road traffic crashes alone are estimated to cost between $0.3 \%$ and $5 \%$ of Gross National Product (ranging from USD72 million in Vietnam to USD358 million in the US (Jacobs 2008)). Therefore, understanding the clinical and cost-effectiveness of preventive interventions is an important issue.

The risk of harm from unintentional injuries varies by socioeconomic group, age, gender, culture and ethnicity, and location (Grossman 2000; Laflamme 2010; Mulvaney 2012). Childand family-related risk factors for injury in school-aged children include male sex (Cooper 2004; Laing 1999; Lalloo 2003); psychological, behavioural and risk-taking behaviour problems (Sindelar 2004; Wazana 1997); having a large number of siblings (Bijur 1988; Mytton 2009); and having a young mother (Ekeus 2004; Mytton 2009). Falls are consistently the most common mechanism of injury, but injury mechanisms change with age (Grossman 2000; Mytton 2009).

Injuries can be classified according to intent (i.e. intentional or unintentional), injury type (e.g. head injury, burn injury), mechanism (e.g. burns due to fire, hot liquid scald or chemicals), location (e.g. playground, home, road), activity (e.g. sports or occupational injury) and risk factors (e.g. age, sex, risk-taking behaviour). This review set out to explore interventions aimed at preventing a range of injury mechanisms, defined as two or more mechanisms aligned to International Classification of Disease codes (ICD10). We excluded studies of single injury mechanisms because there are already existing reviews on, for example, cycle helmet wearing (Owen 2011), and we did not want to duplicate these results. In addition, there are a range of schoolbased programmes provided in different countries that address preventing injuries from a range of mechanisms, such as Think First For Kids, Risk Watch, Injury Minimization Programme for Schools (IMPS), Skills for Preventing Injury in Youth (SPIY), Injury Prevention Through Physical Education (I-Play), Learn Not To Burn, Gearing Everyone to Act Health Each Day (Go AHEAD) and Agricultural Disability Awareness and Risk Education programme (AgDARE) etc. and there is a lack of systematic review evidence on how effective they are. Given that these programmes may be more complex and time and resource intensive than programmes aimed at preventing injuries from single injury mechanisms, it is important to review their effectiveness.

\section{Description of the intervention}

Schools provide a unique setting in which to deliver health improvement interventions (Poland 2000). They have been used to help reduce smoking (Thomas 2006) and violence (Mytton 2006) and increase positive behaviours such as cycle helmet wearing (Owen 2011). Community-based injury prevention interventions aimed at children and young people often include a school component (Klassen 2000; Towner 2002).
School-based programmes may include primary, secondary or tertiary injury prevention education. Primary prevention is aimed at preventing the situation in which the injury can occur, while secondary prevention aims to minimise the risk of injury should an event occur with the potential to cause injury. Examples of secondary prevention include implementing a fire evacuation plan in the event of a house fire or wearing a cycle helmet to minimise head trauma in the event of a collision. Tertiary prevention minimises the harm incurred from an injury that has happened, for example, through first aid treatment. This review focusses on primary and secondary prevention programmes aimed at preventing a range of unintentional injury mechanisms. Therefore, we excluded studies evaluating programmes aimed at preventing single injury mechanisms. It includes interventions delivered in full or in part in a school as part of the curriculum, by a teacher or other people with an injury prevention role and both single component or multi-component interventions.

\section{How the intervention might work}

Behaviour change theory may help us understand how injury prevention interventions could work. Behaviours related to injury prevention include risk-taking behaviour (e.g. diving into water of unknown depth), adoption of safety practices (e.g. storage of medicines out of reach of children) and efforts to improve safety skills (e.g. safe cycling or road crossing), Glanz and Rimer described three levels of influence on injury prevention which may each lend themselves to different prevention approaches (Glanz 1997). The three levels are: intrapersonal level, whereby interventions may target self-efficacy, knowledge, skills and beliefs; interpersonal level, where prevention may target social/peer influences and norms and community level which may include interventions involving the environment or settings and policies (Glanz 1997). Theories of behaviour change that relate to the individual level (intrapersonal and interpersonal) that have been most widely applied to injury prevention include the health belief model (Janz 1984), the theory of reasoned action/planned behaviour (Fishbein 1975), the stages of change/trans-theoretic model (Prochaska 1983), and applied behavioural analysis (Hovell 1986). For injury prevention, the health belief model might relate to belief about susceptibility to injury occurrence, severity of injury outcomes and competence to intervene. The theory of reasoned action could be used to describe prevention activity in relation to the intention to undertake action and how this and consequences relate to subjective norms. The stages of change model described how people move through a dynamic process of pre-contemplation through to contemplation, action and maintenance and might, for example, inform strategies such as education to move people into contemplation and then skill development as people move into the action stage. Finally, applied behavioural theories describe how behaviours are learned and influenced by reinforcement activity, feedback and punishment.

However, no one theory of behaviour change underpins injury prevention and not all studies used theory-based interventions. Tobler provided a useful classification scheme for different types of school-based drug prevention programmes that might also be usefully applied to safety interventions (Tobler 1986). Components of this classification were: imparting knowledge about the topic; developing self-esteem, attitudes and beliefs; developing generic skills, for example, communication and assertiveness skills that then help to establish desirable behaviours; developing specific 
skills; diversionary activities, for example, organised sports; and finally, 'other' types of programmes, such as those that involve parents. School-based educational programmes aimed at preventing unintentional injuries may work in a similar way to those described by Tobler. For example, they may help to improve knowledge and awareness of high-risk activities, or help children choose play and leisure activities that are within their physical abilities and competence. In addition, such programmes may provide participants with the skills to identify and avoid highrisk situations or behaviours. Targeting children's attitudes and behaviour as a mechanism for changing family behaviour has also been used successfully, for example, in the use of motor vehicle restraints (Klassen 2000).

Injury prevention interventions, targeting the individual level factors, may be delivered using different learning approaches and theories. These may utilise different formats, such as during classes, via homework or correspondence with parents, or making use of larger-scale approaches such as campaigns. One systematic review by Bruce found successful school-based programmes to include group sessions with multiple interactive learning tools, for example, group activities and opportunities for the children to develop and practice problem-solving skills rather than contentspecific knowledge alone (Bruce 2005). There is also good evidence that whole-school approaches to health improvement are effective. In one Cochrane Review of the effectiveness of the World Health Organization's Health Promoting school framework for improving health and well-being of students, Langford found that schoolbased educational interventions can have a positive impact on improving some health outcomes such as body mass index, physical activity, fruit and vegetable intake, and likelihood of being bullied (Langford 2014). The framework includes activities relating to the school curriculum, ethos or environment of the school (or both), and engagement with families or communities (or both). Not all health outcomes were improved but the review was unable to determine whether certain components of the framework were more important than others due to the designs of the included studies. Although not specifically included in this review, injury prevention may work well in the context of a wholeschool approach to health and well-being.

To pull together the theory of how injury prevention education interventions might work and the outcomes we chose to review, we have developed a logic model as seen in Figure 1.

Figure 1. Logic model, based on Langford 2014

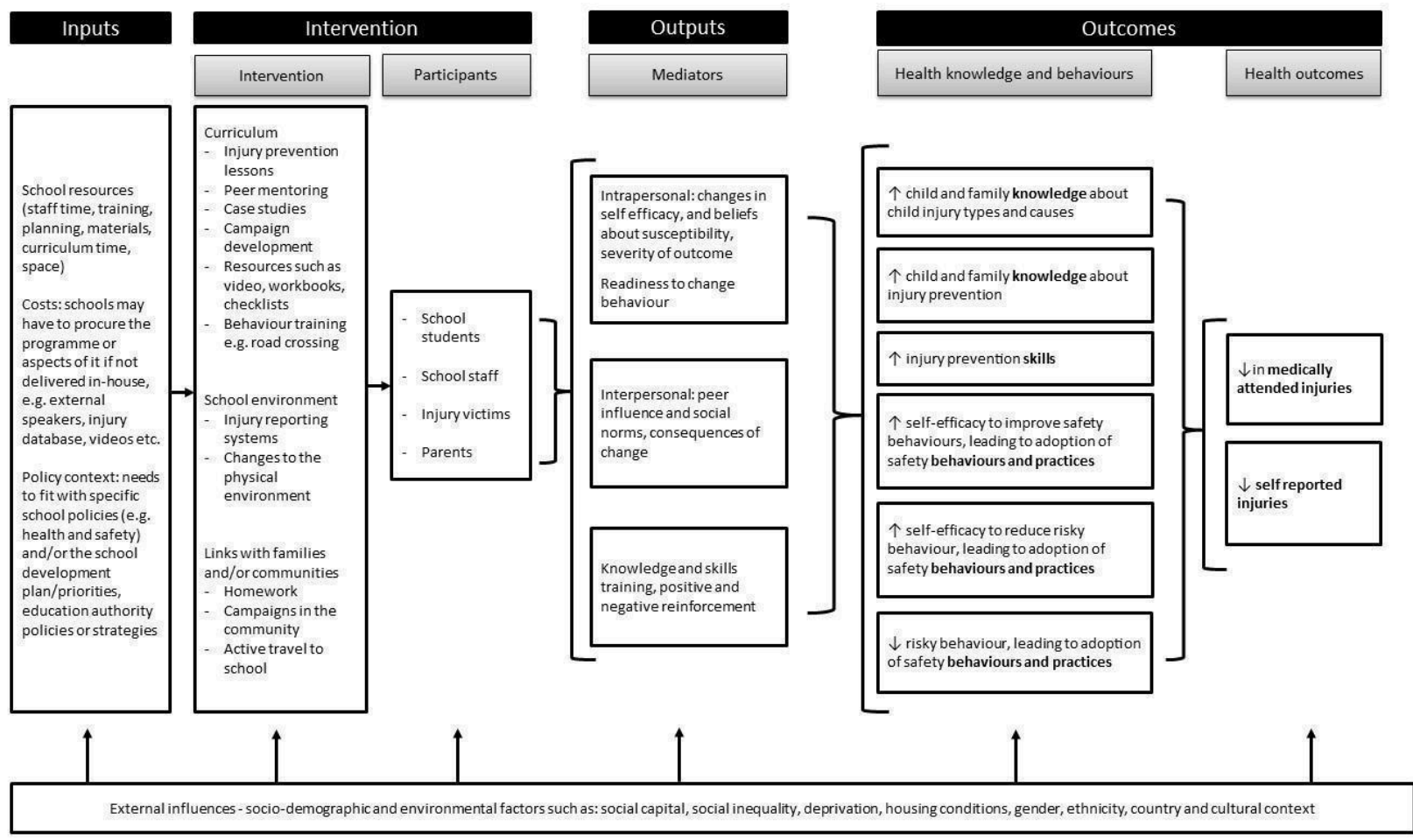




\section{Why it is important to do this review}

A previous review of safety education, showed that education delivered in a range of settings including, but not limited to schools, can improve children's knowledge, risk-taking behaviour and skills (Mulvaney 2012). However, an assessment of impact on injury rates was not possible owing to the lack of relevant studies identified in the searches. In addition, this review was restricted to English language only and a limited number of databases were searched. We sought to re-assess the current evidence of effectiveness of school-based injury prevention programmes, building upon this previous review by updating and expanding the literature searches. In doing this we sought to provide evidence for those working with children in schools and those commissioning preventative interventions to make informed decisions about the effectiveness of school-based injury prevention programmes. This is important to ensure appropriate resource allocation because schools have to prioritise health-promoting activities, given restrictions on time and resources.

\section{O B JECTIVES}

To assess the effects of school-based educational programmes for the prevention of injuries in children and evaluate their impact on improving children's safety skills, behaviour and practices, and knowledge, and assess their cost-effectiveness.

\section{METHODS}

\section{Criteria for considering studies for this review Types of studies}

We included individually and cluster randomised controlled trials (RCTs), non-randomised controlled trials (non-RCTs) and controlled before-and-after studies (CBAs) (prospective studies with a concurrent control group allocated using a non-random method and with a baseline period of assessment of outcomes). The control groups received no intervention, a delayed injuryprevention intervention or alternative school-based curricular activities.

For the economic analysis, we used any health economic data that was reported as part of an included study to undertake an economic analysis of the cost-effectiveness of that programme.

\section{Types of participants}

The provision of state-based preschool education and the age of compulsory school entry (normally four to seven years of age), varies across the world. For this review, we included interventions for non-institutionalised children aged four to 18 years who are enrolled in a formal state-based or independent/private school.

\section{Types of interventions}

Interventions included in the review were primary and secondary injury prevention interventions aimed at reducing a range of unintentional injury mechanisms. We excluded studies of a single injury type, such as burns, but included prevention aimed a range of mechanisms (e.g. burns from flames, chemical burns, electrical burns or scalds). We excluded studies that only focused on one these, for example chemical burns. Similarly, we included studies aimed at preventing spinal cord injuries by addressing issues such as driving fast in a car, diving into shallow water or not wearing protective equipment, but excluded studies preventing spinal cord injury through just one cause (e.g. a sport such as horse riding or rugby). Interventions had to be delivered in full or in part in schools catering for children aged four to 18 years and delivered by a teacher or other people with an injury prevention role. The latter included children trained to deliver injury prevention interventions to their peers in a school setting. We chose schools as the primary setting as many programmes are currently delivered in schools (e.g. Think First For Kids, Risk Watch, IMPS, etc.) and we wanted to evaluate the evidence to inform decisions about provision of such programmes in schools.

We excluded the following types of interventions:

- tertiary prevention interventions aimed at minimising the harm associated with injury occurrence (e.g. first aid interventions);

- quaternary prevention interventions aimed at preventing repeat injuries;

- interventions to prevent intentional injuries (e.g. violence in the home and weapon safety);

- any intervention where the prevention of a range of injury mechanisms was not stated in the aims or objectives or that involved a multiple intervention programme in which it was not possible to isolate the relative effects of the injury prevention component;

- interventions aimed at preventing a single injury mechanism (e.g. cycling injury or drowning);

- community or national campaigns supported by classroom or school activities but where the school was not the primary delivery setting (e.g. community-based media campaigns);

- interventions delivered in youth clubs, social clubs or parenting groups;

- interventions delivered without a school-based component (e.g. the Lifeskills "Learning for Living" (Lamb 2006) intervention which was delivered in a safety education 'village' outside the school setting).

\section{Types of outcome measures}

\section{Primary outcomes}

- Self-reported medically or non-medically attended unintentional injuries or injuries with an unspecified intent. In addition, included self-reports ascertained from parents/carers, teachers or other people considered to be in loco parentis. Medically attended injuries were those in which the participants sought healthcare advice by attendance at either a primary or secondary healthcare setting.

\section{Secondary outcomes}

- Observed safety skills (e.g. exiting a building during a fire drill).

- Observed behaviour (e.g. number of children observed wearing seat belts on journeys to and from school).

- Self-reported behaviour and safety practices (e.g. self-reported wearing of helmet when cycling).

- Safety knowledge (e.g. knowing to check water depth before diving into a pool).

- Health economic outcomes, including cost per unit of utility gained (e.g. incremental cost per quality-adjusted life year), cost per unit of effect (e.g. cost per injury prevented), cost as 
measured in inputs and benefits (e.g. costs not incurred by preventing injuries or cost:benefit ratios) or resource costs.

\section{Search methods for identification of studies}

We did not restrict the search by date, language, geographical location or publication status. However, we limited the population group to children aged four to 18 years.

\section{Electronic searches}

We ran searches in August 2013 and updated these to the end of June 2015. We conducted a final pre-publication search in September and October 2016, and placed potential studies for this search in the Characteristics of studies awaiting classification section of this review.

The search strategies were devised using terms to identify injuries, safety skills, behaviour and practices, safety knowledge and health economic outcomes in RCTs, non-RCTs and CBAs.

\section{Early search (August 2013)}

The Cochrane Injuries Group's Information Specialist searched the following databases (to August 2013, in the first instance):

- Cochrane Injuries Group Specialised Register (SR-INJ) (29 August 2013);

- Cochrane Central Register of Controlled Trials (CENTRAL) (2013, Issue 7);

- Health Economics Evaluations Database (HEED) (29 August 2013);

- Health Technology Assessment Database (HTA) (the Cochrane Library) (2013, Issue 7);

- Ovid $\operatorname{Med} \ln (\mathrm{R})$, Ovid MedLINE(R) In-Process \& Other Non-Indexed Citations, Ovid MEDLINE(R) Daily and Ovid OLDMEDLINE(R) 1946 to 29 August 2013;

- Embase and Embase Classic (Ovid) (1947 to 28 August 2013);

- CINAHL Plus (EBSCO) (1939 to 29 August 2013);

- ISI Web of Science: Science Citation Index Expanded (1970 to 29 August 2013);

- ISI Web of Science: Conference Proceedings Citation IndexScience (1990 to 29 August 2013);

- ISI Web of Science: Social Sciences Citation Index (1970 to 29 August 2013);

- ISI Web of Science: Conference Proceedings Citation Index Social Sciences \& Humanities (1990 to 29 August 2013);

- ZETOC (1993 to 29 August 2013).

\section{Update search (September 2016): CENTRAL, MEDLINE, Embase and SR-INJ}

The earlier search strategies (to August 2013) were designed to favour specificity (precision) over sensitivity (recall of all potentially relevant reports) to reduce screening vast numbers of irrelevant records. This is an appropriate strategy when designing a search based on population and intervention alone (i.e. without applying a controlled trials filter). When searches were re-run in September 2016, the Cochrane Injuries Group's Information Specialist validated these earlier searches by checking the provenance of included studies (to date) and information contained in the title, abstract and subject heading fields, of study reports in CENTRAL, MEDLINE and Embase. This exercise revealed that less than $65 \%$ of the included studies were retrieved using the earlier search strategies (figure adjusted for three included studies not indexed on these databases). As a consequence of this validation exercise, searches of the Cochrane Injuries Group's Specialised Register, CENTRAL, MEDLINE and Embase were appended as appropriate. Searches were also back-dated where necessary.

A further citation search on the Web of Science Core Collection was also conducted on 16 September 2016.

Searches performed by the Cochrane Injuries Group's Information Specialist (all years) are presented in Appendix 1.

The review authors also conducted their own, extensive searches on a host of other social science and educational resources to compliment Cochrane Methodological Expectations of Cochrane Intervention Reviews (MECIR) conduct standard (c24). For further details of MECIR, see editorial-unit.cochrane.org/mecir.

\section{Complimentary searches conducted by the review author team}

We ran additional searches on the following databases and websites, with prepublication searches run on the 14 October 2016 (Appendix 2).

Databases:

- LILACS (Latin American and Caribbean Health Sciences Literature database) (1982 to June 2015 and then updated to 14 October 2016);

- PsycINFO (Ovid) (1806 to June 2015 and then updated to 14 October 2016);

- ERIC (Educational Resources Information Centre) (1966 to June 2015 and then updated to 14 October 2016);

- Dissertation Abstracts Online (1988 to June 2015 and then updated to September 2016);

- IBSS (International Bibliography of Social Sciences) (1951 to June 2015 and then updated to 14 October 2016);

- BEI (British Education Index) (1975 to June 2015 and then updated to 14 October 2016);

- ASSIA (1987 to June 2015 and then updated to 14 October 2016);

- CSA Sociological Abstracts (1952 to June 2015 and then updated to 14 October 2016);

- Injury Prevention Web (up to June 2015 and then updated to 14 October 2016);

- SafetyLit (US) (1998 to June 2015 and then updated to 14 October 2016);

- EconLit (US) (1886 to June 2015 and then updated to 14 October 2016);

- Public Affairs Information Service (PAIS) International (1972 to June 2015 and then updated to 14 October 2016).

Websites:

- UK Clinical Research Network Study Portfolio (public.ukcrn.org.uk/search/; searched June 2015 and then updated to 14 October 2016);

- Open Grey (System for Information on Grey Literature in Europe) (1980 to June 2015 and then updated to 14 October 2016); 
- Index to Theses in the UK and Ireland (up to June 2015 and then updated to 14 October 2016);

- Bibliomap EPPI-Centre database of health promotion research (to June 2015 and then updated to 14 October 2016);

- TRoPHI (The Trials Register of Promoting Health Interventions) (2004 to June 2015 and then updated to 14 October 2016);

- International Trial registries (to 14 October 2016);

- WHO International Clinical Trials Registry Platform (ICTRP) (to 14 October 2016).

\section{Searching other resources}

We handsearched the reference lists of all included studies as well as published reviews. We searched the Internet for grey literature using the search engines Google Scholar (scholar.google.co.uk/).

We also handsearched the following sources:

- abstracts from the first to the eleventh World Conference on Injury Prevention and Safety Promotion (1989 to 2012);

- Table of contents of the journal Injury Prevention from 1995 to August 2016.

\section{Data collection and analysis}

\section{Selection of studies}

For the results of the electronic database searches, two review authors (shared between EO, MC, JMM, JW and MB) independently judged the eligibility of studies by assessing the titles and abstracts. We obtained full-text reports of all potentially relevant studies and independently assessed whether each met the predefined inclusion criteria. For those articles where no abstract was available and it was unclear from the title alone whether they met the eligibility criteria, we retrieved full-text reports. If there was disagreement between review authors, then they consulted a third review author (shared between EO, MC, MW and JMM). Where English translations for studies published in another language were not available at the screening stage, we obtained fulltext reports and a native speaker translated the manuscript into English. Reasons for excluding full text reports are detailed in the Characteristics of excluded studies table. Two review authors conducted handsearches separately (shared between BB, CM, MC and EO) and identified potentially relevant abstracts. They resolved any disagreements through discussions with a third review author (MW).

\section{Data extraction and management}

Two review authors (shared between DK, MW, CM, EO, MC, JS, JMM and JW) independently extracted data from studies meeting the inclusion criteria and entered them onto a piloted data extraction form, after which they compared results. The two review authors agreed any discrepancies through discussion and if necessary referred the issue to a third review author (shared between MW and EO).

\section{We extracted the following data:}

- details of participants (e.g. age, gender, school setting (type, level and location of the school));

- details of intervention (e.g. types of injury mechanisms targeted, the setting of the intervention (i.e. if there was also a non-school component)), who delivered the intervention and the nature of the comparison group;

- details of the primary and secondary outcomes and the time over which outcomes were measured. For the primary outcome, we extracted the number of injury events and person time at risk at baseline and after the intervention.

Where necessary, we requested missing data from study authors. We were alert to multiple reports relating to the same individual studies to avoid duplication of results when extracting the data. We translated studies published in a language other than English prior to data extraction and assessment of bias.

\section{Assessment of risk of bias in included studies}

Two review authors independently assessed the quality of included studies using Cochrane's tool for assessing the risk of bias (shared between DK, MW, CM, EO, MC, JS, JMM and JW). For RCTs, we assessed the risk of bias for: random sequence generation, allocation concealment, blinding of participants and personnel, blinding of outcome assessment, completeness of data, selective reporting and other sources of bias. For non-RCTs, we omitted random sequence generation and allocation concealment, but included an assessment of allocation to intervention/control (selection bias), and risk of bias due to confounding. We categorised studies as high risk of bias due to insufficient blinding if they did not describe the blinding (because participants were likely to know whether they received the intervention or not) or if they explicitly stated that they did not blind. We categorised studies at high risk of bias due to confounding if they did not adjust for confounding in the analysis. The review authors completed 'risk of bias' tables based on these criteria, incorporating a judgement of low risk, high risk or unclear risk with explanations provided for each judgement made. We compared our assessments, and if the review pair was unable to reach a consensus, they consulted a third review author.

\section{Measures of treatment effect}

We entered details of included papers into Review Manager 5 for analysis (RevMan 2014). We described self-reported medically or non-medically attended injuries in terms of injury incidence rates or as the percentage of children reporting at least one injury, depending on how injuries were measured and reported in the included studies. Dichotomous outcomes (e.g. observed safety skills) were described in terms of the proportion or differences in proportions exhibiting that outcome. We described observed or self-report safety knowledge in terms of test scores, percentages or differences in percentages with $95 \%$ confidence intervals $(\mathrm{Cl})$. We presented continuous outcomes as means or standardised means or differences in means with standard deviations (SD).

\section{Unit of analysis issues}

Where studies were allocated by cluster (e.g. by school or by class), we adjusted the number of injury events and the number of personyears for clustering by dividing by the inflation factor. We calculated the inflation factor using the formula described by Donner and Klar (equation 5.6) (Donner 2000), with a coefficient of variation of 0.25 as described by Hayes and Bennett (Hayes 1999). For studies with more than two arms, we only included those arms that met inclusion criteria in the review. None of the studies included in the meta-analysis had more than two arms. 


\section{Dealing with missing data}

We based meta-analyses on complete-case data. Primary outcome data were missing for $2.3 \%$ of intervention group participants, but the percentage of participants missing data in the control group was unreported in the study by Lu 2000. Primary outcome data were missing for $13 \%$ of the intervention group and $4 \%$ of the control group in the study by Wang 2009. Zhao 2006 presented data on the number of students in the academic year and the number of injuries before and after the intervention and there did not appear to be any missing data for the intervention or control group. None of the three studies included in the meta-analysis presented any analyses to allow assessment of whether data were missing at random or not.

\section{Assessment of heterogeneity}

We assessed heterogeneity by using the $\mathrm{I}^{2}$ statistic and the $\mathrm{Chi}^{2}$ test for heterogeneity where a $\mathrm{P}$ value of less than 0.1 indicated statistically significant heterogeneity. We explored heterogeneity in effect sizes by a sensitivity analysis excluding one non-RCT from the meta-analysis. We based our interpretation of the $1^{2}$ statistic on categories outlined in the Cochrane Handbook for Systematic Reviews of Interventions.

\section{Assessment of reporting biases}

We did not assess reporting bias using funnel plots or Egger's test as there were only three studies in the meta-analysis.

\section{Data synthesis}

We estimated a pooled incidence rate ratio (IRR) for studies reporting injury incidence rates using a random-effects model, and included both RCTs (Wang 2009; Zhao 2006) and non-RCTs (Lu 2000) in the meta-analysis. We considered the non-RCT similar enough to the RCTs in terms of populations, interventions and outcomes to combine in a meta-analysis. There was no information provided about how the intervention and control groups were selected in the non-RCT, but baseline injury incidence rates were similar (517/1000 person-years in intervention group and 527/1000 person-years in control group). Use of adjusted effect sizes and standard errors (SE) is recommended for non-RCTs (Higgins 2011), therefore, we included in the meta-analysis follow-up injury incidence rates adjusted for baseline injury incidence rates, for the non-RCT. We performed this adjustment using Poisson regression with a time by treatment arm interaction term. This represented the ratio of: (intervention arm follow-up injury incidence rate/intervention arm baseline injury incidence rate)/(control arm follow-up injury incidence rate/control arm baseline injury incidence rate).

We used the regression coefficient (and the SE) for this ratio of rates as the effect size (and the $\mathrm{SE}$ ) in the meta-analysis adjusted for baseline injury incidence rates. Therefore, this analysis required the use of the generic inverse variance method,

In one study the control group received education on the prevention of pneumonia, iron-deficiency anaemia, rickets and common communicable diseases (Zhao 2006). The other two studies had control groups which did not receive any intervention (Lu 2000; Wang 2009). As it is unlikely that the disease prevention education provided in the study by Zhao would impact on injury incidence, we considered it appropriate to include this study in the meta-analysis.
We synthesised the remaining studies in a narrative review. We grouped studies by outcome, and subdivided into different injury mechanisms.

\section{Subgroup analysis and investigation of heterogeneity}

We planned to undertake three subgroup analyses if numbers allowed. These would have been: child age/school setting and type of intervention such as information giving, skills training, multicomponent and duration of the intervention. However, we did not undertake these subgroup analyses due to the small number of studies included in the meta-analysis.

\section{Sensitivity analysis}

We performed sensitivity analysis by excluding the single non-RCT from the meta-analysis.

\section{Presentation of main results}

We developed a 'Summary of findings' tables for all outcomes of this review (medically or non-medically attended injury rates, observed safety skills, observed behaviour and self-reported behaviour and safety practices, safety knowledge and costeffectiveness) following GRADE methods (GRADE 2004), and using GRADEpro GDT software. We assessed the quality of the body of evidence with reference to the overall risk of bias of the included studies, inconsistency of the results (heterogeneity), indirectness of the evidence (generalisability), precision of the estimates, risk of publication bias, whether the effect size was large, whether there was plausible confounding and dose response effects. We assessed the quality of the body of evidence for each comparison and main outcome as high, moderate, low or very low.

\section{RESULTS}

\section{Description of studies}

\section{Results of the search}

We retrieved 8180 articles from the electronic searches and 247 from other sources (to 26 June 2015). After duplicates were removed, we screened 6930 articles for inclusion in the review. We assessed 265 full-text articles for eligibility and retrieved 218 in full ( 47 were unobtainable). Of these 265 , we excluded 188 because the study design (70 articles), participants (two articles), intervention (115 articles) or outcomes measured (one article) did not meet the inclusion criteria of the review (see Characteristics of excluded studies table). We included 27 studies reported in 30 articles in the review and described these in the Characteristics of included studies table. We contacted 22 authors for further information and included seven of these reports in the review. Of the seven included in the review, four authors responded. We have included a table of all authors that responded in the Acknowledgements.

Results are summarised in Summary of findings for the main comparison. Three articles report the same agriculture injury prevention study outcomes (Reed 2001). Two further articles reported the same study but different outcomes (Collard 2010). Three studies were translated from Chinese by a native speaker who is also an epidemiologist (Lu 2000; Wang 2009; Zhao 2006). The 27 studies included approximately 73,557 participants (range from 63 to 18,876 participants). 
Along with Cochrane Injuries' Information Specialist, we ran a prepublication search in September and October 2016, retrieving a further 3834 records (making 12,014 in total). We have screened these and placed any relevant studies in the Characteristics of studies awaiting classification table $(n=48)$. These studies will be incorporated into the next version of this review as appropriate.

The process of study selection is documented in Figure 2. 
Figure 2. PRISMA flow chart detailing the process of study selection for all studies included in the review. CBA: controlled before-and-after study; RCT: randomised controlled trial.

\section{2,014 potentially relevant articles identified and screened for retrieval from bibliographic databases}

247 potentially relevant articles identified and screened for retrieval from other sources

45 systematic reviews

13 already had

151 World Conference handsearches

11 Injury Prevention journal handsearches

27 reference lists of included primary studies

9567 articles after duplicates removed

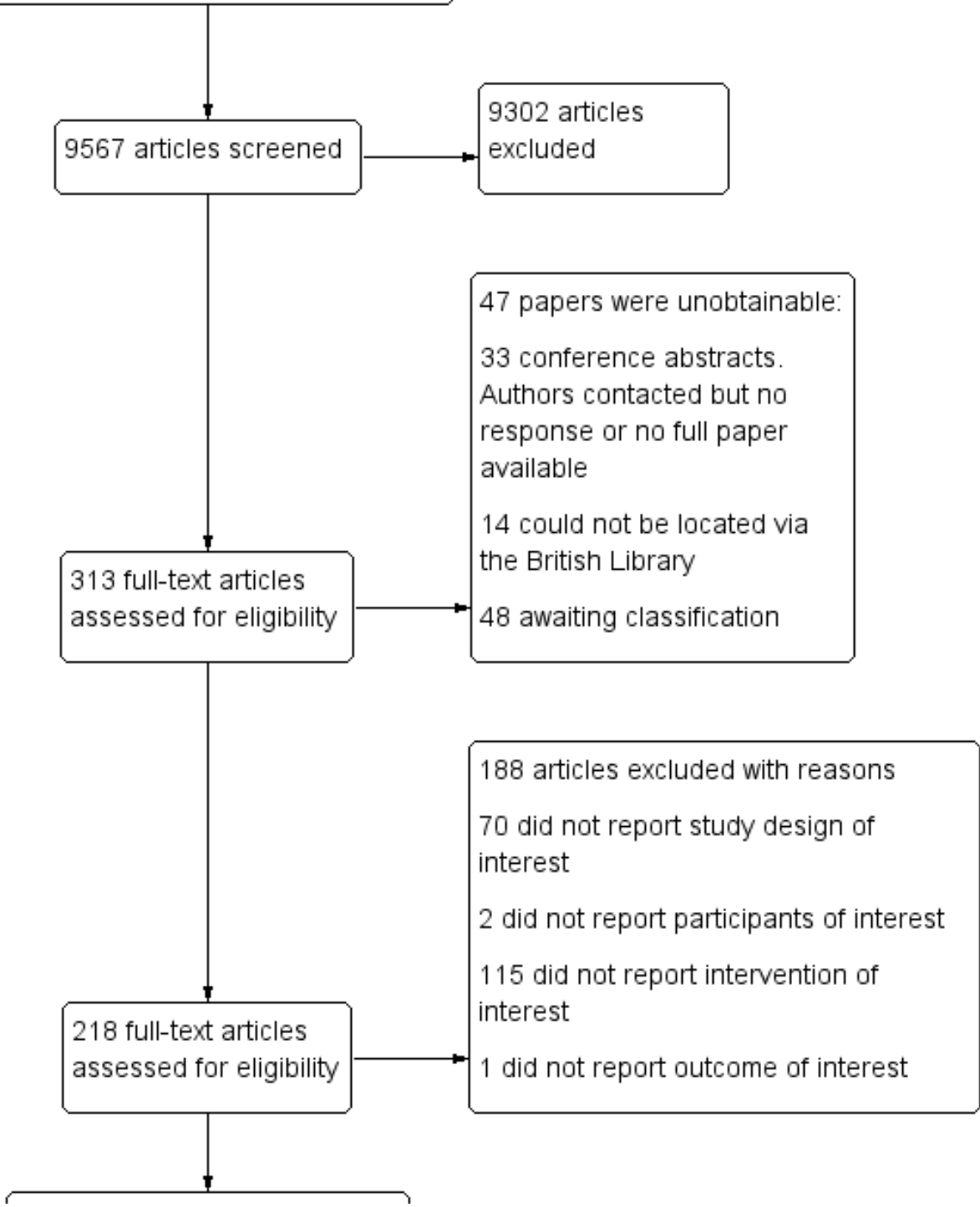


Figure 2. (Continued)

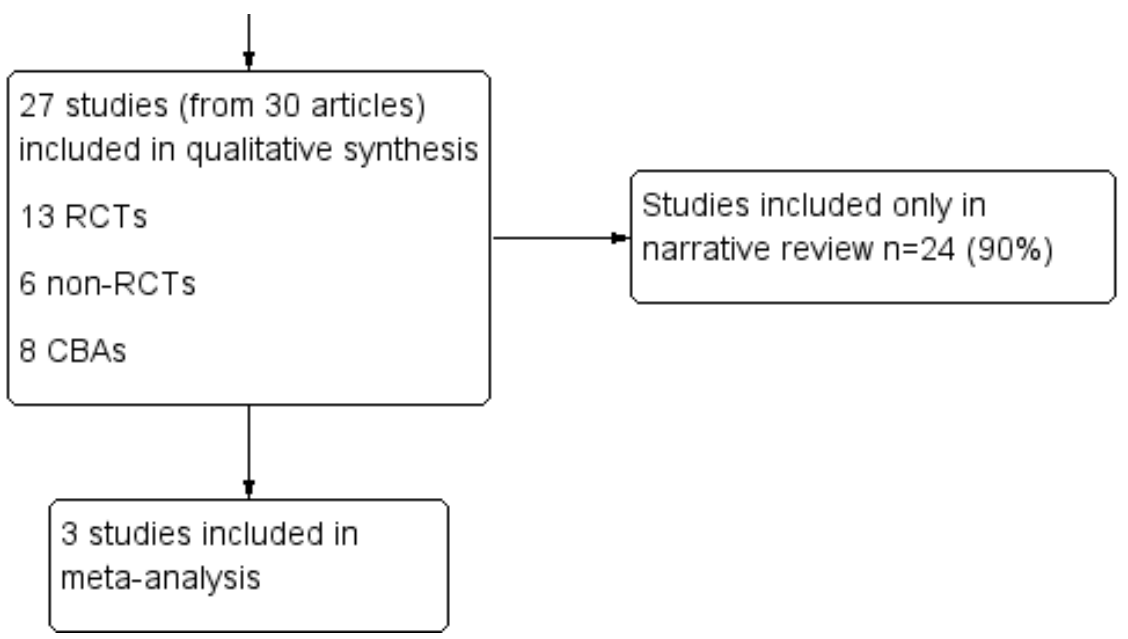

\section{Included studies}

See Characteristics of included studies table.

\section{Types of studies}

Thirteen studies (48\%) were RCTs (Campbell 2001; Carmel 1991; Chapman 2013; Collard 2010; Falavigna 2012; Grant 1992; Gresham 2001; Kendrick 2007; Lee 2004; Reed 2001; Sun 2004; Wang 2009; Zhao 2006), six (22\%) were non-RCTs (Cook 2006; Martinez 1996; Morrongiello 1998; Richards 1991; Terzidis 2007; Twisk 2013), and eight (30\%) were CBAs (Azeredo 2003; Buckley 2010; Frederick 2000; Greene 2002; Lu 2000; Wesner 2003; Wright 1995; Zirkle 2005). Twelve studies (41\%) were from the US (Azeredo 2003; Campbell 2001; Cook 2006; Grant 1992; Greene 2002; Gresham 2001; Lee 2004; Martinez 1996; Reed 2001; Richards 1991; Wright 1995; Zirkle 2005); four (14\%) were from China (Lu 2000; Sun 2004; Wang 2009; Zhao 2006); two (7\%) were from each of Australia (Buckley 2010; Chapman 2013), Canada (Morrongiello 1998; Wesner 2003), the Netherlands (Collard 2010; Twisk 2013), and the UK (Frederick 2000; Kendrick 2007); and one from each of Israel (Carmel 1991), Greece (Terzidis 2007), and Brazil (Falavigna 2012).

\section{Types of participants and settings}

The school year/age nomenclature varied across studies from different countries. Some studies provided the exact ages of participants, age ranges or mean ages. However, other studies referred only to the year group or grade (e.g. year one to 13 in the UK or grade one to 12 in Australia, Canada, China and the US, with some systems also having a foundation or kindergarten stage) or else they referred to the type of school (e.g. primary, middle and high).

Eighteen studies (67\%) provided some element of the intervention in children aged four to 11 years (Azeredo 2003; Carmel 1991; Collard 2010; Cook 2006; Frederick 2000; Grant 1992; Greene 2002; Gresham 2001; Kendrick 2007; Lu 2000; Morrongiello 1998; Richards 1991; Sun 2004; Terzidis 2007; Twisk 2013; Wesner 2003; Zhao 2006; Zirkle 2005), 17 (63\%) included children aged 11 to 14 years (Buckley 2010; Campbell 2001; Carmel 1991; Chapman 2013; Collard 2010; Cook 2006; Falavigna 2012; Lee 2004; Lu 2000; Martinez 1996; Reed 2001; Sun 2004; Terzidis 2007; Twisk 2013;
Wang 2009; Wright 1995; Zhao 2006), and nine (33\%) included children aged 14 to 18 years (Buckley 2010; Campbell 2001; Lee 2004; Lu 2000; Martinez 1996; Reed 2001; Terzidis 2007; Wang 2009; Wright 1995) (see Table 1). Some studies included children in more than one of these groups. Only three (11\%) studies included children from all age groups (Lu 2000; Sun 2004; Terzidis 2007).

Nineteen (70\%) studies specified that boys and girls were included in the analysis (Buckley 2010; Campbell 2001; Carmel 1991; Chapman 2013; Collard 2010; Cook 2006; Falavigna 2012; Gresham 2001; Kendrick 2007; Lee 2004; Martinez 1996; Morrongiello 1998; Reed 2001; Terzidis 2007; Twisk 2013; Wang 2009; Wesner 2003; Wright 1995; Zirkle 2005), but the remaining eight (30\%) did not make this clear (Azeredo 2003; Frederick 2000; Grant 1992; Greene 2002; Lu 2000; Richards 1991; Sun 2004; Zhao 2006). A total of $13(48 \%)$ studies specified that the intervention was delivered in state-funded schools (Buckley 2010; Campbell 2001; Carmel 1991; Collard 2010; Grant 1992; Kendrick 2007; Lee 2004; Morrongiello 1998; Richards 1991; Sun 2004; Wang 2009; Wesner 2003; Wright $1995)$, three $(11 \%)$ were in both state and independent schools (Azeredo 2003; Cook 2006; Falavigna 2012), and 11 (41\%) did not specify the type of school (Chapman 2013; Frederick 2000; Greene 2002; Gresham 2001; Lu 2000; Martinez 1996; Reed 2001; Terzidis 2007; Twisk 2013; Zhao 2006; Zirkle 2005). Five (5\%) programmes were only in urban schools (Carmel 1991; Falavigna 2012; Gresham 2001; Kendrick 2007; Sun 2004) and three (9\%) were only in a rural school (Grant 1992; Lee 2004; Reed 2001). For the others, three $(9 \%)$ were based in a rural and urban setting (Azeredo 2003; Richards 1991; Zhao 2006); one (4\%) was in urban and suburban areas (Collard 2010); one (4\%) was in urban, suburban and rural areas (Wright 1995); and for 14 (52\%) studies details of the setting were not provided (Buckley 2010; Campbell 2001; Chapman 2013; Cook 2006; Frederick 2000; Greene 2002; Lu 2000; Martinez 1996; Morrongiello 1998; Terzidis 2007; Twisk 2013; Wang 2009; Wesner 2003; Zirkle 2005).

\section{Types of interventions}

All studies included primary prevention in the intervention. In addition, 16 (59\%) studies also had secondary prevention components (Azeredo 2003; Cook 2006; Falavigna 2012; Grant 1992; Greene 2002; Gresham 2001; Kendrick 2007; Lee 2004; Martinez 
1996; Morrongiello 1998; Reed 2001, Richards 1991; Wesner 2003; Wright 1995; Zhao 2006; Zirkle 2005), and three (11\%) had elements of tertiary prevention (e.g. first aid) but these components were not included in the analysis (Buckley 2010; Campbell 2001; Zhao 2006). The injury mechanisms that each intervention was aimed at are described in Table 2.

Eighteen (66\%) interventions were targeted at children alone (Carmel 1991; Chapman 2013; Cook 2006; Falavigna 2012; Frederick 2000; Grant 1992; Greene 2002; Lee 2004; Martinez 1996; Morrongiello 1998; Reed 2001; Richards 1991; Terzidis 2007; Twisk 2013; Wang 2009; Wesner 2003; Wright 1995; Zirkle 2005), and nine (34\%) were targeted at children and families (Azeredo 2003; Buckley 2010; Campbell 2001; Collard 2010; Gresham 2001; Kendrick 2007; Lu 2000; Sun 2004; Zhao 2006). While the major component of all interventions was based in the school setting, three (11\%) also had a component in the family home (Campbell 2001; Lu 2000; Terzidis 2007), two (7\%) in the community (Lee 2004; Lu 2000), and one (4\%) in a hospital (Frederick 2000). Sixteen (59\%) studies were delivered in whole or part by a teacher (Azeredo 2003; Buckley 2010; Carmel 1991; Chapman 2013; Collard 2010; Frederick 2000; Grant 1992; Greene 2002; Gresham 2001; Kendrick 2007; Lu 2000; Morrongiello 1998; Richards 1991; Terzidis 2007; Wesner 2003; Zhao 2006), and nine (33\%) were delivered by professionals with an injury prevention role (Campbell 2001; Cook 2006; Falavigna 2012; Lee 2004; Martinez 1996; Reed 2001; Wang 2009; Wright 1995; Zirkle 2005). One (4\%) study trained students to be peer educators (Wang 2009), and two (7\%) studies did not explicitly report who delivered the intervention in the school (Sun 2004; Twisk 2013).

Studies used a variety of components as part of their education programmes: nine (33\%) interventions utilised information giving (Carmel 1991; Falavigna 2012; Greene 2002; Richards 1991; Terzidis 2007; Twisk 2013; Wesner 2003; Wright 1995; Zirkle 2005), one (4\%) used peer education (Wang 2009), and the other 17 studies (63\%) had multi-component programmes (Azeredo 2003; Buckley 2010; Campbell 2001; Chapman 2013; Collard 2010; Cook 2006; Frederick 2000; Grant 1992; Gresham 2001; Kendrick 2007; Lee 2004; Lu 2000; Martinez 1996; Morrongiello 1998; Reed 2001; Sun 2004; Zhao 2006). Multi-component programmes included combinations of elements such as information giving, safety equipment provision, skills training and testing, physical training, cognitive behaviour change methods, telling of 'real life' stories by or about injured individuals and interactive learning (e.g. developing campaign materials).

Seven (26\%) studies involved single education sessions (Cook 2006; Falavigna 2012; Morrongiello 1998; Terzidis 2007; Twisk 2013; Wesner 2003; Wright 1995); nine (33\%) involved between three and eight sessions (Buckley 2010; Campbell 2001; Chapman 2013; Greene 2002; Gresham 2001; Lu 2000; Martinez 1996; Richards 1991; Zhao 2006); one (4\%) involved 18 to 27 sessions (Azeredo 2003), and one (4\%) involved over 50 sessions (Collard 2010). Nine (33\%) studies did not document the number of sessions (Carmel 1991; Frederick 2000; Grant 1992; Kendrick 2007; Lee 2004; Reed 2001; Sun 2004; Wang 2009; Zirkle 2005).

Interventions were varied in terms of the duration of individual sessions, the frequency of these sessions and the overall duration of the intervention. Seven (26\%) interventions were of very short duration, lasting only one day or one or two sessions (Cook 2006; Falavigna 2012; Morrongiello 1998; Terzidis 2007; Twisk 2013; Wesner 2003; Wright 1995). Two (7\%) interventions lasted for between one and four weeks (Campbell 2001; Martinez 1996), seven
(26\%) lasted between one and six months (Azeredo 2003; Buckley 2010; Campbell 2001; Chapman 2013; Greene 2002; Gresham 2001; Richards 1991), and six (22\%) lasted longer than six months (Collard 2010; Lu 2000; Sun 2004; Wang 2009; Zhao 2006; Zirkle 2005). Five (19\%) studies did not document the length of the intervention (Frederick 2000; Grant 1992; Kendrick 2007; Lee 2004; Reed 2001).

Thirteen (48\%) studies described 'branded' programmes including Think First and Think Well (brain and spinal cord injury prevention programmes: Falavigna 2012; Greene 2002; Gresham 2001; Wesner 2003; Wright 1995; Zirkle 2005), SPIY (Buckley 2010), I-Play (Collard 2010), IMPS (Frederick 2000) based in schools and emergency departments, Learn Not To Burn (Grant 1992), Risk Watch (delivered by the fire service but covering a range of injury mechanisms: Kendrick 2007), Go AHEAD, including a range of road safety and sports injury prevention (Morrongiello 1998), and AgDARE, aimed at young people working on farms (Reed 2001).

The studies covered a range of injury mechanisms: $18(67 \%)$ reported transport safety (including 12 (44\%) pedestrian (Buckley 2010; Cook 2006; Frederick 2000; Greene 2002; Kendrick 2007; Lu 2000; Martinez 1996; Richards 1991; Twisk 2013; Wright 1995; Zhao 2006; Zirkle 2005), 17 (63\%) cycling (Azeredo 2003; Buckley 2010; Chapman 2013; Cook 2006; Falavigna 2012; Frederick 2000; Greene 2002; Gresham 2001; Kendrick 2007; Lu 2000; Martinez 1996; Morrongiello 1998; Richards 1991; Twisk 2013; Wesner 2003; Wright 1995; Zirkle 2005), nine (33\%) motor cycle (Buckley 2010; Chapman 2013; Falavigna 2012; Frederick 2000; Lu 2000; Martinez 1996; Wright 1995; Zhao 2006; Zirkle 2005), and 17 (63\%) nonspecific vehicle injuries (Azeredo 2003; Buckley 2010; Chapman 2013; Cook 2006; Falavigna 2012; Frederick 2000; Greene 2002; Gresham 2001; Lu 2000; Martinez 1996; Morrongiello 1998; Richards 1991; Wesner 2003; Wright 1995; Zhao 2006; Zirkle 2005)), five (19\%) reported falls safety (Falavigna 2012; Kendrick 2007; Lu 2000; Richards 1991; Sun 2004), 10 (37\%) reported water/drowning safety (Azeredo 2003; Falavigna 2012; Frederick 2000; Greene 2002; Gresham 2001; Morrongiello 1998; Richards 1991; Terzidis 2007; Wesner 2003; Zhao 2006), seven (26\%) reported smoke/fire safety (Azeredo 2003; Campbell 2001; Carmel 1991; Frederick 2000; Grant 1992; Kendrick 2007; Lu 2000), seven (26\%) reported sports safety (Campbell 2001; Collard 2010; Greene 2002; Gresham 2001; Lu 2000; Morrongiello 1998; Richards 1991), three (11\%) reported household safety (Campbell 2001; Frederick 2000; Zhao 2006), two (7\%) reported agricultural safety (Lee 2004; Reed 2001), and five (19\%) reported poisoning safety (Buckley 2010; Campbell 2001; Frederick 2000; Kendrick 2007; Zhao 2006). Table 2 shows the injury mechanisms targeted by each study.

Twenty-one $(78 \%)$ studies documented that the control groups had no intervention or the usual curriculum (not related to injury prevention) with either no access to the intervention or delayed until the end of the study (Azeredo 2003; Buckley 2010; Carmel 1991; Chapman 2013; Collard 2010; Cook 2006; Falavigna 2012; Frederick 2000; Grant 1992; Greene 2002; Kendrick 2007; Lee 2004; Lu 2000; Martinez 1996; Morrongiello 1998; Reed 2001; Terzidis 2007; Twisk 2013; Wang 2009; Wesner 2003; Wright 1995). In three studies (11\%), the control groups received an alternative educational programme (e.g. tobacco and alcohol prevention programmes or general information on food hygiene and disease prevention) (Campbell 2001; Sun 2004; Zhao 2006), and in the remaining three $(11 \%)$, it was unclear what the control group received (Gresham 2001; Richards 1991; Zirkle 2005). 


\section{Types of outcome measures}

For the primary outcomes, five studies (19\%) included nonmedically attended injury occurrence (Chapman 2013; Collard 2010; Lee 2004; Sun 2004; Wang 2009), one (4\%) included medically attended injury occurrence (Zhao 2006), and one (4\%) included both medically and non-medically attended injuries (Lu 2000). Of these, five studies reported injury incidence rates (Collard 2010; Lu 2000; Sun 2004; Wang 2009; Zhao 2006), and two reported injury incidence proportion (Chapman 2013; Lee 2004).

For the secondary outcome measures, two studies (7\%) reported observed safety skills (Frederick 2000; Kendrick 2007), four (15\%) reported observed safety behaviours (Azeredo 2003; Reed 2001; Wright 1995; Zirkle 2005), 19 (70\%) reported self-reported behaviour and practices (Azeredo 2003; Buckley 2010; Campbell 2001; Chapman 2013; Collard 2010; Falavigna 2012; Frederick 2000; Gresham 2001; Kendrick 2007; Lee 2004; Martinez 1996; Morrongiello 1998; Reed 2001; Richards 1991; Sun 2004; Twisk 2013; Wesner 2003; Wright 1995; Zirkle 2005), and 21 (78\%) reported safety knowledge (Azeredo 2003; Campbell 2001; Carmel 1991;
Collard 2010; Cook 2006; Falavigna 2012; Frederick 2000; Grant 1992; Greene 2002; Gresham 2001; Kendrick 2007; Lee 2004; Lu 2000; Martinez 1996; Morrongiello 1998; Richards 1991; Terzidis 2007; Wang 2009; Wesner 2003; Wright 1995; Zirkle 2005). One study reported health economic outcomes (Lu 2000).

\section{Excluded studies}

See Characteristics of excluded studies table.

\section{Risk of bias in included studies}

The risk of bias across all included studies is summarised in Figure 3 and Figure 4 and is included in the Characteristics of included studies table. Many of the risks of bias across all studies were unclear due to inadequate reporting. Major sources of bias within included studies were from inadequate blinding of both participants and personnel: in most studies, it was not possible to blind participants to allocation, and teachers delivering the intervention were responsible for administering and marking outcome assessments.

\section{Figure 3. Risk of bias graph: review authors' judgements about each risk of bias item presented as percentages} across all included studies.

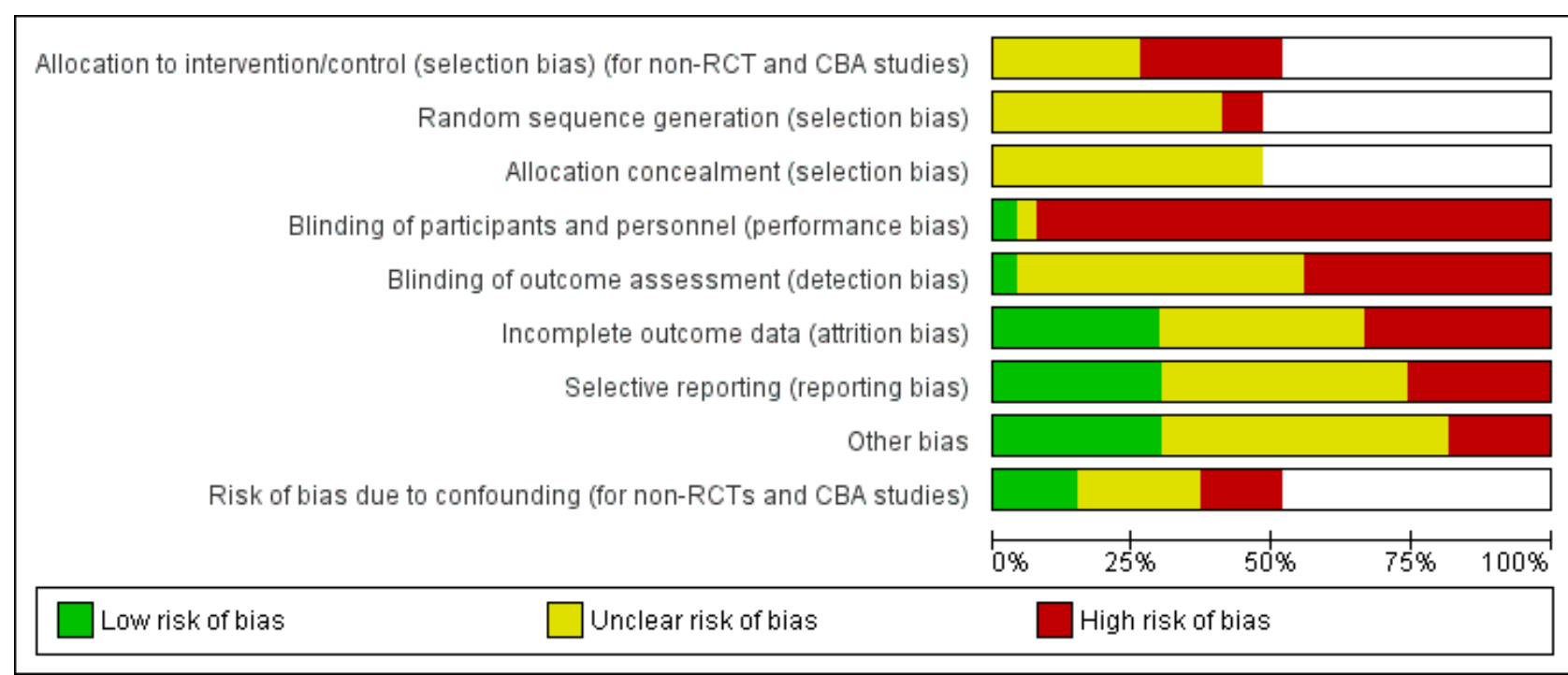


Figure 4. Risk of bias summary: review authors' judgements about each risk of bias item for each included study.

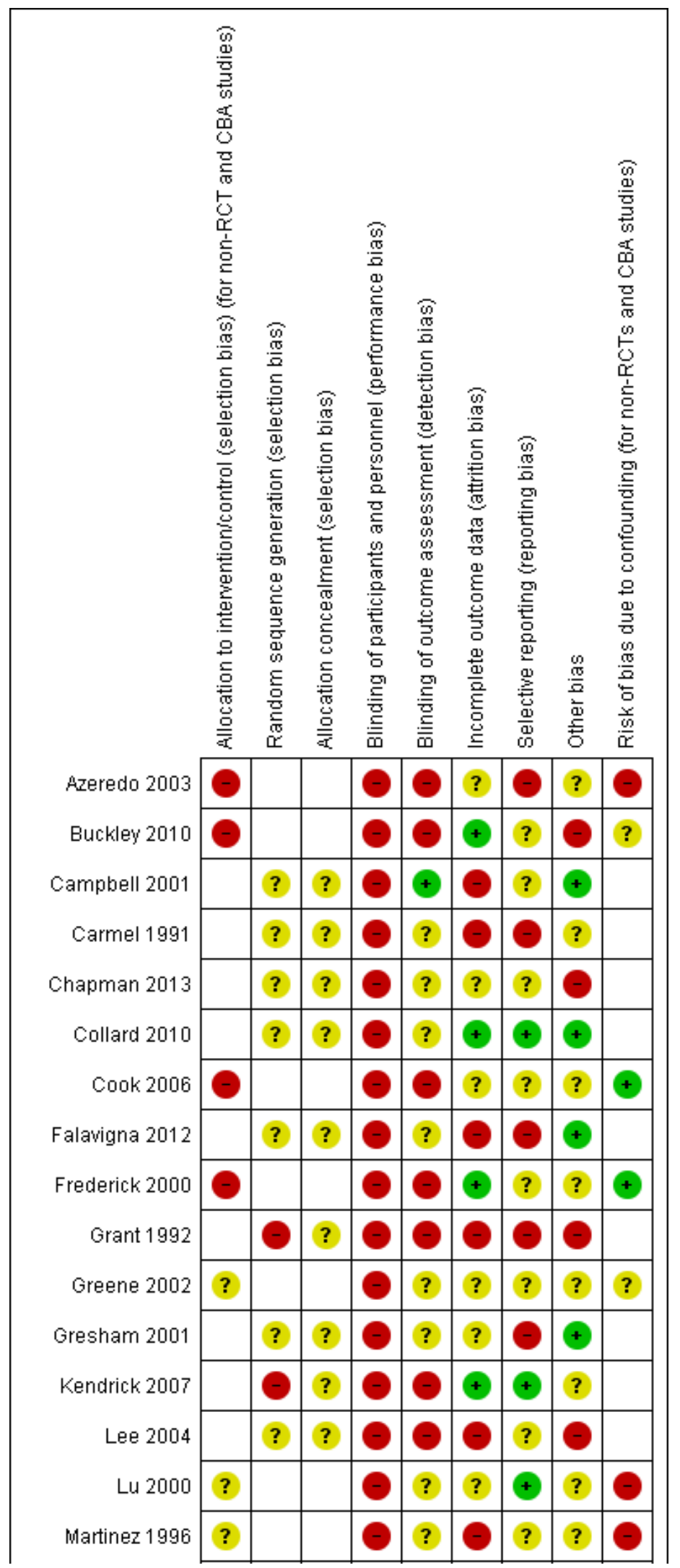


Figure 4. (Continued)

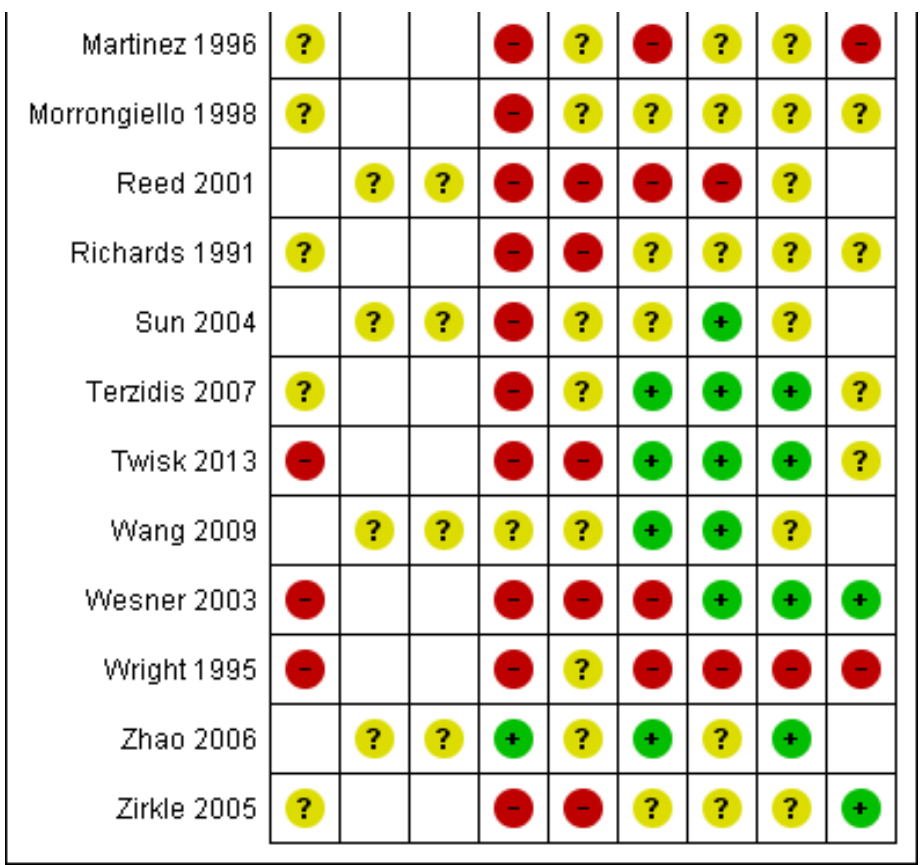

\section{Allocation}

Out of the 27 included studies, 13 were RCTs and 14 were nonRCTs and CBAs. We only assessed random sequence generation and allocation concealment for the RCTs. Of the RCTs, we judged $11(85 \%)$ to have an unclear risk of adequate random sequence generation (Campbell 2001; Carmel 1991; Chapman 2013; Collard 2010; Falavigna 2012; Gresham 2001; Lee 2004; Reed 2001; Sun 2004; Wang 2009; Zhao 2006), and two (15\%) a high risk (Grant 1992; Kendrick 2007). For allocation concealment, we concluded that all 13 RCTs had an unclear risk of bias, mostly due to inadequate reporting.

For the 14 non-RCTs, we judged that seven (50\%) had a high risk of allocation bias (selection bias), mostly due to schools selecting themselves to be part of the study (Azeredo 2003; Buckley 2010; Cook 2006; Frederick 2000; Twisk 2013; Wesner 2003; Wright 1995), and seven $(50 \%)$ had an unclear risk of allocation bias, again largely due to inadequate reporting (Greene 2002; Lu 2000; Martinez 1996; Morrongiello 1998; Richards 1991; Terzidis 2007; Zirkle 2005).

\section{Blinding}

We judged $18(67 \%)$ studies to be at high risk of performance bias due to inadequate blinding of participants and personnel. Of these, eight were RCTs (Campbell 2001; Chapman 2013; Collard 2010; Falavigna 2012; Grant 1992; Kendrick 2007; Lee 2004; Wang 2009), and 10 were non-RCTs (Azeredo 2003; Buckley 2010; Cook 2006; Frederick 2000; Martinez 1996; Morrongiello 1998; Richards 1991; Twisk 2013; Wesner 2003; Wright 1995). We judged that a further eight (30\%) had an unclear risk, and of these four were randomised (Carmel 1991; Gresham 2001; Reed 2001; Sun 2004), and four were non-randomised (Greene 2002; Lu 2000; Terzidis 2007; Zirkle 2005). We considered only one study (3\%), an RCT, to be at low risk of bias (Zhao 2006).

Regarding blinding of those assessing study outcomes, we judged $12(44 \%)$ to be at high risk of bias due to non-blinding, $14(52 \%)$ had an unclear risk of bias and only one (randomised) study (Campbell 2001) had a low risk of bias. For the high risk of bias, four were randomised (Grant 1992; Kendrick 2007; Lee 2004; Reed 2001), and eight were non-randomised (Azeredo 2003; Buckley 2010; Cook 2006; Frederick 2000; Richards 1991; Twisk 2013; Wesner 2003; Zirkle 2005). For the studies at unclear risk of bias (again mostly due to non-reporting) eight were randomised (Carmel 1991; Chapman 2013; Collard 2010; Falavigna 2012; Gresham 2001; Sun 2004; Wang 2009; Zhao 2006) and six were non-randomised (Greene 2002; Lu 2000; Martinez 1996; Morrongiello 1998; Terzidis 2007; Wright 1995). We assessed all studies measuring self-reported outcomes to be at high risk of bias.

\section{Incomplete outcome data}

The risk of bias due to incomplete outcome data varied across studies. We assessed $10(36 \%)$ studies at unclear risk (three randomised (Chapman 2013; Gresham 2001; Sun 2004) and seven non-randomised (Azeredo 2003; Cook 2006; Greene 2002; Lu 2000; Morrongiello 1998; Richards 1991; Zirkle 2005)), we judged eight (30\%) at low risk (four randomised (Collard 2010; Kendrick 2007; Wang 2009; Zhao 2006) and four non-randomised (Buckley 2010; Frederick 2000; Terzidis 2007; Twisk 2013)), and we assessed nine (33\%) at high risk (six randomised (Campbell 2001; Carmel 1991; Falavigna 2012; Grant 1992; Lee 2004; Reed 2001) and three non-randomised (Martinez 1996; Wesner 2003; Wright 1995)). Often, our assessment of unclear risk was due to the number of participants allocated at baseline not being clearly defined. We made judgements of high risk when less than $80 \%$ of the baseline sample provided outcome data at follow-up (Wesner 2003; Wright 1995), when the studies lacked matched data (Lee 2004; Martinez 1996; Reed 2001), contained incomplete data returns from schools (Grant 1992), or when studies contained participants that had not received parental consent (Falavigna 2012).

School-based education programmes for the prevention of unintentional injuries in children and young people (Review) 


\section{Selective reporting}

We considered the risk of selective outcome reporting to be unclear in 12 (44\%) studies; four were randomised (Campbell 2001; Chapman 2013; Lee 2004; Zhao 2006) and eight were nonrandomised (Buckley 2010; Cook 2006; Frederick 2000; Greene 2002; Martinez 1996; Morrongiello 1998; Richards 1991; Zirkle 2005). We assessed the risk to be high in seven (26\%) studies, of which five were randomised (Carmel 1991; Falavigna 2012; Grant 1992; Gresham 2001; Reed 2001) and two were non-randomised (Azeredo 2003; Wright 1995). The risk of selective outcome reporting was low in eight studies (30\%) (four randomised (Collard 2010; Kendrick 2007; Sun 2004; Wang 2009) and four non-randomised (Lu 2000; Terzidis 2007; Twisk 2013; Wesner 2003)). The reasons for our 'high risk' assessment included incomplete reporting for some outcomes of interest (Azeredo 2003; Carmel 1991; Falavigna 2012; Grant 1992), no clear description of method of scoring for assessment tools used (Reed 2001), and only selected items being reported in tables (Wright 1995).

\section{Other potential sources of bias}

We judged five (18\%) studies to be at high risk of other bias, for reasons including: failure to adjust for clustering effects (Buckley 2010 (non-randomised); Lee 2004 (randomised)), misclassification bias (Grant 1992 (randomised)), lack of signed parental consent (Chapman 2013 (randomised)) and differences in test instrument used between intervention and control group (Wright 1995 (nonrandomised)). We judged 14 (52\%) studies at unclear risk: five were randomised (Carmel 1991; Kendrick 2007; Reed 2001; Sun 2004; Wang 2009) and nine were non-randomised (Azeredo 2003; Cook 2006; Frederick 2000; Greene 2002; Lu 2000; Martinez 1996; Morrongiello 1998; Richards 1991; Zirkle 2005). We judged eight $(29 \%)$ to be at low risk of other bias, five being randomised (Campbell 2001; Collard 2010; Falavigna 2012; Gresham 2001; Zhao 2006) and three being non-randomised (Terzidis 2007; Twisk 2013; Wesner 2003).

\section{Risk of bias due to confounding (non-randomised and controlled before-and-after studies)}

We assessed four (29\%) of the non-RCT/CBA studies at high risk of bias due to confounding (Azeredo 2003; Lu 2000; Martinez 1996; Wright 1995). This was due to a lack of matching in the study design or adjustment in the analysis or statistically significant differences in characteristics between groups of participants. We judged six (43\%) to have an unclear risk (Buckley 2010; Greene 2002; Morrongiello 1998; Richards 1991; Terzidis 2007; Twisk 2013) and four (29\%) to be at low risk (Falavigna 2012; Frederick 2000; Wesner 2003; Zirkle 2005).

\section{Effects of interventions}

See: Summary of findings for the main comparison School injury prevention programmes compared to controls for the prevention of unintentional injuries in children and young people
Self-reported or medically attended unintentional injuries or injuries with an unspecified intent

Five (19\%) studies reported non-medically attended injury occurrence (Chapman 2013; Collard 2010; Lee 2004; Sun 2004; Wang 2009); one (4\%) study reported medically attended injury occurrence (Zhao 2006), and one (4\%) study reported both medically and non-medically attended injuries (Lu 2000). Five studies reported injury incidence rates (Collard 2010; Lu 2000; Sun 2004; Wang 2009; Zhao 2006), and two reported injury incidence proportions (Chapman 2013; Lee 2004).

Lu 2000 was a clustered CBA, and the remaining six were cluster RCTs. The interventions included: a programme using cognitive behavioural change methods to modify risk-taking behaviour in young people aged 13 to 14 years (Chapman 2013); an exercisebased intervention to prevent sport injuries in children aged 10 to 12 years (Collard 2010); an intervention to prevent agricultural injuries in young farmers aged 13 to 18 years (Lee 2004); a teacher-led health education programme with content designed by participating children to prevent a range of injuries in primary and middle school students in China (age range six to 16 years) (Lu 2000; Sun 2004; Zhao 2006); and a peer-educator intervention for preventing a range of injuries in middle school children in China (Wang 2009).

Four studies, all conducted in China, were similar in terms of the interventions, adopting a health education approach for primary or middle school-age children (Lu 2000; Sun 2004; Wang 2009; Zhao 2006, and three of these studies were included in a metaanalysis of injury incidence rates (Lu 2000; Wang 2009; Zhao 2006; see Figure 5). We were unable to include Sun 2004 as this was a $\mathrm{PhD}$ thesis and only the abstract was available. We sought further information from the author but were unsuccessful in obtaining this. For the studies in the meta-analysis, the participants $(12,977$ in total, with 2073 person-years after adjusting for clustering) were aged from six to 16 years (Lu 2000), 12 to 15 years (Wang 2009), and seven to 13 years (Zhao 2006). The interventions comprised providing students with booklets and classes on injury prevention, letters to families encouraging co-operation with safety education, a mass media campaign and training teachers to enhance safety in physical activity classes and at school drop-off and pick-up times (Lu 2000); weekly injury prevention sessions for students provided by peer educators which included activities, presentations, games or themed discussions (Wang 2009); and lectures and leaflets provided to teachers, parents and students, plus safety posters and a safety course provided to children before summer and winter school holidays (Zhao 2006). In two studies, the control arm received no intervention (Lu 2000; Wang 2009), and in one study, they received disease prevention education (pneumonia, irondeficiency anaemia, rickets and common communicable diseases) (Zhao 2006). The three studies had 2073 person-years of follow-up after adjusting for clustering. The pooled IRR was $0.73(95 \% \mathrm{Cl} 0.49$ to 1.08 ) and there was substantial heterogeneity between effect sizes $\left(\mathrm{Chi}^{2}=5.46\right.$, degrees of freedom $\left.(\mathrm{df})=2, \mathrm{P}=0.07 ; \mathrm{I}^{2}=63 \%\right)$ (Analysis 1.1). We assessed the quality of evidence as low, due to the high heterogeneity and wide Cls. 
Figure 5. Forest plot of comparison: 1 Injury rates, outcome: 1.1 Injury rates at follow-up.

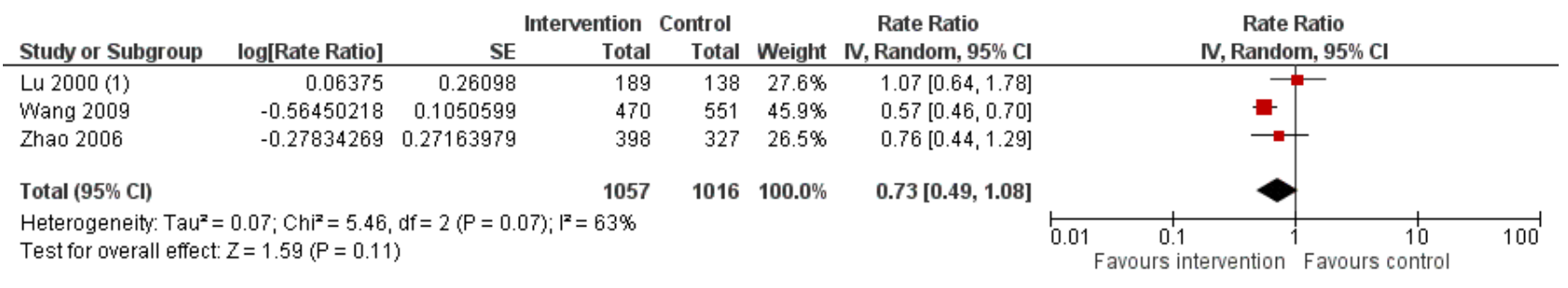

Footnotes

(1) Lu 2008 is a non-randomised study and follow-up rates have been adjusted for baseline rates

We undertook sensitivity analysis and excluded the non-RCT (Lu 2000). This had the effect of lowering the injury IRR in the intervention versus control groups (IRR $0.59,95 \% \mathrm{Cl} 0.49$ to 0.72 ) and there was no heterogeneity between effect sizes $\left(\mathrm{Chi}^{2}=0.97\right.$, $\left.\mathrm{df}=1, \mathrm{P}=0.33 ; \mathrm{I}^{2}=0 \%\right)$. This implies that the non-RCT design may explain the heterogeneity in the pooled analysis.

Sun 2004 reported a reduction in injury in the intervention schools that delivered an injury prevention campaign, including the distributing booklets and information leaflets, helping children with "blackboard bulletins" and offering posters on safety education to schools (adjusted risk ratio $0.65,95 \% \mathrm{Cl} 0.57$ to 0.76 ).

The remaining three studies that were not included in the metaanalysis described self-reported (non-medically attended) injury. Chapman 2013 reported the proportion of students who had at least one transport injury in a three-month period before and after the intervention for both the control and intervention groups. While the proportions of students who experienced at least one transport injury decreased by $6.0 \%$ from baseline in the intervention group and increased by $4.8 \%$ from baseline in the control group, the odds ratio (OR) showed no evidence of an effect (using intervention group as a reference, OR 1.42, 95\% $\mathrm{Cl} 0.62$ to $3.17, \mathrm{P}=0.387$ ). Collard 2010 investigated the I-Play programme, a physical activity injury prevention scheme. They found weak evidence of a reduction in injury incidence (hazard ratio $0.81,95 \% \mathrm{Cl} 0.41$ to 1.59 , adjusted for clustering) and this effect was stronger in children with lower initial levels of activity (hazard ratio $0.47,95 \% \mathrm{Cl} 0.21$ to 1.06). Lee 2004 described the impact of the Future Farmers of America (FFA) programme, comparing a standard intervention (promotional material, guides, newsletters and training for trainers) and enhanced intervention (with additional national trainer conventions and contact with a programme facilitator) with a control group. The control group received marketing and promotion of the Partners programme only (via newsletters, videos or conferences). In the standard intervention group, at three-month follow-up, $22 \%$ of children reported an injury in the past three months, as did $24 \%$ of children in the enhanced intervention group, and $24 \%$ in the control group. No $P$ values were reported.

\section{Observed safety skills}

Two studies reported on observed safety skills for 1506 children after the intervention had been delivered (Kendrick 2007; Frederick 2000). While both studies found an improvement in the observed safety skills, we assessed the quality of evidence for this outcome to be low. This was due to the high risk of selection bias of included schools (as one of the two studies was a CBA), inconsistency of interventions and outcome measures, and imprecision as there were wide $\mathrm{Cls}$ in one of the two included studies and a paucity of data. However, the effect sizes were large. This rating of the evidence for this outcome was low quality means that our confidence in these effect estimates was limited.

Kendrick 2007 studied the Risk Watch programme targeting cycle and pedestrian injuries, falls, fire and burns, and poisonings. Children's safety skills were observed in scenarios including 'stop, drop and roll', road safety (including cycle helmet wearing) and poisoning secondary prevention. This study found some evidence of improvement in combined scores for all safety skills (mean difference 11.9, SD 1.4 to $22.5, P=0.03$ ) but only fire and burn prevention skills individually showed an improvement (OR 8.93, $95 \% \mathrm{Cl} 1.67$ to $47.78, \mathrm{P}=0.01$ ).

Frederick 2000 evaluated the impact of the IMPs programme. This was a multi-component intervention based in the classroom and in the emergency department at local hospitals and aimed at preventing and minimising the impact of a range of injury mechanisms including road safety, accidents in the home, fire, electricity, poisoning and waterway injuries. They used scenarios to test skills practices and retention, and found a higher percentage of children in the intervention group compared to the control group exhibited correct basic life support skills at the five-month post-intervention test (e.g. assessment of danger: $36 \%$ in the intervention group versus $3 \%$ in the control group, $\mathrm{P}<0.0005$; assessment of responsiveness: $58 \%$ in the intervention group versus $12 \%$ in the control group, $\mathrm{P}<0.0005$; assessment of circulation: $7 \%$ in the intervention group versus $1 \%$ in the control group, $\mathrm{P}<0.0005)$.

\section{Behaviour}

We divided this outcome into observed and self-reported behaviour. All four studies (five articles) that reported observed safety behaviour showed improved practices, and 13 out of 19 studies describing self-reported behaviour showed improved practices.

However, we assessed the quality of the evidence for this outcome to be very low, due to the high risk of selection bias of included schools, inconsistency in the methods of collecting data and intervention types, and wide $\mathrm{Cls}$ in the results presented. This means we have very little confidence in the effect estimates presented. 


\section{Observed behaviour}

Four studies reported directly observed behaviour for 7022 children after the intervention had been delivered (Azeredo 2003; Reed 2001; Wright 1995; Zirkle 2005).

Azeredo 2003, studying school children aged five to 11 years and their families, introduced multiple interventions in 18 to 27 lessons, depending on the grade of child. The intervention included smokealarm giveaways, school cycle fairs with helmet giveaways, safety pen-pal letters, a letter to parents and injury prevention talks at parent-teacher meetings. The control group had no intervention. Seat-belt use was observed before, during and two weeks after the intervention. In the intervention group, observed seat-belt use for passengers increased from $21 \%$ before the intervention, to $36 \%$ after completion. However, there was noted to be a $1 \%$ decrease in observed seat-belt use within the control group. Among the intervention group, observed cycle helmet use increased from $0 \%$ to $10 \%$ (no P values given), although it is unclear to what extent this was affected by free helmet giveaways. There were no data given on the control group.

Reed 2001 implemented the AgDARE programme among highschool agriculture students in the ninth and tenth grades in Kentucky, US. This incorporated two elements; narrative (cognitive) simulations, involving problem-solving activities and a written component, and physical simulations whereby they could gain a better understanding of the difficulty of performing certain farm jobs with a disability. The control group received no intervention. After one year, researchers and agricultural teachers made a farm visit to 29 students who had received the intervention. Seventysix percent of students had made at least one positive safe work behaviour change, although no $P$ values were presented. The control group participants were not visited.

Wright 1995 studied the implementation of the Think First programme aimed at reducing brain and spinal cord injuries, among school children aged between 11 and 15 years. The intervention programme was delivered by project staff and a person who had a brain/spinal cord injury. It included a film, lecture and talk by the injured person describing the traumatic injury. The programme covered areas such as seat-belt use, use of motorbike and cycle helmets, avoiding drugs and alcohol when driving or participating in sport, and checking the depth of water when swimming or diving. The control group received the same programme after the study had finished. Behaviour was observed at one control school, one intervention middle school, and one intervention high school. Assessment took place before the intervention, two weeks and three months after the intervention for the intervention group, and two weeks before and one day before a Think First assembly for the control group. Statistical comparisons were within-group only. Among middleschool children in the intervention group there was very weak evidence of an increase in observed seat-belt use at two weeks from $31 \%$ to $36 \%(P=0.03)$, but decrease to $27 \%$ by three months $(P<0.05)$. There was no evidence of a change in cycle helmet use although the numbers of children observed were small. There was also no evidence of a change in the control group between the first and second observations of helmet or seat-belt use.

Zirkle 2005 also reported on the Think First programme among primary school children. Behaviour was observed by parents, who noted a range of pedestrian, sport, interpersonal and car safety behaviours and the intervention was reported to have resulted in positive behaviour changes, although there were no data presented.

\section{Self-reported behaviour and practices}

Nineteen studies assessed the impact of interventions on selfreported behaviour and practices for an approximated 48,000 children following the intervention delivery (Azeredo 2003; Buckley 2010; Campbell 2001; Chapman 2013; Collard 2010; Falavigna 2012; Frederick 2000; Gresham 2001; Kendrick 2007; Lee 2004; Martinez 1996; Morrongiello 1998; Reed 2001; Richards 1991; Sun 2004; Twisk 2013; Wesner 2003; Wright 1995; Zirkle 2005).

\section{Safety equipment wearing}

Eight studies reporting on safety equipment wearing (Azeredo 2003; Falavigna 2012; Martinez 1996; Morrongiello 1998; Richards 1991; Wesner 2003; Wright 1995; Zirkle 2005).

Azeredo 2003, in a study incorporating a safety curriculum, smokealarm giveaway, school cycle fairs, safety pen-pal letters and school letters to parents, found that among the intervention group, selfreported passenger seat-belt use increased from $42 \%$ at baseline to $65 \%$ after the programme in children from grades kindergarten to grade one $(P=0.04)$. Self-reported passenger seat-belt use was not reported in the control group. Driver seat-belt use increased by $2 \%$ in the intervention group, but there was no increase in the control group (no $\mathrm{P}$ values given). Among the children in the intervention group, there was some evidence of an increase in cycle helmet use (in children in kindergarten to grade one $(P=0.03)$ and children in grades two to five $(P<0.01))$. The study did not mention the effects of the smoke-alarm giveaway component of the programme.

Falavigna 2012 reported the Think Well programme, which is similar to the Think First For Kids programme. This involved a 60-minute session provided by trained researchers, and comprised watching a video of a child describing their injury and its impact, and a brain and spinal cord trauma prevention programme. This study reported weak evidence of an increase in cycle helmet wearing from $8.6 \%$ at baseline to $14.5 \%$ at one-week postintervention $(P=0.039)$ and $17.7 \%$ at five months postintervention $(P=0.034)$. The study reported some evidence of an increase in use of skateboard and rollerblading safety equipment one-week postintervention (from $28 \%$ at baseline to $33.6 \%$ at one week, $\mathrm{P}=0.460$ ), and the effect was stronger at five months (from $33.6 \%$ at one-week postintervention to $40.4 \%$ at five months, $P=0.037$ ). There was no evidence of a decrease in use of skateboarding and rollerblading equipment in the control group (from $28.4 \%$ at baseline to $27.3 \%$ at one week, $P=0.992$, and $22.6 \%$ at five months, $P=0.421$ ). They did not report evidence of a change in the proportion of young people using seat belts or motorcycle helmets. However, there was some evidence that the proportion of young people in the intervention group who would sometimes ride in a car when someone had drunk alcohol increased after the intervention ( $36.9 \%$ before intervention to $42.1 \%$ after intervention, $\mathrm{P}=0.046$ ). No data were presented for the control group.

Martinez 1996 introduced a five-component course into grades 10, 11 and 12 in a US high school. This consisted of audiovisual aids, a physical demonstration and a didactic lecture. The sessions covered a basic lesson on types of energy, particularly kinetic energy; safety features of vehicles; occupant kinematics and forces/crash prevention; a demonstration of a rollover, followed 
by designing and testing of crash vehicles. The control group received their normal physics lesson. Self-reported behaviour was collected at baseline, two weeks and six months after the end of the intervention. After adjusting for baseline measures, they found evidence of a difference between the control and intervention groups at six months in favour of the intervention for wearing a seat belt as a passenger $(P<0.001)$ but no evidence of an effect of wearing a seat belt as the driver $(P=0.63)$.

Morrongiello 1998 looked at several injury mechanisms, particularly focusing on head injuries caused by cycling, sport and vehicles. The intervention covered general safety education, including swimming, sun safety and stranger danger and was delivered by a teacher in the presence of a project co-ordinator. It consisted of four activity stations. The control group received no intervention. Among the intervention group, there was a higher self-reported use of helmets when cycling and rollerblading postintervention, compared to pre-intervention (from 62\% to $83 \%$ when cycling and from $45 \%$ to $65 \%$ when rollerblading, $P<0.05$ ), but not in the use of a seat belt (from $87 \%$ to $95 \%$, no P values given). Outcomes from the control group were not reported.

Richards 1991 implemented an injury prevention curriculum delivered over three months by a teacher. There was an eightcomponent curriculum which included spinal cord awareness and water safety. For each component, teachers could choose from a variety of activities. It was not clear what the control group received. There was an increase in seat-belt use for children in different school grades. Baseline levels of seat-belt use in the intervention group ranged from $60 \%$ to $80 \%$, and rose to between $72 \%$ and $86 \%$ post-intervention. In the control group, baseline levels of seat-belt use were between $74 \%$ and $84 \%$, which decreased to between $60 \%$ and $82 \%$ at the second observation.

Wesner 2003 used the Think First programme, which involved the intervention group receiving a one-hour session, incorporating a video of teenagers with a spinal cord injury, an educational session with audio-visual aids, a description of brain anatomy and pathophysiology, and an account from a teenager with a spinal cord injury. This study reported (using within-group analyses) an increase in self-reported cycle helmet use among the intervention group from $32.6 \%$ before to $40.1 \%$ after the intervention $(P=0.05)$, but a decrease in the control group from $40.9 \%$ to $40.0 \%$ (no $P$ values given); an increase in protective equipment wearing while rollerblading in the intervention group from $70.6 \%$ to $72.8 \%$ ( $P=$ 0.049 ) compared to from $66.5 \%$ to $68.4 \%$ in the control group (no $P$ value given); and an increase in protective equipment wearing while skateboarding in the intervention group from $1.4 \%$ to $3.0 \%$ ( $P$ $=0.01$ ) compared to from $4.8 \%$ to $7.4 \%$ in the control group (no $\mathrm{P}$ value given).

Wright 1995, in an analysis of the Think First programme, found little impact on self-reported behaviours, with no evidence of an increase in seat-belt wearing or motorcycle helmet wearing, even though baseline levels of motorcycle helmet wearing were lower than in the Falavigna study at $60 \%$ to $80 \%$ (Falavigna 2012).

Zirkle 2005 described an increase in self-reported safety behaviours following the Think First For Kids programme but no data were provided (this was a PhD thesis and only the summary was available).

\section{Risk behaviour relating to the road}

Four studies reported self-reported risky behaviour relating to the road (Chapman 2013; Gresham 2001; Martinez 1996; Twisk 2013).

Chapman 2013 studied the impact of the SPIY programme aimed at reducing transport injuries among 13- to 14-year-old school children in Australia. The intervention group was presented with risk-taking injury scenarios, incorporating activities such as role play and discussion. These used cognitive behavioural change principles. The control group received no intervention. The outcome of interest for this review was self-reported transport risk behaviour. Comparing the control with the intervention (reference) group there was no evidence of a difference in the post-test reporting of transport risk behaviour (OR $1.37,95 \% \mathrm{Cl} 0.64$ to 2.93 , $P=0.415)$

In the Think First For Kids programme, Gresham 2001 found that both the intervention and control groups showed an improvement in risk behaviour scores (within-group before-andafter comparison), with scores increasing significantly more in the intervention than control groups in all grades. This varied between the different grades. In grade one, there was a score increase of 3.06 $(95 \% \mathrm{Cl} 2.76$ to $3.35, \mathrm{P}<0.01$ ) in the intervention group compared to $1.70(95 \% \mathrm{Cl} 1.35$ to $2.06, \mathrm{P}<0.01)$ in the control group. In grade two, this was $2.80(95 \% \mathrm{Cl} 2.46$ to $3.14, \mathrm{P}<0.01)$ in the intervention group versus $1.10(95 \% \mathrm{Cl} 0.74$ to $1.46, \mathrm{P}<0.01)$ in the control group and in grade three it was $3.27(95 \% \mathrm{Cl} 2.92$ to $3.63, \mathrm{P}<0.01)$ in the intervention group versus $1.55(95 \% \mathrm{Cl} 1.17$ to $1.93, \mathrm{P}<0.01)$ in the control group.

Martinez 1996, incorporating road safety into a physics curriculum, also assessed driving-related risky behaviour (e.g. speeding and drink driving) with data collected at baseline, two weeks and six months after the end of the intervention. After adjusting for baseline measures, they found some evidence of a difference between the control and intervention groups at six months in favour of the intervention for speeding $(P<0.001)$ but no evidence of a difference for drink driving $(P=0.7)$.

Twisk 2013 used a lorry at primary schools to give pedestrian and cyclist safety instruction. Students could visualise the driver's field of view and were given information on safe road behaviour. There were two intervention groups, one targeting awareness of blind spot programmes (addressing carelessness) and the other targeting competency (addressing blind spot hazards). The control group received no intervention. Compared to the control group, there was no evidence of a change in the self-reported correct positioning of cycle or self as a pedestrian, in either intervention group. For the awareness group, mean scores (for correct positioning) increased from a baseline of 9.5 (SD 1.4) to 9.7 (SD 1.1) in the intervention group compared to a decrease in mean scores from 9.6 (SD 1.2) at baseline to 9.3 (SD 1.5) in the control group (analysis of covariance (ANCOVA) $\mathrm{P}=0.84$ ). For the competency group, the mean score increased from 8.2 (SD 2.5) to 9.5 (SD 1.8) in the intervention group compared to a decrease in the mean score from 8.7 (SD 1.4) to 8.5 (SD 1.8) in the control group (ANCOVA P = 0.30).

\section{Agriculture-related injuries}

Two studies (reported in three articles) described self-reported behaviour related to agriculture-related injury prevention (Lee 2004; Reed 2001). 
Lee 2004 described the impact of the FFA Partners programme, with a standard (promotional material, guides, newsletters and training for trainers) and enhanced intervention (with additional national trainer conventions and contact with a programme facilitator). The control group received marketing and promotion of the Partners programme only (via newsletters, videos or conferences). This study found no evidence of a difference between the intervention and control groups for self-reported safety consciousness (standard post-test mean score 2.9 (SD 0.72), enhanced post-test mean score 3.0 (SD 0.69), control post-test mean score 3.0 (SD 0.77); $\mathrm{P}=0.47)$ ), or dangerous risk taking (standard post-test mean score 3.2 (SD 0.73), enhanced post-test mean score 3.2 (SD 0.72), control post-test mean score 3.2 (SD 0.78); $\mathrm{P}=0.38)$.

Reed 2001 implemented the AgDARE programme among highschool agriculture students in the ninth and tenth grades in Kentucky. This incorporated two elements; narrative (cognitive) simulations, involving problem-solving activities and a written component, and physical simulations, whereby they could gain a better understanding of the difficulty of performing certain farm jobs with a disability. This study used a 10-item Stages of Change instrument to assess the agricultural students' transitions from contemplation to action to make a positive work behaviour change. They found that there was some evidence of a higher mean Stages of Change score in the intervention compared to the control groups (mean: 31.1 (SE 0.6) in the intervention group, 21.4 (SE 0.5) in the control group, F statistic (df) $134.5(2 ; 604) \mathrm{P}<0.001)$. A higher Stages of Change score indicates that those participants were more likely to make a behaviour change.

\section{Sports injuries}

Collard 2010, in a study from the Netherlands, looked at the impact of the I-PLAY programme on self-reported safety behaviours among 10- to 12-year-old children. This involved two physical exercise (PE) lessons per week, over eight months, delivered by a teacher with monthly newsletters and access to online information. The control group received their normal PE classes. There was no evidence of a difference between the intervention and control group according to self-reported safety behaviours (measured on a Likert scale). The differences between means were $0.05(95 \% \mathrm{Cl}-0.04$ to 0.14$)$ for wearing protective equipment during organised sport, 0.01 (95\% $\mathrm{Cl}-0.21$ to 0.19$)$ for wearing protective equipment during leisure activities and $0.07(95 \% \mathrm{Cl}-0.13$ to 0.27$)$ for wearing appropriate footwear during PE.

\section{Multiple injury types}

Five studies, reporting on interventions aimed at preventing multiple injury types, included self-reported behaviour and practices (Buckley 2010; Campbell 2001; Frederick 2000; Kendrick 2007; Sun 2004).

Buckley 2010 reported on the SPIY programme aimed at 13to 14-year-old children in a deprived urban area in Australia. The intervention schools received teacher training, a teacher's manual and a student workbook for eight sessions. These were 50 minutes in duration and included presentations about risktaking and injury scenarios, introduction to first aid and cognitive behavioural activities to prevent the risk-taking behaviour, including protecting friends. The control schools continued with their normal curriculum, but could use the SPIY programme after the end of the study. The intervention group had a greater positive change in their self-reported risk-taking score compared to the control group (from 2.39 to 1.93 with intervention versus 1.67 to 1.85 with control, $\mathrm{P}=0.014$ ).

Campbell 2001 reported on the impact of a first aid and home safety programme among 11- to 18-year-old children with a Hispanic background and their parents. The intervention focused on prevention of injuries and responding to emergency situations and included household safety, emergency care, controlling bleeding and treating burns, presented in eight sessions. The control group received an alcohol and tobacco prevention programme. At oneyear follow-up both the intervention and control groups reported making home safety behaviour changes. For example, $81 \%$ of all those surveyed reported removing small objects, $90 \%$ reported keeping chemicals and 95\% reported keeping medicines out of reach, and $43 \%$ had purchased fire extinguishers. The only evidence of difference between intervention and control groups was in the percentage of families who had practised a fire escape plan ( $47 \%$ in the intervention group, $31 \%$ in the control group, $\mathrm{P}<0.01$ ).

To assess self-reported behaviour following the IMPs programme, Frederick 2000 used a video showing dangerous scenarios to provide students with the opportunity to describe what they would do in those situations. There appeared to be some weak evidence of a difference between the intervention and control groups in the percentages of children reporting a range of safe practices. These included, for example, situations such as not playing near water ( $25 \%$ in the intervention group versus $17.8 \%$ in the control group, $\mathrm{P}$ $<0.01)$ and identifying dangers for electrocution risk (18.1\% in the intervention group versus $7.3 \%$ in the control group, $\mathrm{P}<0.01$ ).

For the Risk Watch programme, Kendrick 2007 found a difference in the adjusted OR between the intervention and control groups in the number of children self-reporting using matches $(83.0 \%$ with intervention versus $74.7 \%$ with control, adjusted OR $1.84,95 \% \mathrm{Cl}$ 1.06 to $3.20, P=0.031$ ). However, on other measures (e.g. having smoke-alarms, cooking food, getting medicine without an adult present and road safety), there was no evidence of a difference between groups.

Sun 2004 studied the impact of a safety intervention among over 7000 Chinese school pupils. This intervention included distributing booklets and information leaflets, helping children with "blackboard bulletins" and offering posters on safety education to schools. The control group received general information on food hygiene and disease prevention. In the questionnaire follow-up at one year, there was reported to be a greater decrease in the score of risk-taking behaviour for the intervention group than the control group (no $P$ values given).

\section{Safety knowledge}

Twenty-one studies reported on changes in safety knowledge for 46,550 children following the intervention (Azeredo 2003; Campbell 2001; Carmel 1991; Collard 2010; Cook 2006; Falavigna 2012; Frederick 2000; Grant 1992; Greene 2002; Gresham 2001; Kendrick 2007; Lee 2004; Lu 2000; Martinez 1996; Morrongiello 1998; Richards 1991; Terzidis 2007; Wang 2009; Wesner 2003; Wright 1995; Zirkle 2005). Of these, 19 reported an improvement in at least one question domain in the intervention compared to the control group. 
However, we assessed the quality of this evidence as very low, meaning that we have little confidence these results. This is because 11 studies were CBA or non-RCT design with a high risk of selection bias of included schools. There was also considerable inconsistency in knowledge tested, questionnaire designs and methods of collecting data, and a wide range of intervention types and pedagogical approaches, which may have contributed to the wide range of effect sizes. In addition, results were presented in a way that often made precision difficult to compare.

\section{Vehicle and road safety knowledge}

Four studies reporting on road and vehicle safety included safety knowledge as an outcome (Cook 2006; Martinez 1996; Wright 1995; Zirkle 2005).

Cook 2006 reported the effect on class safety knowledge when an injured classmate participated in safety education sessions. In the intervention group, the child gave a presentation and then interacted with his or her classmates. A nurse gave a presentation on injury occurrence and prevention, which involved discussions, short videos, written materials and a workbook. The first control group received the same information and the injured child's scenario, but without an actual injured child (enhanced control), while the second control group only received some anatomy education (basic control). Six classrooms were in the intervention group, and six in each of the control groups. There was improvement between the pre- and post-test scores in both the intervention and enhanced control group, with five out of six classrooms in each group showing improvement $(P<0.05)$. At one-month post-intervention, $100 \%$ of the intervention classes maintained significantly higher test scores $(P<0.05)$ compared to $66 \%$ of the enhanced control group classes.

Martinez 1996 used a seven-item questionnaire, which included questions about the physics of crashes, demographics of people involved in crashes and characteristics of automobiles. Compared to the control group, the intervention group showed higher safety knowledge scores two weeks' post-intervention ( 0.77 with intervention versus 0.94 with control, $\mathrm{P}<0.001$ ), and six months' post-intervention ( 0.75 with intervention versus 0.89 with control, $\mathrm{P}<0.001)$.

Wright 1995 used a 22-item questionnaire for the intervention schools, and a five-item questionnaire for the control schools. For the intervention schools, these were administered before the intervention, at two weeks' post-intervention, and three months' post-intervention and for control schools two weeks before, and one day before the assembly where they were given the same curriculum information as the intervention group. From baseline to three months' post-intervention there was a significant increase in safety knowledge in the middle school (from 15.0/22 to 16.2/22, P $<0.05$ ), but a decrease in scores in the high school (from 16.1/22 to $14.6 / 22, \mathrm{P}<0.05)$. There were no significant changes in knowledge scores in the control school from two weeks before to one day before (from $4.6 / 5$ to $4.6 / 5$ ).

Zirkle 2005 implemented the Think First programme in five control and five intervention schools. There was very limited information on the actual content of the curriculum in the article, but similar Think First programmes include activities or teaching aimed at reducing brain and spinal cord injuries. This study reported a significantly greater improvement in safety knowledge in the intervention versus the control group, although they provided no data or $\mathrm{P}$ values.

\section{Multiple injury safety knowledge}

Twelve studies involving multiple injury mechanisms reported on safety knowledge (Azeredo 2003; Campbell 2001; Falavigna 2012; Frederick 2000; Greene 2002; Gresham 2001; Kendrick 2007; Lu 2000; Morrongiello 1998; Richards 1991; Wang 2009; Wesner 2003).

Azeredo 2003 used two different instruments to measure children's safety knowledge (a four-item activity and written questions for children in kindergarten to grade one and a 20-item multiple choice questionnaire for children in grades two to five). These included questions on emergency telephone numbers, good safety habits, intersection/stop signs, train warnings and good swimming habits for the younger children, and how to handle emergencies, pedestrian rules, cycle rules, water safety rules and home fire safety for the older children. The study showed an increase between the baseline and post-test scores in the intervention schools ( $P$ values all $<0.01$ ). In both age groups, there also was a difference in the post-test scores between the intervention and control schools ( $P$ values between $<0.01$ and 0.04 ).

Campbell 2001 reported that a higher proportion of students in the intervention group could correctly identify more items in a first aid kit than students in the control group. The baseline number of items correctly identified in the control group was 3.8, rising to 4.1 immediately post-intervention, and 4.3 at the one-year follow-up. The baseline number of items correctly identified in the intervention group was slightly lower than the control at 3.7. This rose to 4.6 post-intervention and remained at 4.6 at the one-year follow-up $(\mathrm{P}<0.001$ immediately post-intervention and $\mathrm{P}<0.01$ at one-year follow-up).

Among intervention group children, Falavigna 2012 found no evidence of a difference in the effects of traumatic brain injury, occipital lobe function and seat-belt use knowledge scores between the control and intervention groups at baseline, but there was an improvement in traumatic brain injury $(P<0.001)$ and occipital lobe function $(P<0001)$ immediately post-intervention and at five months in the intervention group. Knowledge about seat-belt use was similar in both the intervention and control groups at baseline and did not change during the intervention (no $P$ values provided).

Frederick 2000 assessed the impact of the IMPS programme on students' knowledge by a quiz, administered before and five months after the intervention. There was an increase in safety knowledge scores from baseline in both groups $(P<0.01)$, although the intervention group demonstrated greater knowledge than controls in calling 999 (UK's emergency telephone number), first aid for burns and for choking. Data comparing scores for intervention and control groups were not presented.

Greene 2002 reported on Phase III of the Think First For Kids curriculum. This was a six-week, six-subject curriculum which was integrated into the usual school curriculum. The units covered the structure and function of the brain and spinal cord, road traffic safety, conflict resolution, and water, sports, playground and recreational safety. The control group received no intervention. In the post-intervention questionnaire, administered one week after the six-week teaching period, all school grades in the intervention 
group had higher safety knowledge scores related to brain and spinal cord injury than the controls (between the grades, $P$ values ranged from 0.0001 to 0.0037 ) and there was an indication of increased water safety knowledge ( $P$ values between 0.0001 and 0.0489). In cycle safety questions, the intervention group had higher scores than the control groups in two grades (grade three, $P=0.02$; grade one, $P=0.07$; grade two not significant (no $P$ value given)). Regarding the motor vehicle/pedestrian safety questions, there was no evidence of a difference between the intervention and control groups in grade one. However, among children in grades two and three, the scores for the intervention group were higher than those of the control group $(\mathrm{P}=0.0143$ for grade two and 0.0134 for grade three). There was no evidence of a difference in safety knowledge regarding playground and sports safety between the intervention and control groups.

Gresham 2001, also using the Think First For Kids programme, reported that the intervention group had a larger increase in their knowledge score than the control group $(P<0.001)$. In the intervention group, there was an increase from pre-test scores of between $19 \%$ and $23 \%$, measured by individual grades of children. Scores for the control group were not reported.

In the Risk Watch programme, Kendrick 2007 used an ageappropriate questionnaire to assess knowledge, with questions illustrated pictorially. In the post-test questionnaire, compared to the control group, the intervention group children answered more fire and burn protection questions correctly (difference between means $7.0 \%, 95 \% \mathrm{Cl} 1.5 \%$ to $12.6 \%, \mathrm{P}=0.01$ ) but there was no evidence of a difference in safety knowledge relating to poisoning prevention $(P=0.57)$, cycle and pedestrian safety $(P=0.66)$ or falls prevention (OR $0.48,95 \% \mathrm{Cl} 0.21$ to $1.10, \mathrm{P}=0.08$ ). Analysis of specific questions indicated that intervention group children may have been more aware of action to take if clothes caught fire (difference between means $35.3 \%, 95 \% \mathrm{Cl} 22.7 \%$ to $47.9 \%$, no $\mathrm{P}$ values given), and were more likely to know the correct way to wear a cycle helmet (difference between mean $6.3 \%, 95 \% \mathrm{Cl} 1.4 \%$ to $11.1 \%$, no $P$ values given)

Lu 2000 reported on an intervention incorporating classes, letters home and family involvement. There was also teacher training and involvement in supervision of potentially risky behaviour, and a reporting system. This study found a higher post-test score in students' safety knowledge in the intervention group compared to the control group $\left(\mathrm{Chi}^{2}=56.63, \mathrm{P}<0.001\right)$. The study did not report on the content of the questionnaire, but stated that it comprised 10 questions.

Morrongiello 1998 reported the impact on safety knowledge of the activity-based sessions in the intervention group. These sessions focused on four safety topics; bicycling and road use, reducing sports injury, creating a safety banner, and vehicle and road safety. Postintervention, Morrongiello found that the intervention group correctly answered $89 \%$ of the questions on knowledge of safety facts compared to $55 \%$ in the control group. The intervention group also correctly answered $84 \%$ of questions about which safety equipment should be worn for which sport, compared to $64 \%$ in the control group (no $\mathrm{P}$ values given).

Richards 1991 introduced an intervention which was tailored to the different grades of children. The intervention group received an eight-component curriculum, which included topics such as spinal cord awareness and water safety. The authors did not report whether the control group received an intervention. The study found some evidence of a difference between the intervention group and control group in the post-test questionnaire ( $P$ values ranged from $P<0.0001$ and $P<0.05$, between different school grades).

Wang 2009 measured safety knowledge with an eight-point questionnaire, including topics such as the term unintentional injury itself, sports, falls, traffic and burns. The intervention group answered a higher number of questions correctly compared to children in the control group $(82.7 \%$ in the intervention group versus $57.2 \%$ in the control group, $\mathrm{P}<0.05$ ).

Wesner 2003 asked a set of 13 questions to test students' knowledge and found an increase in the intervention group compared to baseline in knowledge of motor vehicle accidents being the most common cause of brain and spinal cord injury (from 37.7\% to $61.0 \%, P<0.001)$, the severe and permanent nature of brain and spinal cord injuries (from $60.3 \%$ to $69.4 \%, P=0.022$ ) and that injuries are most common in 15- to 24-year-old people (from $42.9 \%$ to $81.4 \%, P<0.001$ ). There was no evidence of a change in their scores relating to the laws about the use of helmets on motorbikes (from $74.9 \%$ to $74.5 \%, P=0.71$ ) and cycles (from $64.9 \%$ to $62.7 \%$, $\mathrm{P}=0.54$ ), or that brain injury affects walking, talking and thinking (from $88.3 \%$ to $93.2 \%, P=0.75$ ). In the control group, there was no evidence of a change from baseline in scores on any of the questions.

\section{Burn safety knowledge}

Two studies reported on burns safety knowledge (Carmel 1991; Grant 1992).

Carmel 1991 used multiple methods of teaching to deliver a burns prevention programme, including a presentation, a home checklist, a set of photographs and a colouring book. The aim of this programme was to raise awareness, increase knowledge, and change attitudes and behaviour related to burn prevention. Compared to the control group, who received no intervention, the study authors reported that the intervention group could answer a higher number of safety questions correctly, both immediately at the end of the programme (mean values: 84.74 (SD 12.65) in the intervention group versus 69.85 (SD 14.18) in the control group, $P<0.001)$, and 10 weeks after the end of the programme (84.46 (SD 12.31) in the intervention group versus 71.73 (SD 13.33) in the control group, $\mathrm{P}<0.001$ ).

However, this was not found by Grant 1992, who introduced the "Learn Not To Burn" curriculum to children in grades three and four in US primary schools. This covered 22 key behaviours for burn prevention. The control groups either used "other methods of fire safety education" or "no established fire safety education". There was no evidence of a difference in percentage scores between the intervention and control group (from 81.37 to 90.75 in the intervention group versus from 81.10 to 90.58 in the control group, $P=0.96)$.

\section{Sports safety knowledge}

Collard 2010 investigated the I-PLAY programme to prevent sportrelated injuries by introducing regular exercises. They used a nineitem questionnaire to assess safety knowledge and found weak evidence of a difference, with the intervention group scoring higher 
than the control groups at follow-up (mean difference $0.49,95 \% \mathrm{Cl}$ 0.20 to 0.78$)$.

\section{Agricultural safety knowledge}

Lee 2004 implemented a school-based educational programme to reduce unintentional injury rates among youths involved in agricultural work. The standard intervention involved working with big agricultural businesses, marketing and promotion of safety information aimed at reducing agriculture-related injuries, and working with trainers. For the enhanced intervention group, there was more support for trainers, with regular conferences and access to the public health office. The study did not show evidence of a difference in mean safety knowledge scores between the groups (mean score 2.7 (SD 0.75) in the standard group versus 2.8 (SD 0.88) in the enhanced group versus 2.7 (SD 0.82) in the control group, $\mathrm{P}$ $=0.43$ ).

\section{Water safety knowledge}

Terzidis 2007 studied prevention of water-related injuries. The intervention group attended a day event, which consisted of a short audio-visual presentation, a discussion about pupils' personal experiences, comments on how relevant events could have been averted and drama plays. There were also take-home materials. The control group received no intervention. Among children in kindergarten and grade one, children in the intervention groups showed higher water safety knowledge postintervention compared to children in the control group (mean difference $17.40 \%, 95 \% \mathrm{Cl}$ $6.41 \%$ to $28.39 \%, P=0.005$ ). However, among children in higher grades in elementary school and in high school there was no evidence of a difference $(P=0.08$ in elementary school and $P=0.92$ in high school).

The quality of the evidence relating to both observed and selfreported safety behaviours and practices was very low. This was due to studies being highly heterogeneous in their methods and with very poor reporting of methodologies, and many studies with high or unclear risk of bias across domains.

\section{Health economic outcomes}

Only one study included an economic analysis (Lu 2000). This was a multi-component intervention involving classes, a booklet on injury prevention, letter to families, a mass media campaign, training of teachers in being alert to unsafe behaviour and a school injury reporting system. The overall cost of the programme was 9000 RMB (Chinese Yuan). Before the intervention, there were 2016 cases of injuries, representing 12,418 lost school days. After the intervention, there were 708 lost school days (a decrease of 1162 from baseline) though this was not described in terms of cost-effectiveness. The cost of treating injuries reduced from $145,152 \mathrm{RMB}$ before the intervention to $11,019 \mathrm{RMB}$ after the intervention, resulting in a saving of $134,136 \mathrm{RMB}$. This was a $92.4 \%$ decrease from baseline and resulted in a net benefit of 125,136RMB after subtracting programme costs, giving a cost:benefit ratio of $1: 13.90$, that is, for every 1 RMB spent, 13.90RMB was saved.

We assessed the evidence for this outcome to be very low, due to its limited applicability and high or unclear risk of bias across multiple domains.

\section{DISCUSSION}

\section{Summary of main results}

The review includes 30 articles from 27 studies. Seven studies assessed injury occurrence, of which three were included in a meta-analysis. This showed no strong evidence of a lower incidence rate in the intervention than control groups, and there was substantial heterogeneity (Summary of findings for the main comparison). We rated this evidence as low quality because of this heterogeneity (inconsistency) and imprecision in the results. However, when we performed a sensitivity analysis and removed the non-RCT from the analysis, there was stronger evidence of an effect and no heterogeneity, suggesting study design may explain the heterogeneity that occurred in the meta-analysis. There was insufficient evidence to determine whether schoolbased educational programmes can prevent unintentional injuries.

We were unable to pool data for our secondary outcomes, so our conclusions were limited, as they were drawn from highly diverse single studies and the body of evidence was rated as low (safety skills) or very low (behaviour, safety knowledge, health economic outcomes).

Two studies reported observed safety skills and both showed evidence of an improvement in the intervention group. However, again our confidence in this effect was limited as the evidence was of low quality (serious risk of selection bias, imprecision and inconsistency, but a large effect size countering this to some extent).

All four studies reporting observed safety behaviours and 13 of 19 studies describing self-reported behaviour presented very low quality evidence in favour of the intervention. There was very low evidence in favour of an improvement in safety knowledge in the intervention group versus the control, with 19 of the 21 studies reporting improvements in all or some of the safety knowledge scores in the intervention groups. Studies which showed stronger evidence of an increase in knowledge comprised broadly similar elements as those which did not, so it was not possible to determine which elements might be most effective. The duration of the intervention did not appear to be associated with effectiveness.

Studies that examined self-reported behaviour showed greater variation in findings, with over two-thirds (13 out of $19,68 \%$ ) reporting an improvement and the remainder showing no evidence of a difference. The reason for this heterogeneity was not clear, as most incorporated similar elements (interactive sessions and audio-visual equipment) into their curricula. Only one study reported economic outcomes and estimated a positive return on investment (very low quality evidence).

More high-quality studies are needed to evaluate the impact of educational programmes on injury occurrence.

\section{Overall completeness and applicability of evidence}

We searched multiple large databases, in addition to handsearching, to obtain as many relevant full-text reports as possible. We also included full-text reports and abstracts written in languages other than English, and placed no time restrictions on the searches. 
The review included studies from several high- and middle-income countries, with rural and urban populations and children aged four to 18 years. This spread of populations and countries is likely to improve the generalisability of the review to similar populations, although there were only five studies from low- or middle-income countries (China, Israel and Brazil). While some studies covered a broad range of mechanisms, others focused on more specific mechanisms or injury types (e.g. burns, pedestrian or agricultural injuries), thus potentially limiting their generalisability to other injury mechanisms.

Seven of the 27 studies reported the primary outcome. Of these, only three studies were similar enough to allow inclusion in the meta-analysis. All three were based in China and so it is unclear how generalisable the results were to other countries and school systems. There was a wide range of injury mechanisms studied and types of interventions aimed at improving outcomes. These included a range of approaches (e.g. the provision of safety equipment, inclusion of families with letters and homework and in-school lessons), often with some student involvement (peer teaching) and over differing times and intensities of one session to multiple sessions over one year. Only seven studies in our review referred to having used behavioural change or learning theories (or both) to develop the intervention they evaluated and how they were applied was often not described in detail. Specific examples included using the theory of planned behaviour which was used to develop the SPIY programme (Buckley 2010), social learning theory which was used to develop the i-Play programme (Collard 2010), and self-determination theory which capitalised on the 'teachable moment' after an injury to develop a post-trauma programme (Cook 2006). Other authors referred more generally to having used applied behaviour or social theories, without describing their application in detail (e.g. Azeredo 2003; Greene 2002; Gresham 2001; Reed 2001).

Similarly, very few studies described the educational components of their interventions (e.g. learning theories, learning objectives, teaching methods, techniques or communication vehicles) in sufficient detail to enable us to assess how these impacted on our outcomes. While some studies did report using different pedagogical approaches for different age children, again there was insufficient detail reported to be able to define what worked best for children at different developmental stages.

\section{Quality of the evidence}

The quality of evidence was low for our primary outcome and low or very low for the secondary outcomes, indicating that further research is very likely to have an important impact on our confidence in the estimate of the effect. There are several reasons why the quality of the evidence was rated in this way.

Risk of bias has a serious impact on the overall quality of studies. For many of the included studies, it was difficult to assess the risk of bias due to inadequate reporting. Consequently, we judged a large number of studies to have an unclear risk of each source of bias. The majority of relevant studies had an unclear risk of random sequence generation and of allocation bias, with the remaining studies having high risk. The risk of performance and detection bias was high in most studies. The risk of attrition bias and reporting bias was split quite evenly between low, unclear and high risk. This was also true of confounding bias in the relevant studies. Most studies were at unclear risk of other bias, with the remaining studies split evenly between high and low risk. When only RCTs were examined for risk of bias, the findings were very similar to when we included all study designs. Common limitations in study design and reporting included: reporting only the number of participants for whom outcomes were measured rather than defining the selected groups of participants to be followed up, failing to include adequate detail on randomisation and failing to adequately take account of clustering, not undertaking intention-to-treat analyses and failing to present participant flow charts. Major sources of bias across most studies arose from an inability to blind participants to their allocation due to the nature of the interventions and a lack of blinding during outcome ascertainment.

Inconsistency was also a major factor in our lack of confidence in these study findings. The quality of the evidence for our primary outcome of medically or non-medically attended injuries was downgraded for inconsistency, in part due to substantial statistical heterogeneity $(12=63 \%)$. When we performed sensitivity analysis and restricted the meta-analysis to only RCTs, this had a substantial impact on the results, with the IRR reducing (from $0.73(95 \% \mathrm{Cl}$ 0.49 to 1.08$)$ to $0.59(95 \% \mathrm{Cl} 0.49$ to 0.72$))$ and the heterogeneity disappearing $\left(1^{2}=0 \%\right)$. This suggests that the non-random study design of Lu 2000 may have contributed substantially to the heterogeneity we observe in the pooled analysis.

However, this may also be due to other differences between studies; for example, the intervention in the non-RCT included a mass media campaign which the two RCTs did not, and which could have resulted in contamination between treatment groups (Lu 2000). Outcomes were also measured using different data collection methods, with varying potential for detection bias in the three studies: Lu 2000 collected injury data via weekly student injury events being entered into a central reporting system; Wang 2009 collected injury data via student self-completed questionnaires administered at baseline and follow-up and Zhao 2006 used a school injury surveillance system based on hospital and insurance company reports of injuries. In addition, it was unclear when injury data were collected in relation to the end of the intervention and difference in this may have contributed to heterogeneity.

For each of the other outcomes, there was substantial heterogeneity in terms of the size and in some cases, direction of the effect. This may be explained by variation in terms of what was measured and how. For example, there were 21 studies that assessed safety knowledge and 19 of these reported an improvement in at least one knowledge domain. However, the knowledge tested was extremely variable, as were the methods of data collection and instruments used.

Imprecision was also an issue for some of our outcomes, particularly safety skills, where we considered it to be serious due to the wide $\mathrm{Cls}$ in one of the two included studies and the paucity of data.

The quality of the evidence was not downgraded due to directness or generalisability, as most studies included all students in the school or class, and schools were mostly state schools which are likely to have children of a broad range of backgrounds, abilities and affluence. 


\section{Potential biases in the review process}

We undertook a comprehensive search that included 28 bibliographic databases and websites. Although the database searches were conducted in English, LILACS includes studies from Latin American countries, and no language restrictions were placed on the search results. Several potential studies screened were translated from other languages including Russian, French, German and Chinese by native speakers prior to assessment for inclusion. We searched conference abstracts and the grey literature for unpublished studies. We were unable to assess publication bias using a funnel plot as only three studies were included in the metaanalysis. It is possible that our searches failed to find some studies eligible to be included in our review.

\section{Agreements and disagreements with other studies or reviews}

There has been one previous review of school-based injury prevention programmes (Mulvaney 2012), and several Cochrane and non-Cochrane reviews of school-based interventions aimed at changing safety behaviours relating to single injury mechanisms (Duperrex 2009; Mytton 2006; Owen 2011).

Mulvaney 2012 described safety education for a range of injury mechanisms but only one of the included studies in the review (Collard 2010) fulfilled the criteria for inclusion in our review. This was because the other school-based studies in Mulvaney 2012 either did not have an appropriate control, or were focused on a single injury mechanism. They found no papers reporting the impact of safety education on injury rates but, consistent with our review, found a positive impact on knowledge, behaviour and skills although knowledge did not always translate into behaviour change. The authors highlighted the importance of involving children, families and communities in formulating injury prevention programmes, as well as using a multi-disciplinary approach to deliver them.

Owen 2011 undertook a Cochrane Review of non-legislative interventions to increase uptake of cycle helmet use. Although community-based programmes were most effective in increasing helmet use, the review also reported evidence of an improvement among school-based interventions (8 studies; OR 1.73, Cl 95\% 1.03 to 2.91). Free helmet giveaways were most effective in increasing helmet use, while programmes with subsidised helmets or education only had limited impact (3 studies; OR $1.43,95 \% \mathrm{Cl}$ 1.09 to 1.88). This was echoed in a systematic review by Nauta 2014 of both community- and school-based programmes, which also found that free safety equipment (e.g. cycle helmets) was most effective at increasing use of safety devices. Only one study in our review reported on the effect of free helmet giveaways, but did not find evidence of an impact of that intervention on observed behaviour (Azeredo 2003).

One Cochrane Review of school-based education initiatives to prevent dog bites by Duperrex 2009 was not able to assess the primary outcome of reduced bites because of a lack of studies reporting this outcome. However, they did report changes in behaviour and found that education involving a 30-minute session and letters to parents could improve children's knowledge, attitudes and behaviour when around dogs.
Mytton 2006 conducted a systematic review of school-based initiatives aimed at children who were at risk of aggressive behaviour. The review found that elements (e.g. teaching relationship skills, as well as to a lesser extent, non-response to provocative situations) could reduce aggressive behaviour in both primary- and secondary-aged children although again, there was no clear evidence that this reduced violence-related injury. This suggests that school-based interventions can have a positive impact on behaviour, and mirrors the findings in some of the studies in our review.

There are also systematic reviews of school-based interventions to reduce pupils' risky behaviour. Thomas 2006, in a Cochrane Review of school-based programmes for preventing smoking, highlighted the importance of incorporating elements focused on social influences and social competence when designing a programme. This was also a finding by Faggiano 2005, who reported that programmes combining social influences and social competence were most effective at preventing marijuana use. In contrast, one Cochrane Review by Foxcroft 2011 found no conclusive evidence that school-based interventions to prevent alcohol misuse were effective. In that review, in agreement with our review, some studies showed a positive effect in the intervention group, and others showed no effect.

Our review was unable to identify how useful surrogate measures, such as safety knowledge, were in predicting the impact of the intervention on the primary income of injury rates.

Finally, though not specifically assessing the impact on injury prevention outcomes, the results of one Cochrane Review of the World Health Organization's Health Promoting School framework provided evidence for the effectiveness this approach for some health behaviour interventions but not others, further supporting the school as a suitable setting for health improvement (Langford 2014).

\section{AUTHORS' CONCLUSIONS}

\section{Implications for practice}

There is insufficient evidence to determine whether school-based educational programmes can prevent unintentional injuries, and more high-quality studies are required to evaluate this. This review found some weak evidence that school-based injury prevention education programmes can improve students' skills, behaviour (self-reported and observed) and safety knowledge, although the evidence is of low quality (safety skills) and very low quality behaviour and safety knowledge). We found insufficient economic studies to assess cost-effectiveness.

\section{Implications for research}

The lack of studies reporting injury rates is a major limitation of this review and an obvious area for future study. More high-quality studies are needed to contribute to the pooled estimates of injury risk. As many of the included studies had an unclear risk of bias due to insufficient detail in study reports, more complete reporting would allow a better assessment of the actual risks of bias and to assist this studies should confirm to the CONSORT reporting standards (see www.consort-statement.org/downloads). We also found a paucity of evidence on the cost-effectiveness of the injuryprevention interventions. This may be due in part to the difficulties 
of assigning monetary benefits to knowledge and self-reported behaviour change.

We did not include adverse events in the outcomes for this review, although we acknowledge that this is an important outcome and we intend to consider this in future systematic reviews. Very few studies currently report adverse events, and future studies should consider the importance of this and more detailed reporting of adverse events.

Some of the heterogeneity in outcomes found in our review may reflect differences in theoretical approaches and educational processes used by our included studies. It is important that future studies report their theoretical basis and describe their educational processes in greater detail than is present practice.

The use of standardised data collection tools, particularly for branded programmes (e.g. Think First For Kids, IMPS and Risk Watch) would be useful to provide homogeneity and thus facilitate meta-analysis. However, this may be difficult to accomplish where different mechanisms of injury are studied, as these are likely to need different knowledge questions and observations of different safety practices.

\section{ACKNOWLEDGEMENTS}

We thank the following people who helped with this review in many capacities.

Dr Lu Ban and Dr Yana Vinogradova for translating papers. Wendy Stanton for support with developing the search strategies. Dr Brian Bell for undertaking handsearches of Injury Prevention and conference abstracts, and the Cochrane Injuries group for assisting with database searches.

We would also like to thank the following people for responding to requests for additional information.

\begin{tabular}{ll}
\hline Name & Paper reference \\
\hline Prof JA Morris & Hazinski 1995 \\
\hline Dr L Buckley & Buckley 2010 \\
\hline Dr G Floerchinger-Franks & Floerchinger-Franks 2000 \\
\hline Dr E Neuwelt & Greene 2002 \\
\hline Professor L Mori & Mori 1986 \\
\hline Professor FP Rivara & Wright 1995 \\
\hline Professor D Kendrick & Kendrick 2007 \\
\hline Professor JS Richards & Richards 1991 \\
\hline Dr D Moher & Morag 2002. \\
\hline
\end{tabular}




\section{RE F E R E N C E S}

\section{References to studies included in this review}

Azeredo 2003 \{published data only\}

Azeredo R, Stephens-Stidham S. Design and implementation of injury prevention curricula for elementary schools: lessons learned. Injury Prevention 2003;9(3):274-8. [MEDLINE: 1353-8047]

\section{Buckley 2010 \{published data only\}}

Buckley L, Sheehan M, Shochet I. Short-term evaluation of a school-based adolescent injury prevention program: determining positive effects or iatrogenic outcomes. Journal of Early Adolescence 2010;30(6):834-53. [ERIC: 0272-4316]

\section{Campbell 2001 \{published data only\}}

Campbell NR, Ayala GX, Litrownik AJ, Slymen DJ, Zavala F, Elder JP. Evaluation of a first aid and home safety program for Hispanic migrant adolescents. American Journal of Preventive Medicine 2001;20(4):258-65.

\section{Carmel 1991 \{published data only\}}

Carmel S, Shani E, Rosenberg L. Evaluation of a burn prevention program in Israeli schools. Health Promotion International 1991;6(2):87-92. [EMBASE: 0957-4824]

\section{Chapman 2013 \{published data only\}}

Chapman RL, Buckley L, Sheehan M, Shochet IM. Pilot evaluation of an adolescent risk and injury prevention programme incorporating curriculum and school connectedness components. Health Education Research 2013;28(4):612-25. [Central : 02681153]

Collard 2010 \{published data only\}

* Collard DCM, Chinapaw MJM, Verhagen E, Bakker I, Mechelen W. Effectiveness of a school-based physical activityrelated injury prevention program on risk behavior and neuromotor fitness a cluster randomized controlled trial. International Journal of Behavioral Nutrition and Physical Activity 2010;28:7-9.

Collard DCM, Verhagen E, Chinapaw MJM, Knol DL, van Mechelen W. Effectiveness of a school-based physical activity injury prevention programme. Archives of Pediatric Adolescent Medicine 2010;164(2):145-50.

\section{Cook 2006 \{published data only\}}

Cook BS, Ricketts CD, Brown RL, Garcia VF, Falcone RA. Effect of safety education on classmates of injured children: a prospective clinical trial. Journal of Trauma Nursing 2006;13(3):96-101.

\section{Falavigna 2012 \{published data only\}}

Falavigna A, Teles AR, Velho MC, Medeiros GS, Canabarro CT, de Braga GL, et al. Impact of an injury prevention program on teenagers' knowledge and attitudes: results of the Pense Bem-Caxias do Sul Project. Journal of Neurosurgery: Pediatrics 2012;9(5):652-8.
Frederick 2000 \{published data only\}

Frederick E, Bixby E, Orzel M-N, Stewart-Brown S, Willett K. An evaluation of the effectiveness of the Injury Minimization Programme for Schools (IMPS). Injury Prevention 2000;6(2):92-5. [MEDLINE: 1353-8047]

\section{Grant 1992 \{published data only\}}

Grant E, Turney E, Bartlett M, Winbon C, Peterson HD. Evaluation of a burn prevention program in a public school system. Journal of Burn Care \& Rehabilitation 1992;13(6):703-7. [MEDLINE: 0273-8481]

\section{Greene 2002 \{published data only\}}

Greene A, Barnett P, Crossen J, Sexton G, Ruzicka P, Neuwelt E. Evaluation of the THINK FIRST For KIDS injury prevention curriculum for primary students. Injury Prevention 2002;8(3):257-8. [MEDLINE: 1353-8047]

\section{Gresham 2001 \{published data only\}}

Gresham LS, Zirkle DL, Tolchin S, Jones C, Maroufi A, Miranda J. Partnering for injury prevention: evaluation of a curriculumbased intervention program among elementary school children. Journal of Pediatric Nursing 2001;16(2):79-87.

\section{Kendrick 2007 \{published and unpublished data\}}

Kendrick D, Groom L, Stewart J, Watson M, Mulvaney C, Casterton R. 'Risk Watch': cluster randomised controlled trial evaluating an injury prevention program. Injury Prevention 2007;13(2):93-8.

\section{Lee 2004 \{published data only\}}

Lee BC, Westaby JD, Berg RL. Impact of a national rural youth health and safety initiative: results from a randomized controlled trial. American Journal of Public Health 2004;94(10):1743-9.

\section{Lu 2000 \{published data only\}}

Lu G, Zhou C, Wu A, Zhou Y. A comprehensive evaluation on intervention measures for injuries in primary and middle school students. Chung-Hua Yu Fang I Hsueh Tsa Chih [Chinese Journal of Preventive Medicine] 2000;34(4):209-11. [MEDLINE: 0253-9624]

\section{Martinez 1996 \{published data only\}}

Martinez R, Levine DW, Martin R, Altman DG. Effect of integration of injury control information into a high school physics course. Annals of Emergency Medicine 1996;27(2):216-24.

\section{Morrongiello 1998 \{published data only\}}

Morrongiello BA, Miron J, Reutz R. Prevention of paediatric acquired brain injury: an interactive, elementary-school program. Revue Canadienne de Sante Publique [Canadian Journal of Public Health] 1998;89(6):391-6. [MEDLINE: 0008-4263]

\section{Reed 2001 \{published data only\}}

Kidd P, Reed D, Weaver L, Westneat S, Rayens MK. The transtheoretical model of change in adolescents: 
implications for injury prevention. Journal of safety research 2003;34(3):281-8. [PUBMED: 12963074]

Reed DB, Kidd PS. Collaboration between nurses and agricultural teachers to prevent adolescent agricultural injuries: the Agricultural Disability Awareness and Risk Education model. Public Health Nursing 2004;21(4):323-30. [MEDLINE: 0737-1209]

* Reed DB, Kidd PS, Westneat S, Rayens MK. Agricultural Disability Awareness and Risk Education (AgDARE) for high school students. Injury Prevention 2001;7, Suppl 1:i59-63. [MEDLINE: 1353-8047]

\section{Richards 1991 \{published and unpublished data\}}

Richards JS, Hendricks C, Roberts M. Prevention of spinal cord injury: an elementary education approach. Journal of Pediatric Psychology 1991;16(5):595-609. [MEDLINE: 0146-8693]

\section{Sun 2004 \{published data only\}}

Sun Y. Unintentional Injuries Among Primary and Middle School Students and a Randomized Controlled Intervention Study on Prevention in a Midsize City [PhD thesis]. Sha Tin, Hong Kong: The Chinese University of Hong Kong, 2004.

\section{Terzidis 2007 \{published data only\}}

Terzidis A, Koutroumpa A, Skalkidis I, Matzavakis I, Malliori M, Frangakis CE, et al. Water safety: age-specific changes in knowledge and attitudes following a school-based intervention. Injury Prevention 2007;13(2):120-4

\section{Twisk 2013 \{published data only\}}

Twisk D, Vlakveld W, Mesken J, Shope JT, Kok G. Inexperience and risky decisions of young adolescents, as pedestrians and cyclists, in interactions with lorries, and the effects of competency versus awareness education. Accident; Analysis and Prevention 2013;55:219-25. [ISI WOS: 0001-4575]

\section{Wang 2009 \{published data only\}}

Wang X, Zhu Y. Peer education's effects on preventing accidental injuries in middle school students. Wei Sheng Yan Jiu [Journal of Hygiene Research] 2009;38(4):449-51.

\section{Wesner 2003 \{published data only\}}

Wesner ML. An evaluation of Think First Saskatchewan: a head and spinal cord injury prevention program. Revue Canadienne de Sante Publique [Canadian Journal of Public Health] 2003;94(2):115-20. [MEDLINE: 0008-4263]

\section{Wright 1995 \{published data only\}}

Wright M, Rivara FP, Ferse D. Evaluation of the Think First head and spinal cord injury prevention program. Injury Prevention 1995;1(2):81-5. [SR INJ: 1353-8047]

\section{Zhao 2006 \{published data only\}}

Zhao CH, Qiu HS, Qiu HX. Interventions to prevent accidental injuries in children between 7 and 13 years of age. Zhongguo Dang Dai Er Ke Za Zhi [Chinese Journal of Contemporary Pediatrics] 2006;8(4):331-3.
Zirkle 2005 \{published data only\}

Zirkle DL. Think First For Kids (TFFK): a Longitudinal Analysis of a School-based Injury Prevention Curriculum [PhD thesis]. San Diego: University of San Diego, 2005.

\section{References to studies excluded from this review}

Anisimov 1987 \{published data only\}

Anisimov VS. Prevention of child traumatism. Ortopediia Travmatologiia i Protezirovanie 1987, issue 8:55-60. [MEDLINE: 0030-5987]

\section{Anonymous 1986 \{published data only\}}

Anonymous. Pressing problems in childhood injuries (results of a discussion of the article by V. S. Anisimov). Ortopediia Travmatologiia i Protezirovanie 1986, issue 3:71-4. [MEDLINE: 0030-5987]

\section{Arbogast 2014 \{published data only\}}

Arbogast H, Burke R, Muller V, Ruiz P, Knudson M, Upperman J. Randomised controlled trial to evaluate the effectiveness of a video game as a child pedestrian educational tool. Journal of Trauma and Acute Care Surgery 2014;76(5):1317-21.

\section{Aronson 1986 \{published data only\}}

Aronson SS. Health update: priorities for health and safety in child care. Child Care Information Exchange 1986, issue 50:14-8.

Asher 1995 \{published data only\}

Asher KN, Rivara FP, Felix D, Vance L, Dunne R. Water safety training as a potential means of reducing risk of young children's drowning. Injury Prevention 1995; Vol. 1, issue 4:228-33.

\section{Avolio 1992 \{published data only\}}

Avolio AE, Ramsey FL, Neuwelt EA. Evaluation of a program to prevent head and spinal cord injuries: a comparison between middle school and high school. Neurosurgery 1992;31(3):557-62. [MEDLINE: 0148-396X]

\section{Banfield 2010 \{published data only\}}

Banfield JM, Gomez M, Kiss A, Redelmeier DA, Brenneman F. Effectiveness of the P.A.R.T.Y. (Prevent Alcohol and Risk-related Trauma in Youth) program in preventing traumatic injuries: a 10-year analysis. Injury Prevention 2010;16:A170.

\section{Banfield 2011 \{published data only\}}

Banfield JM, Gomez M, Kiss A, Redelmeier DA, Brenneman F. Effectiveness of the P.A.R.T.Y. (Prevent Alcohol and Risk-related Trauma in Youth) program in preventing traumatic injuries: a 10-year analysis. Journal of Trauma - Injury, Infection, and Critical Care 2011;70(3):732-5.

\section{Bass 1991 \{published data only\}}

Bass JL, Mehta KA, Ostrovsky M. Childhood injury prevention in a suburban Massachusetts population. Public Health Reports 1991; Vol. 106, issue 4:437-42. [0033-3549; PUBMED: PMC1580271] 
Bennett 1999 \{published data only\}

Bennett E, Cummings P, Quan L, Lewis FM. Evaluation of a drowning prevention campaign in King County, Washington. Injury Prevention 1999;5(2):109-13.

\section{Berfenstam 1995 \{published data only\}}

Berfenstam R. Sweden's pioneering child accident programme: 40 years later. Injury Prevention 1995;1(2):68-9. [1353-8047]

\section{Bergman 1982 \{published data only\}}

Bergman AB. Use of education in preventing injuries. Pediatric Clinics of North America 1982;29(2):331-8. [0031-3955]

\section{Bernardo 1992 \{published data only\}}

Bernardo LM, Gardner MJ. Implementing a pediatric safety education program. Nursing Management 1992; Vol. 23, issue 4:82-4. [0744-6314]

\section{Birkland 1993 \{published data only\}}

Birkland P. International update: two successful Canadian programs teach teenagers trauma prevention. Journal of Emergency Nursing 1993;19(3):35A-6A. [0099-1767]

\section{Bjerre 1998 \{published data only\}}

Bjerre B, Jonell A-C. The community safety approach in Falun, Sweden. What makes it work?. International Journal of Injury Control and Safety Promotion 1998;5(3):139-53. [BJERRE: 2000]

\section{Bohman 2004 \{published data only\}}

Bohman TM, Barker ED, Bell ML, Lewis CM, Holleran L, Pomeroy E. Early intervention for alcohol use prevention and vehicle safety skills: evaluating the "Protecting You/Protecting Me" curriculum. Journal of Child and Adolescent Substance Abuse 2004;14(1):17-40. [1067-828X,: 1067-828X]

\section{Bondurant 2009 \{published data only\}}

Bondurant E. Unintentional childhood injuries. Ncs/ Legisbrief 2009;17(44):1-2. [1068-2716]

\section{Bouvette 1990 \{published data only\}}

Bouvette J. Nurse develops high-school prevention program. Dimensions of Critical Care Nursing 1990;9(2):65.

\section{Buckley 2013 \{published data only\}}

Buckley L, Sheehan M, Shochet I, Chapman R. Towards an integration of the theory of planned behaviour and cognitive behavioural strategies: an example from a school-based injury. Educational Studies 2013;39(3):285-97.

\section{Bulska 2008 \{published data only\}}

Bulska J. Carrying out the education for safety as a chance to minimise risky behaviour of school-age children and youth. New Educational Review 2008;16(3-4):261-9. [1732-6729]

\section{Burgus 2007 \{published data only\}}

Burgus S, Rademaker A. Testing a novel child farm safety intervention for Anabaptist audiences. Journal of Agromedicine 2007;12(4):63-70. [1059-924X]

\section{Cao 2014 \{published data only\}}

Cao Z, Chen Y, Wang S. Health belief model based evaluation of school health education programme for injury prevention among high school students in the community context. BMC Public Health 2014;14(26):3903-14.

Cao 2015 \{published data only\}

Cao B, Shi X, Qui Y, Hui Y, Yang H, Shi S, et al. Effect of a multilevel education intervention model on knowledge and attitudes of accidental injuries in rural children in Zunyi, Southwest China. International Journal of Environmental Research and Public Health 2015;12:3903-14.

Cardon 2002 \{published data only\}

Cardon GM, De Clercq DL, De Bourdeaudhuij IM. Back education efficacy in elementary schoolchildren: a 1-year follow-up study. Spine 2002;27(3):299-305. [1528-1159]

\section{Carrabba 2012 \{published data only\}}

Carrabba J, Wyckoff S, Scribani M, Jenkins P, May J. Farm safety education in New York Mennonite schools. Journal of Agromedicine 2012;17(3):338-44. [1545-0813]

\section{Carruth 2010 \{published data only\}}

Carruth AK, Pryor S, Cormier C, Bateman A, Matzke B, Gilmore K. Evaluation of a school-based train-the-trainer intervention program to teach first aid and risk reduction among high school students. Journal of School Health 2010; Vol. 80, issue 9:453-60. [1746-1561]

\section{CDC 1991 \{published data only\}}

Centers for Disease Control and Prevention. Effectiveness of a health education curriculum for secondary school students United States, 1986-1989. MMWR - Morbidity \& Mortality Weekly Report 1991; Vol. 40, issue 7:113-6. [0149-2195]

\section{Chapman 2010 \{published data only\}}

Chapman R, Buckley L, Sheehan M, Shochet I. A process evaluation of a comprehensive school based injury prevention programme. Injury Prevention 2010; Vol. 16:A91. [1353-8047]

\section{Chapman 2011 \{published data only\}}

Chapman R, Buckley L, Sheehan M. The Development of the Extended Adolescent Injury Checklist (E-AIC): a measure for injury prevention program evaluation. Youth Studies Australia 2011;30(1):49-58. [1038-2569,: 1038-2569]

\section{Chiarelli 1995 \{published data only\}}

Chiarelli A, Danielli E, Casadei A, Siliprandi L, Milone A. Burn prevention in children. [La Prevenzione Delle Ustioni in Eta Pediatrica]. Rivista Italiana di Chirurgia Plastica 1995;27(4):549-52. [0391-2221]

\section{Christophersen 1989 \{published data only\}}

Christophersen ER. Injury control. American Psychologist 1989;44(89):237-41.

\section{Clapham 2010 \{published data only\}}

Clapham K, Khavarpour F, Bolt R, Stevenson M. Child injury in urban Australian indigenous community: the Safe Koori Kids intervention. Injury Prevention 2010;16:A138. 
Coggan 2000 \{published data only\}

Coggan C, Patterson P, Brewin M, Hooper R, Robinson E. Evaluation of the Waitakere Community Injury Prevention Project. Injury Prevention 2000;6(2):130-4.

\section{Coles 2007 \{published data only\}}

Coles CD, Strickland DC, Padgett L, Bellmoff L. Games that "Work": using computer games to teach alcohol-affected children about fire and street safety. Research in Developmental Disabilities: a Multidisciplinary Journal 2007;28(5):518-30.

\section{Collard 2009 \{published data only\}}

Collard DC, Chinapaw MJ, van Mechelen W, Verhagen EA. Design of the iPlay study: systematic development of a physical activity injury prevention programme for primary school children. Sports Medicine 2009;39(11):889-901. [MEDLINE: 0112-1642]

Collins 1995 \{published data only\}

Collins JL, Small ML, Kann L, Pateman BC, Gold RS, Kolbe LJ. School health education. Journal of School Health 1995;65(8):302-11.

\section{Cook 2003 \{published data only\}}

Cook DJ, Cusimano MD, Tator CH, Chipman ML. Evaluation of the Thinkfirst Canada, Smart Hockey brain and spinal cord injury prevention video. Injury Prevention 2003;9(4):361-6.

\section{Crespo 1974 \{published data only\}}

Crespo Santillana A, Oso Cantero A. Prevention of different types of accidents [in Spanish]. Anales Espanoles de Pediatria 1974;7 Suppl 1:62-7.

\section{Danin 1978 \{published data only\}}

Danin JP. Accidents in children: their prevention [in French]. Revue de L'Infirmiere 1978;28(10):819-24.

Day 2001 \{published data only\}

Day LM, Ozanne-Smith J, Cassell E, Li L. Evaluation of the Latrobe Valley Better Health Injury Prevention Program. Injury Prevention 2001;7(1):66-9.

\section{Duff 2002 \{published data only\}}

Duff S, Ryan M, Mullan C, O'Keefe B, Nicholson AJ. The use of local accident and emergency injury surveillance to monitor the impact of a lay safety community programme. Irish Medical Journal 2002;95(5):143-5.

\section{Eckelt 1985 \{published data only\}}

Eckelt K, Fannon M, Blades B, Munster AM. A successful burn prevention program in elementary schools. Journal of Burn Care \& Rehabilitation 1985;6(6):509-10.

\section{Eichel 2001 \{published data only\}}

Eichel JDS, Goldman L. Safety makes sense: a program to prevent unintentional injuries in New York City public schools. Journal of School Health 2001;71(5):180-3.

\section{Ellis 2009 \{published data only\}}

Ellis MC. Injury prevention: planning an evidence-based and fundable injury-prevention program. Journal of Emergency
Nursing. Elsevier Ltd, The Netherlands, 2009; Vol. 35, issue 5:462-4.

\section{El-Otiefy 2010 \{published data only\}}

El-Otiefy M, Zakhary M. A comprehensive approach for reducing the incidence of domestic burns in rural upper Egypt. Injury Prevention 2010;16:A14

\section{El-Sayed 2010 \{published data only\}}

El-Sayed H, Gad S, Saied H, Gamal D. School-based program for injury prevention and safety promotion in Ismailia city, Egypt. Injury Prevention 2010;16:A25.

\section{Englander 1993 \{published data only\}}

Englander J, Cleary S, O'Hare P, Hall KM, Lehmkuhl LD. Implementing and evaluating injury prevention programs in the traumatic brain injury model systems of care. Journal of Head Trauma Rehabilitation 1993;8(2):101-13.

\section{Floerchinger-Franks 2000 \{published data only\}}

Floerchinger-Franks G, Machala M, Goodale K, Gerberding S. Evaluation of a pilot program in rural schools to increase bicycle and motor vehicle safety. Journal of Community Health 2000;25(2):113-24.

\section{Franco-Diaz 1974 \{published data only\}}

Franco-Diaz A. Prevention of burns in children [Prevencion de quemaduras en ninos]. Anales Espanoles de Pediatria 1974;7 Suppl 1(0):53-5. [PUBMED: 4429298]

Frank 1992 \{published data only\}

Frank RG, Bouman DE, Cain K, Watts C. A preliminary study of a traumatic injury prevention program. Psychology and Health 1992;6(1\&2):129-40.

\section{Frederick 2006 \{published data only\}}

Frederick K, Barlow J. The Citizenship Safety Project: a pilot study. Health Education Research 2006;21(1):87-96.

Gallagher 1982 \{published data only\} Gallagher SS, Guyer B, Kotelchuck M, Bass J, Lovejoy FH Jr, McLoughlin E, et al. A strategy for the reduction of childhood injuries in Massachusetts: SCIPP. New England Journal of Medicine 1982;307(16):1015-9.

\section{Gallagher 1987 \{published data only\}}

Gallagher SS, Messenger KP, Guyer B. State and local responses to children's injuries: the Massachusetts Statewide Childhood Injury Prevention Program. Journal of Social Issues 1987;43(Summer 87):149-62.

\section{García 2005 \{published data only\}}

García LC. School children committees for accident and injury prevention [Comité escolar de prevención de accidentes y lesiones]. Gac Med Caracas 2005;113(1):114-34.

\section{Ghosh 2000 \{published data only\}}

Ghosh A, Bharat R. Domestic burns prevention and first aid awareness in and around Jamshedpur, India: strategies and impact. Burns 2000;26(7):605-8. 
Gielen 1996 \{published data only\}

Gielen AC, Dannenberg AL, Ashburn N, Kou J. Teaching safety: evaluation of a children's village in Maryland. Injury Prevention 1996;2:26-31.

\section{Gittelman 2007 \{published data only\}}

Gittelman MA, Pomerantz WJ, McNealy T. Reducing injury rates using a community-based approach. Journal of Trauma-Injury Infection \& Critical Care 2007;63(3 Suppl):S44-9.

\section{Gong 2001 \{published data only\}}

Gong D. Evaluation of an Unintentional Injury Prevention Curriculum for Korean-American Students [dissertation]. Athens, US: University of Georgia, 2001.

\section{Grigorovich 1985 \{published data only\}}

Grigorovich LP. Health education work in preventing injuries to children in preschools. Meditsinskaia Sestra 1985;44(2):54-6.

\section{Guo 2010 \{published data only\}}

Guo QZ, Ma WJ, Xu HF, Nie SP, Xu YJ, Song XL, et al. Evaluation on the health education program regarding prevention of nonfatal drowning among school-aged children in Lianping county, Guangdong province [in Chinese]. Chung-Hua Liu Hsing Ping Hsueh Tsa Chih Chinese Journal of Epidemiology 2010;31(1):22-6.

\section{Guyer 1989 \{published data only\}}

Guyer B, Gallagher SS, Chang BH, Azzara CV, Cupples LA, Colton T. Prevention of childhood injuries: evaluation of the Statewide Childhood Injury Prevention Program (SCIPP). American Journal of Public Health 1989;79(11):1521-7.

Hall-Long 2001 \{published data only\} Hall-Long BA, Schell K, Corrigan V. Youth safety education and injury prevention program. Pediatric Nursing 2001;27(2):141-6.

\section{Hamilton 2010 \{published data only\}}

Hamilton M, Hewitt C. Injury prevention: injury prevention in a winter wonderland. Journal of Emergency Nursing 2010;36(1):65-6.

\section{Harré 2000 \{published data only\}}

Harré N, Coveney A. School-based scalds prevention: reaching children and their families. Health Education Research 2000;15(2):191-202.

\section{Hazinski 1995 \{published data only\}}

Hazinski MF, Eddy VA, Morris JA Jr. Children's traffic safety program: influence of early elementary school safety education on family seat belt use. Journal of Trauma: Injury, Infection, and Critical Care 1995;39(6):1063-8. [MEDLINE: 0022-5282]

\section{Heck 2001 \{published data only\}}

Heck A, Collins J, Peterson L. Decreasing children's risk taking on the playground. Journal of Applied Behavior Analysis 2001;34(3):349-52.

\section{Heinle 1995 \{published data only\}}

Heinle JA, Jensen RW, Lewis RW, Kealey GP. An effective method of educating junior high-aged children in fire and burn safety without disruption of the school curriculum. Journal of Burn Care \& Rehabilitation 1995;16(1):91-5.

Hidalgo-Solorzano 2008 \{published data only\}

Hidalgo-Solorzano E, Hijar M, Mora-Flores G, Trevino-Siller S, Inclan-Valadez C. Road traffic injuries among youth: measuring the impact of an educational intervention [in Mexican]. Salud Publica de Mexico 2008;50 Suppl 1:S60-8.

Hobbie 1991 \{published data only\}

Hobbie C. The Injury Prevention Program (TIPP). Journal of Pediatric Health Care 1991;5(5):279-80.

Hunter 1991 \{published data only\}

Hunter LK, Lloyd-Kolkin D. Entering adulthood: skills for injury prevention. A curriculum guide for grades 9-12. Classroom Use - Teaching Guides (for Teacher). Santa Cruz, CA: Network Publications, 1991:115.

\section{Jones 1981 \{published data only\}}

Jones RT, Kazdin AE, Haney JI. Social validation and training of emergency fire safety skills for potential injury prevention and life saving. Journal of Applied Behavior Analysis 1981; Vol. 14, issue 3:249-60

\section{Josse 2006 \{published data only\}}

Josse JM, Cusimano M. The effect of a skiing/snowboarding safety video on the increase of safety knowledge in Canadian youths - a pilot study. International Journal of Circumpolar Health 2006;65(5):385-8.

\section{Kamsiuk 1987 \{published data only\}}

Kamsiuk LG, Zubkova NZ, Golovina N. Prevention of injuries in children of preschool age [Profilaktika travmatizma u detei doshkol'nogo vozrasta]. Sovetskoe Zdravookhranenie 1987;12:16-20. [MEDLINE: 0038-5239]

\section{Karataeva 1982 \{published data only\}}

Karataeva NB, Maksimova MV, Niskanen LG, Shirokova TI, Ledovskikh NV. Teaching young schoolchildren measures for preventing injuries [Obuchenie mladshikh shkol'nikov meram profilaktiki travmatizma]. Gigiena i Sanitariia 1982;5:49-52. [MEDLINE: 0016-9900]

Kennedy 2009 \{published data only\}

Kennedy C, Chen J. Changes in childhood risk taking and safety behavior after a peer group media intervention. Nursing Research 2009;4:264-73.

\section{Klas 2013 \{published data only\}}

Klas KS, Vlahos PG, Ahrns-Klas KS, McCully MJ, Piche DR, Wang SC. School-based prevention program is associated with increased short- and long-term knowledge retention of fire and life safety. Journal of Burn Care and Research 2013;1:S91. [EMBASE: 1559-047X]

\section{Knapp 1965 \{published data only\}}

Knapp LW Jr. Agricultural injury prevention. Journal of Occupational Medicine 1965;7(11):545-53. [PUBMED: 5831719] 
Korn 2009 \{published data only\}

Korn L, Hemmo-Lotem M, Endy-Findling L. Safe communities for children: insight from a pilot program for preventing unintentional injuries. International Journal of Adolescent Medicine \& Health 2009;21(2):187-95. [PUBMED: 19702198]

\section{Lachapelle 2013 \{published data only\}}

Lachapelle U, Noland RB, Von Hagen LA. Teaching children about bicycle safety: an evaluation of the New Jersey Bike School program. Accident; Analysis and Prevention 2013;52:237-49.

\section{Lamb 2006 \{published data only\}}

Lamb R, Joshi MS, Carter W, Cowburn G, Matthews A. Children's acquisition and retention of safety skills: the Lifeskills program. Injury Prevention 2006;12(3):161-5. [PUBMED: 16751445]

\section{Langley 1996 \{published data only\}}

Langley JD, Alsop JC. Lidkoping Accident Prevention Programme: what was the impact?. Injury Prevention 1996;2(2):131-3. [PUBMED: 9346077]

\section{Lang-Runtz 1983 \{published data only\}}

Lang-Runtz H. Preventing accidents in the home. Canadian Medical Association Journal 1983;129(5):482, 484-5. [PUBMED: 6883239]

\section{Laraque 1995 \{published data only\}}

Laraque D, Barlow B, Durkin M, Heagarty M. Injury prevention an urban setting: challenges and successes. Bulletin of the New York Academy of Medicine: Journal of Urban Health 1995;72(1):16-30. [PUBMED: 1995281487]

Lazaros 2009 \{published data only\} Lazaros EJ, Shackelford R. Safety awareness: empowering students to be technologically literate. Technology Teacher 2009;68(8):5-11. [PUBMED: 61887585]

\section{Lazaros 2012 \{published data only\}}

Lazaros EJ. Teaching technology by assessing vehicle safety. Technical Directions 2012;71(9):26-9. [PUBMED: 1322248280]

\section{Liller 2002 \{published data only\}}

Liller KD, Noland V, Rijal P, Pesce K, Gonzalez R. Development and evaluation of the Kids Count Farm Safety Lesson. Journal of Agricultural Safety and Health 2002;8(4):411-21.

\section{Lim 2009 \{published data only\}}

Lim BO, Lee YS, Kim JG, An KO, Yoo J, Kwon YH. Effects of sports injury prevention training on the biomechanical risk factors of anterior cruciate ligament injury in high school female basketball players. American Journal of Sports Medicine 2009;37(9):1728-34.

\section{Lindqvist 2012 \{published data only\}}

Lindqvist K, Dalal K. The impact of child safety promotion on different social strata in a WHO Safe Community. Journal of Injury \& Violence Research 2012;4(1):20-5. [PUBMED: 21502791]

\section{Linker 2005 \{published data only\}}

Linker D, Miller ME, Freeman KS, Burbacher T. Health and safety awareness for working teens - developing a successful, statewide program for educating teen workers. Family \& Community Health 2005;28(3):225-38.

Lowden 2001 \{published data only\}

Lowden K, Powney J, Davidson J, James C. The Class Moves! ${ }^{\circledR}$ pilot in Scotland and Wales: an evaluation. Research Report Series. SCRE Centre Research in Education 2001; Vol. SCRERR-100:76. [62356051; ED450114]

Luria 2000 \{published data only\}

Luria JW, Smith GA, Chapman JI. An evaluation of a safety education program for kindergarten and elementary school children. Archives of Pediatrics \& Adolescent Medicine 2000;154(3):227-31. [PUBMED: 10710018]

\section{MacKay 1982 \{published data only\}}

MacKay AM, Rothman KJ. The incidence and severity of burn injuries following Project Burn Prevention. American Journal of Public Health 1982;72(3):248-52.

Maddocks 1981 \{published data only\}

Maddocks G. Accidents in childhood: careful - don't touch!. Nursing Mirror 1981;152(21):ii-iv. [PUBMED: 6909950]

\section{Manno 2011 \{published data only\}}

Manno M, Rook A, Yano-Litwin A, Maranda L, Burr A, Hirsh M. On the road with injury prevention - an analysis of the efficacy of a mobile injury prevention exhibit. Journal of Trauma 2011;71(5 Suppl 2):S505-10.

\section{Manuele 2005 \{published data only\}}

Manuele FA. Training, education \& software product focus serious injury prevention. Occupational Health and Safety 2005;74(6):74-83.

\section{Martinez-Lopez 1974 \{published data only\}}

Martinez-Lopez P. Prevention of school accidents and role of the school in fighting the accidents [Prevencion de accidents en la escuela y papel de la escuela en la lucha contra los accidentes]. Anales Espanoles de Pediatria 1974;7 Suppl 1:68-77. [PUBMED: 4429302]

\section{Martino-McAllister 2001 \{published data only\}}

Martino-McAllister JM, Thompson JM, Caulkins P. Developing a community response to reduce youth risk behaviors. American Journal of Health Education 2001;32(5):298-301. [PUBMED: 2002054253]

\section{Mason 2007 \{published data only\}}

Mason M, Christoffel KK, Sinacore J. Reliability and validity of the injury prevention project home safety survey. Archives of Pediatrics \& Adolescent Medicine 2007;161(8):759-65. [PUBMED: 17679657]

May 2005 \{published data only\}

May JJ, Scofield SM. "Safety for agricultural educators": evaluation of an intervention to enhance awareness of 
agricultural hazards. Journal of Agromedicine 2005;10(4):65-70. [PUBMED: 16702124]

\section{Mayshark 1976 \{published data only\}}

Mayshark C. Curriculum development and research for safety education. Health Education 1976;7(3):28-31. [PUBMED: 818057]

\section{McConnell 1996 \{published data only\}}

McConnell CF, Leeming FC, Dwyer WO. Evaluation of a firesafety training program for preschool children. Journal of Community Psychology 1996;24(3):213-27. [MEDLINE: 0090-4392]

\section{McLoughlin 1982 \{published data only\}}

McLoughlin E, Vince CJ, Lee AM, Crawford JD. Project Burn Prevention: outcome and implications. American Journal of Public Health 1982;72(3):241-7.

\section{Mears 2012 \{published data only\}}

Mears CJ, LaBella CR, Patrick BC. Sports injury prevention and rehabilitation program at uplift community school health center. Journal of Adolescent Health 2012:S37-8.

\section{Melenovich 2008 \{published data only\}}

Melenovich PG. Decreasing childhood drowning through education and CPR training. Communicating Nursing Research 2008;41:513. [PUBMED: 2010468341]

\section{Mello 2007 \{published data only\}}

Mello MJ, Getz MA, Lapidus G, Moss J, Soulos P. Innovations in injury prevention education. Journal of Trauma - Injury, Infection and Critical Care 2007;63(3 Suppl):S7-9. [PUBMED: 2007440239]

\section{Messonnier 1999 \{published data only\}}

Messonnier ML Corso PS, Teutsch SM, Haddix AC, Harris JR. An ounce of preventions...what are the returns?. American Journal of Preventative Medicine 1999;16(3):248-63.

Miara 2003 \{published data only\}

Miara C, Gallagher S, Bush D, Dewey R. Developing an effective tool for teaching teens about workplace safety. American Journal of Health Education 2003;34(5):S30-40. [PUBMED: 2004056453]

Mickalide 1994 \{published data only\}

Mickalide A. The National SAFE KIDS Campaign (USA). Injury Prevention 1994;1(2):119-21. [PUBMED: 9346009]

\section{Mickalide 1995 \{published data only\}}

Mickalide A. The National SAFE KIDS Campaign (USA). Injury Prevention 1995;1(2):119-21.

\section{Miles 2012 \{published data only\}}

Miles K. Down the back paddock, a programme to educate local primary school children about safety on rural properties. Injury Prevention 2012;18(Suppl 1):A112.

\section{Mondozzi 2001 \{published data only\}}

Mondozzi MA, Harper MA. In search of effective education in burn and fire prevention. Journal of Burn Care \& Rehabilitation 2001;22(4):277-81. [PUBMED: 11482687]
Monneuse 2008 \{published data only\}

Monneuse OJ, Nathens AB, Woods NN, Mauceri JL, Canzian SL, Xiong W, et al. Attitudes about injury among high school students. Journal of the American College of Surgeons 2008;207(2):179-84. [SR INJ: CN-00650009]

Mori 1986 \{published data only\}

Mori L, Peterson L. Training preschoolers in home safety skills to prevent inadvertent injury. Journal of Clinical Child Psychology 1986;15(2):106-14. [PUBMED: 1987-11745-001]

\section{Morriss 2000a \{published data only\}}

Morriss M, Mann S, Byrnes T. SAFE schools: developing community health partnerships. Australian Journal of Primary Health - Interchange 2000;6(2):102-9. [PUBMED: 2000273724]

Morriss 2000b \{published data only\}

Morriss M, Mann S, Byrnes T. Safe Dreaming Trail to School: community participation and indigenous culture. Australian Journal of Primary Health - Interchange 2000;6(2):110-5. [PUBMED: 2000273725]

\section{Nauta 2013 \{published data only\}}

Nauta J, Knol D, Adriaensens L, Wolt K, van Mechelen W, Verhagen $\mathrm{E}$. Prevention of fall-related injuries in 7-year-old to 12-year-old children: a cluster randomised controlled trial. British Journal of Sports Medicine 2013;47:909-13.

\section{Nelmarie 2004 \{published data only\}}

Nelmarie Du Toit BP. Design and implementation of a child accident prevention resource pack for primary schools: life orientation curriculum. African Safety Promotion 2004;2 (1):83-7.

Neuwelt 1989 \{published data only\}

Neuwelt EA, Coe MF, Wilkinson AM, Avolio AE. Oregon Head and Spinal Cord Injury Prevention Program and evaluation. Neurosurgery 1989;24(3):453-8. [PUBMED: 2927621]

Nishioka, 2011 \{published data only\}

Nishioka N. School-based safety promotion in Japan. Asian Perspectives and Evidence on Health Promotion and Education. New York: Springer, 2011:416-25. [DOI: 10.1007/978-4-431-53889-9_37]

O'Hare 1997 \{published data only\}

O'Hare P, Hall KM. Preventing spinal cord injuries through safety education programs. American Rehabilitation 1997;23(1):15-8. [PUBMED: 1998013875]

\section{O'Neill 2013 \{published data only\}}

O'Neill S, Fleer M, Agbenyega J, Ozanne-Smith J, Urlichs M. A cultural-historical construction of safety education programs for preschool children: findings from See More Safety, the pilot study. Australasian Journal of Early Childhood 2013;38(2):74-84. [PUBMED: WOS:000321818700010]

\section{Olsen 2010 \{published data only\}}

Olsen H, Hudson SD, Thompson D. Strategies for playground injury prevention: an overview of a playground project. American Journal of Health Education 2010;41(3):187-92. [PUBMED: 2010666574] 
Orzel 1996 \{published data only\}

Orzel MN. Injury Minimization Programme for Schools. Accident and Emergency Nursing 1996;4(3):139-44. [PUBMED: 8920398]

\section{Oxford Evaluation Team 2003 \{published data only\}}

Oxford Evaluation Team, Health and Safety Executive. An evaluation of the Lifeskills - Learning for Living programme. Research Report 2003.

\section{Page 2001 \{published data only\}}

Page AN, Fragar LJ. Recall of farm hazards in Australian primary school age children using a 3-d visual cue test. Australian Journal of Rural Health 2001;9(5):216-21. [PUBMED: 11736844]

\section{Patel 2013 \{published data only\}}

Patel D, Sandell JM. Prevention of unintentional injury in children. Paediatrics and Child Health 2013;23(9):402-8. [PUBMED: RN337407467]

\section{Paulson 1981 \{published data only\}}

Paulson JA. Injury prevention in children. Journal of Family Practice 1981;13(1):123-4. [PUBMED: 7252432]

\section{Persaud 1997 \{published data only\}}

Persaud D, Leedom CL. Think First for Kids - new for 1997. SCI Nursing 1997;14(4):118-9. [PUBMED: 9510833]

\section{Peterson 1984a \{published data only\}}

Peterson L. Training comprehensive prevention skills in latchkey children. Behaviour Modification 1984;8(4):474-94. [PUBMED: 6508718]

\section{Peterson 1984b \{published data only\}}

Peterson L. Teaching home safety and survival skills to latch-key children: a comparison of two manuals and methods. Journal of Applied Behavior Analysis 1984;17(3):279-93.

\section{Picanol 1992 \{published data only\}}

Picanol J. Preventive measures in accidents in childhood [Medidas preventivas en los accidentes de la infancia]. Anales Espanoles de Pediatria 1992;36 Suppl 48:160-3. [MEDLINE: 0302-4342]

\section{Pless 1987 \{published data only\}}

Pless IB, Arsenault $L$. The role of health education in the prevention of injuries to children. Journal of Social Issues 1987;43(2):87-103. [PUBMED: WOS:A1987L134700007]

\section{Posner 2005 \{published data only\}}

Posner, M. Working together for safety: a state team approach to preventing occupational injuries in young people. Lace Safety and Health 2005:52.

\section{Pressley 2005 \{published data only\}}

Pressley JC, Barlow B, Durkin M, Jacko SA, Dominguez DR, Johnson L. A national program for injury prevention in children and adolescents: the injury free coalition for kids. Journal of Urban Health 2005;82(3):389-402. [PUBMED: 15958785]

\section{Pusin 1985 \{published data only\}}

Pusin P, Sanka A, Knezevic D, Duric R. Prevention of injuries in children with a review of the approach used in Subotica [Prevencija povrede dece sa osvrtom na pristup u Subotici]. Medicinski Pregled 1985;38(1-2):87-9. [PUBMED: 4033565]

Reed 1990 \{published data only\}

Reed J. Safety programs of the farm safety association in Ontario, Canada. American Journal of Industrial Medicine 1990;18(4):409-11. [PUBMED: 1990360965]

\section{Reed 2000 \{published data only\}}

Reed V, Jernstedt G. Teaching children about health: an example of secondary gain in an academic-community partnership. Education for Health 2000;13(3):357-65. [PUBMED: 57722374

\section{Reed 2002 \{published data only\}}

Reed, D, Kidd, P. AgDARE - Agricultural Disability Awareness and Risk Education. National Agricultural Safety Database 2002.

\section{Reichelderfer 1977 \{published data only\}}

Reichelderfer T. Preventing accidents from fires and burns. Pediatric Annals 1977;6(11):702-3. [PUBMED: 917603]

Reinberg 1995 \{published data only\}

Reinberg O. Accidents in children and adolescents: from analysis to prevention [Les accidents d'enfants et d'adolescents: de l'analyse a la prevention]. Revue Medicale de la Suisse Romande 1995;115(11):863-7. [PUBMED: 8525240]

Repath 1970 \{published data only\}

Repath E. Home accidents - a socio-medical problem. Community Health 1970;2(1):12-7. [PUBMED: 5487955]

Rey 1993 \{published data only\}

Rey S, Courtois X, Zmirou D, Francois M, Oberle D, Navet J. Evaluation of a health educative program against childhood injuries. Pediatrie 1993;48(10):727-33.

Rieman 2012 \{published data only\}

Rieman MT, Kagan RJ. Pilot testing of a burn prevention teaching tool for Amish children. Journal of Burn Care \& Research 2012;33(2):265-71.

Rieman 2013 \{published data only\}

Rieman MT, Kagan RJ. Multicenter testing of a burn prevention teaching tool for Amish children. Journal of Burn Care \& Research 2013;34(1):58-64. [PUBMED: 23292573]

Rigau-Perez 1986 \{published data only\}

Rigau-Perez JG, Vega NI. Prevention of accidents and control of injuries in Puerto Rico: progress toward the National Health Objectives for 1990 (IX) [Prevencion de accidentes y control de lesiones en Puerto Rico: progreso hacia los Objetivos Nacionales de Salud para 1990 (IX)]. Boletin - Asociacion Medica de Puerto Rico 1986;78(12):523-34. [MEDLINE: 3468955]

Rimmer 2010 \{published data only\}

Rimmer RB, Pressman M, Joiner J, Winchester S, Foster KN, Caruso DM. The effectiveness of a culturally sensitive burn 
and fire prevention program designed for inner city school students and parents. Injury Prevention 2010;16:A22. [PUBMED: 2011290761]

\section{Rimmer 2011 \{published data only\}}

Rimmer RB, Pressman MA, Joiner J, Winchester S, Foster KN, Caruso DM. Outcome of a culturally sensitive burn and fire prevention program designed for inner city school families. Journal of Burn Care and Research 2011;32:S109. [PUBMED: 70701619]

\section{Rivara 1991 \{published data only\}}

Rivara F, Booth C, Bergman A, Rogers L, Weiss J. Prevention of pedestrian injuries to children: effectiveness of a school training program. Pediatrics 1991;88:770-5.

Rivara 1998 \{published data only\}

Rivara FP. Injury prevention in practice. Injury Prevention 1998;4(1):4-5. [PUBMED: 9595323]

Roper 2007 \{published data only\}

Roper JD. Making an "A" in playground injury prevention. School Nurse News 2007;24(4):33-5. [PUBMED: 17913105]

Ryan 1971 \{published data only\}

Ryan AJ. Prevention of sports injury: a problem solving approach. Journal of Health, Physical Education, Recreation 1971;42:24-9. [ERIC: 64332336; EJ036582]

\section{Salvarani 2009 \{published data only\}}

Salvarani CP, Colli BO, Carlotti CG. Impact of a program for the prevention of traffic accidents in a Southern Brazilian city: a model for implementation in a developing country. Surgical Neurology 2009;72(1):6-14. [PUBMED: WOS:000267775800002]

San Agustin 1973 \{published data only\}

San Agustin M, Stevens E, Hicks D. An evaluation of the effectiveness of a Children and Youth Project. Health Service Reports 1973;88(10):942-6. [PUBMED: 4762104]

\section{Schaplowsky 1973 \{published data only\}}

Schaplowsky FA. Demonstrations show effectiveness of education in injury control programs. Journal of Environmental Health 1973;35(6):565-70. [ERIC: 64235442; EJ079714]

\section{Schlesinger 1997 \{published data only\}}

Schlesinger E, Dickson D, Westaby J. Lowen L, Logrillo V, Maiwald A. A controlled study of health education in accident prevention: the Rockland County Child Injury Project. Injury Prevention 1997;3:218-23.

\section{Schriever 2012 \{published data only\}}

Schriever J. "Caution summer" - accidents! ["Vorsicht Sommer" - Unfalle!]. Kinderkrankenschwester 2012;31(8):315-8. [MEDLINE: 22937612]

\section{Schulkind 1983 \{published data only\}}

Schulkind ML. Preventing accidents and injuries in children. American Family Physician 1983;28(3):240-5. [PUBMED: 6613802]
Scott-Moncrieff 1989 \{published data only\}

Scott-Moncrieff C. Back to school. Part 2. The Practitioner 1989;233(1475):1229. [PUBMED: 2616478]

\section{Self 2007 \{published data only\}}

Self T, Scudder RR, Weheba G, Crumrine D. A virtual approach to teaching safety skills to children with autism spectrum disorder. Topics in Language Disorders 2007;27(3):242.

Shani 1998 \{published data only\}

Shani E, Rosenberg L. Burn prevention forum. Are we making an impact? A review of a burn prevention program in Israeli schools. Journal of Burn Care \& Rehabilitation 1998;19(1, Part 1):82-6. [PUBMED: 1998034703]

Shani 2003 \{published data only\}

Shani E, Ayalon A, Hammad IA, Sikron F. What picture is worth a thousand words? A comparative evaluation of a burn prevention programme by type of medium in Israel. Health Promotion International 2003;18(4):361-71.

Sibert 1983 \{published data only\}

Sibert JR. Children's accidents. New hope for prevention. Practitioner 1983;227(1376):205-8. [PUBMED: 6866911]

Sidky 1996 \{published data only\}

Sidky M. SAFE KIDS Canada. Injury Prevention 1996;2(1):70-2. [PUBMED: 9346060]

\section{Simko 1978 \{published data only\}}

Simko S. Prevention of juvenile burns based on the evaluation of causes and sequelae of 500 hospitalized cases [Pravention kindlicher Verbrennungen aufgrund der Auswertung von Ursachen und Folgen bei 500 hospitalisierten Fallen]. Hefte zur Unfallheilkunde 1978;130:302-4. [MEDLINE: 659167]

Sims 2003 \{published data only\}

Sims M, Cowburn G. Life skills - Learning for Living: an evaluation study of a safety education programme for children. World Conference on Injury Prevention and Control, Montreal. 2003.

\section{Sinha 2011 \{published data only\}}

Sinha I, Patel A, Kim FS, Maccorkle ML, Watkins JF. Comic books can educate children about burn safety in developing countries. Journal of Burn Care \& Research 2011;32(4):e112-7. [PUBMED: 21593680]

Sloan 1990 \{published data only\}

Sloan KA. The Safety Seal Injury Prevention Program: a response to the epidemic of injury and death in children. Journal of Emergency Nursing 1990;16(2):83-9. [PUBMED: 2181197]

\section{Smith 1994 \{published data only\}}

Smith RS, Vigneux B. Tailor your game plan when implementing mouthguard programs for school and town sports. Journal of the Massachusetts Dental Society 1994;43(4):48, 51-3. [PUBMED: 9509013] 
Sorensen 1976 \{published data only\}

Sorensen B. Prevention of burns and scalds in a developed country. Zentralblatt fur Chirurgie 1976;101(24):1504-18. [PUBMED: 1014990]

\section{Sullivan 2010 \{published data only\}}

Sullivan J, Bayless L, Cook C, Cowles S. Pilot program at Litel elementary school. Injury Prevention 2010;16:A282. [PUBMED: 2011289965]

\section{Summers 2011 \{published data only\}}

Summers J, Tarbox J, Findel-Pyles RS, Wilke AE, Bergstrom R, Williams LW. Teaching two household safety skills to children with autism. Research in Autism Spectrum Disorders 2011;5(1):629-32. [PUBMED: 762456636]

\section{Tamburro 2002 \{published data only\}}

Tamburro RF, Shorr RI, Bush AJ, Kritchevsky SB, Stidham GL, Helms SA. Association between the inception of a SAFE KIDS Coalition and changes in pediatric unintentional injury rates. Injury Prevention 2002;8(3):242-5. [PUBMED: 12226125]

\section{Tellnes 2006 \{published data only\}}

Tellnes G, Lund J, Sandvik L, Klouman E, Ytterstad B. Long-term effects of community-based injury prevention on the island of Vaeroy in Norway: a 20-year follow up. Scandinavian Journal of Public Health 2006;34(3):312-9. [PUBMED: 742731809]

\section{Torres 2006 \{published data only\}}

Torres F, Alessandrini M, Bertazzo C, Noguerol M, Chiolo M. Evaluation of an educational intervention on unintentional injuries in childhood. Pediatric Research 2006;60:639.

Towner 1997 \{published data only\}

Towner E, Jarvis S. The Childhood Injury Prevention and Promotion of Safety Programme (CHIPPS). Injury Prevention 1997;3(1):67-8.

\section{Utley 2010 \{published data only\}}

Utley R, Downs D. Injury prevention: the HEAD FIRST helmet safety program for kids. Journal of Emergency Nursing 2010;36(5):489-91. [PUBMED: 758113391]

\section{Valenzuela 2009 \{published data only\}}

Valenzuela A, Bloomfield J, Blaha K. Preventing accidents in children using community-based learning. Medical Education 2009;43(5):480-1. [PUBMED: 19422500]

\section{Van Schagen 1994 \{published data only\}}

Van Schagen IN, Brookhuis KA. Training young cyclists to cope with dynamic traffic situations. Accident; Analysis and Prevention 1994;26(2):223-30.

\section{Van Schagen 1997 \{published data only\}}

Van Schagen I, Rothengatter T. Classroom Instruction versus Roadside Training in Traffic Safety Education. Journal of Applied Developmental Psychology 1997;18:283-92.

\section{Varas 1988 \{published data only\}}

Varas R, Carbone R, Hammond JS. A one-hour burn prevention program for grade school children: its approach and success.
Journal of Burn Care \& Rehabilitation 1988;9(1):69-71. [PUBMED: 3356743]

\section{Vassilyadi 2009 \{published data only\}}

Vassilyadi M, Duquette C, Shamji MF, Orders S, Dagenais S. Evaluation of ThinkFirst for kids injury prevention curriculum for grades 7/8. Canadian Journal of Neurological Sciences 2009;36(6):761-8. [PUBMED: 19960757]

Vicas-Kunse 1992 \{published data only\}

Vicas-Kunse P. Educating our children: the pilot school program. Occupational Medicine 1992;7(1):173-7. [PUBMED: 1531890]

Victor 1988 \{published data only\}

Victor J, Lawrence P, Munster A, Horn SD. A statewide targeted burn prevention program. Journal of Burn Care \& Rehabilitation 1988;9(4):425-9. [PUBMED: 2464602]

Walls 2006 \{published data only\}

Walls H. To hear the future. Hearing Journal 2006;59(5):56. [PUBMED: 2006252241]

Ward 2010 \{published data only\}

Ward J, de Castro A, Tsai J, Linker D, Hildahl L, Miller M. An injury prevention strategy for teen restaurant workers. Washington State's ProSafety project. AAOHN Journal 2010;58(2):57-65. [EMBASE: 20180503]

Watts 1992 \{published data only\}

Watts C, Eyster EF. National Head and Spinal Cord Injury Prevention Program of the American Association of Neurological Surgeons and the Congress of Neurological Surgeons. Journal of Neurotrauma 1992;9 Suppl 1:S307-12. [PUBMED: 1588621]

\section{West 1996 \{published data only\}}

West MA. Developing a regional network for preventing injuries of children and adolescents: the Region $X$ experience. Injury Prevention 1996;2(3):219-20. [PUBMED: 9346094]

\section{Wigglesworth 1987 \{published data only\}}

Wigglesworth D, Weiss L. Teaching health, safety early. Occupational Health \& Safety 1987;56(5):70-2. [PUBMED: 3587815]

\section{References to studies awaiting assessment \\ Bachman 2015 \{published data only\}}

Bachman SL, Arbogast H, Ruiz P, Farag M, Demeter NE, Upperman JS, et al. A school-hospital partnership increases knowledge of pedestrian and motor vehicle safety. Journal of Community Health 2015;40:1057-64.

\section{Baudier 1988 \{published data only\}}

Baudier F, Marchais M, Ferry B, Bourderont D, Pinochet C, Blum D. The cooperative program for the prevention of domestic accidents in children in the department of the Doubs. II. Training aspects and evaluation. [Programme Cooperatif de Prevention des Accidents Domestiques de l'enfant dans 
le Departement de Doubs. li. Aspects Educatifs et]. Archives Francaises de Pediatrie 1988;45:499-503.

Bell 2005 \{published data only\}

Bell ML, Kelley-Baker T, Rider R, Ringwalt C. Protecting you/ protecting me: effects of an alcohol prevention and vehicle safety program on elementary students. Journal of School Health 2005;75:171-7.

\section{Benassi 1984 \{published data only\}}

Benassi S, Capasso AR, Lacava G, Valmor C. Safety education in the teaching program. The professional nurse enters the school world as an educator for health. Rivista dell'Infermiere 1984;3:230-5.

\section{Benvenuti 2001 \{published data only\}}

Benvenuti L, Gagliardi R. School programs for the prevention of head injuries [Programmi Scolastici di Prevenzione]. Rivista di neurobiologia 2001;47:24-5.

\section{Busch 2015 \{published data only\}}

Busch V, De Leeuw JR, Zuithoff NP, Van Yperen TA, Schrijvers AJ. A controlled health promoting school study in the Netherlands: effects after 1 and 2 years of intervention. Health Promotion Practice 2015;16(4):592-600.

\section{Chung 2004 \{published data only\}}

Chung ES, Jeong IS, Song MG. Development and effect analysis of web-based instruction program to prevent elementary school students from safety accidents [in Korean]. Daehan Ganho Haghoeji 2004;34:485-94.

\section{Dale 2016 \{published data only\}}

Dale R, Shanley DC, Zimmer-Gembeck MJ, Lines K, Pickering K, White $\mathrm{C}$. Empowering and protecting children by enhancing knowledge, skills and well-being: a randomized trial of Learn to BE SAFE with EmmyTM. Child Abuse \& Neglect 2016;51:368-78.

Dalis 1970 \{published data only\}

Dalis GT. Using precise objectives to enhance student achievement in health education. Los Angeles County Superintendent of Schools, Calif 1970:10.

\section{Das Gupta 2007 \{published data only\}}

Das Gupta S, Barua A, Mitra B, Bhutia HL, Sherpa SZ. A study on impact assessment of health education intervention on road safety and accident prevention among primary school children of Tadong Government School, East Sikkim. Journal International Medical Sciences Academy 2007;20:267-9.

\section{Echlin 2014 \{published data only\}}

Echlin PS, Johnson AM, Holmes JD, Tichenoff A, Gray S, Gatavackas H, et al. The Sport Concussion Education Project. A brief report on an educational initiative: from concept to curriculum. Journal of Neurosurgery 2014;121:1331-6.

\section{Emery 2010 \{published data only\}}

Emery CA, Richmond SA, Doyle-Baker PK. The efectivenes of a combined sport injury and obesity prevention program in junior high school. Paediatrics \& Child Health 2010;15:72a.
Ergun 2013 \{published data only\}

Ergun S, Kalkim A, Dolgun E. Child-to-child training for prevention of school injuries in Odemis, Turkey. Journal of School Nursing 2013;29:337-42.

Falavigna 2014 \{published data only\}

Falavigna A, Medeiros GS, Canabarro CT, Barazzetti DO, Marcon G, Carneiro Monteiro GM, et al. How can we teach them about neurotrauma prevention? Prospective and randomized "Pense Bem - Caxias do Sul" study with multiple interventions in preteens and adolescents: Clinical article. Journal of Neurosurgery. Pediatrics 2014;14:94-100.

Gardner 1976 \{published data only\}

Gardner AW, Foster S. Teaching safety, accident prevention and first aid in schools. Burns 1976;2:204-6.

Goossens 2016 \{published data only\}

Goossens L, Cardon G, Witvrouw E, Steyaert A, De Clercq D. A multifactorial injury prevention intervention reduces injury incidence in physical education teacher education students. European Journal of Sport Science 2016;16:365-73.

Hartley 2013 \{published data only\}

Hartley C. Preventing primary spinal cord injuries in adolescents: a 7th grade science education program. Topics in Spinal Cord Injury Rehabilitation 2013;19(2):173.

\section{Heard 2013 \{published data only\}}

Heard JP, Latenser BA, Liao J. Burn prevention in Zambia: a work in progress. Journal of Burn Care \& Research 2013;34:598-606.

\section{Hooshmand 2014 \{published data only\}}

Hooshmand J, Hotz G, Neilson V, Chandler L. BikeSafe: evaluating a bicycle safety program for middle school aged children. Accident; Analysis and Prevention 2014;66:182-6.

\section{Hotz 2013 \{published data only\}}

Hotz G. Evidence based injury prevention programs. Journal of Head Trauma Rehabilitation 2013;28(5):E32.

Ismail 2014 \{published data only\}

Ismail Z. Childhood injury prevention in Malaysia: Make It Safe for Kids (MISK). Southeast Asian Journal of Tropical Medicine and Public Health 2014;45 Suppl 1:53-6.

\section{Jin 2009 \{published data only\}}

Jin HQ, Li YC, Zhang SL, Yu WS. Evaluation on the effects of education regarding road safety among middle school students [in Chinese]. Chung-Hua Liu Hsing Ping Hsueh Tsa Chih (Chinese Journal of Epidemiology) 2009;30:797-801.

Klas 2015 \{published data only\}

Klas KS, Vlahos PG, McCully MJ, Piche DR, Wang SC. Schoolbased prevention program associated with increased short- and long-term retention of safety knowledge. Journal of Burn Care \& Research 2015;36:387-93. 
Knifed 2014 \{published data only\}

Knifed E, MacLellan A, Freund P, Seong A, Ng W. The effectiveness of a brain and spinal cord injury prevention programme in school-aged children. Brain Injury 2014;28(5-6):562.

\section{Knight-Bohnhoff 1999 \{published data only\}}

Knight-Bohnhoff K, Smith J, Deis J, Chavez Y, Horne-Lucero L. "Troo, the Traumaroo" bicycle and playground safety program: a pilot study of kindergarten through second graders in the southwest. Journal of Trauma Nursing 1999;6:28-36.

Koestner 2012 \{published data only\}

Koestner AL. Thinkfirst for teens: finding an injury-prevention approach for teenagers. Journal of Trauma Nursing 2012;19:227-31.

\section{Kozma 2013 \{published data only\}}

Kozma N, Land A, Rains C, Todd G. Quantifying results of a comprehensive school-age child injury prevention program. Annals of Advances in Automotive Medicine Annual Scientific Conference 2013;57:361-2.

\section{Morrongiello 2016 \{published data only\}}

Morrongiello BA, Bell M, Park K, Pogrebtsova K. Evaluation of the Safety Detective Program: a classroom-based intervention to increase kindergarten children's understanding of home safety hazards and injury-risk behaviors to avoid. Prevention Science 2016;17:102-11.

\section{Picanol 1974 \{published data only\}}

Picanol J. Prevention of accidents in children [La Prevencion De Accidentes En Los Ninos]. Anales espanoles de pediatria 1974;7:47-50.

\section{Poulter 2010 \{published data only\}}

Poulter DR, McKenna FP. Evaluating the effectiveness of a road safety education intervention for pre-drivers: an application of the theory of planned behaviour. British Journal of Educational Psychology 2010;80:163-81.

\section{Punke 1971 \{published data only\}}

Punke HH. Safety and early childhood education. Journal of School Health 1971;41:146-53.

\section{Radics 2015 \{published data only\}}

Radics J, Zaragoza M, Lau K, Reeser G Jr, Eckerdt D. Urban city burn prevention program effective in rural community. Journal of Burn Care \& Research 2015;36:S244.

\section{Reed 2003 \{published data only\}}

Reed DB, Westneat SC, Kidd P. Observation study of students who completed a high school agricultural safety education program. Journal of Agricultural Safety and Health 2003;9:275-83

\section{Renaud 1989 \{published data only\}}

Renaud L, Suissa S. Evaluation of the efficacy of simulation games in traffic safety education of kindergarten children. American Journal of Public Health 1989;79:307-9.

\section{Rexen 2014 \{published data only\}}

Rexen CT, Andersen LB, Ersboll AK, Jespersen E, Franz C, Wedderkopp N. Injuries in children with extra physical education in primary schools. Medicine and Science in Sports and Exercise 2014;46:745-52.

Richmond 2014 \{published data only\}

Richmond SA, Zhang YJ, Stover A, Howard A, Macarthur C. Prevention of bicycle-related injuries in children and youth: a systematic review of bicycle skills training interventions. Injury Prevention 2014;20:191-5.

\section{Richmond 2016 \{published data only\}}

Richmond SA, Kang J, Doyle-Baker PK, Nettel-Aguirre A, Emery CA. A school-based injury prevention program to reduce sport injury risk and improve healthy outcomes in youth: a pilot cluster-randomized controlled trial. Clinical Journal of Sport Medicine 2016;26:291-8.

Riley 1978 \{published data only\}

Riley CB. The vital role the school plays in preventing athletic injuries. Journal of School Health 1978;48:97-9.

Schwebel 2016 \{published data only\}

Schwebel DC, Combs T, Rodriguez D, Severson J, Sisiopiku V. Community-based pedestrian safety training in virtual reality: a pragmatic trial. Accident; Analysis and Prevention 2016;86:9-15.

Shen 2016 \{published data only\}

Shen JB, Pang SL, Schwebel DC. Evaluation of a drowning prevention program based on testimonial videos: a randomized controlled trial. Journal of Pediatric Psychology 2016;41:555-65.

\section{Solomon 2013 \{published data only\}}

Solomon R, Giganti MJ, Weiner A, Akpinar-Elci M. Water safety education among primary school children in Grenada. International Journal of Injury Control and Safety Promotion 2013;20:266-70.

\section{Stevenson 1999 \{published data only\}}

Stevenson M, Iredell H, Howat P, Cross D, Hall M. Measuring community/environmental interventions: the Child Pedestrian Injury Prevention Project. Injury Prevention 1999;5:26-30.

\section{Teran 2008 \{published data only\}}

Teran S, Strochlic R, Bush D, Baker R, Meyers J. Reaching teen farm workers with health and safety information: an evaluation of a high school ESL curriculum. Journal of Agricultural Safety and Health 2008;14:147-62.

Teyhan 2016 \{published data only\} Teyhan A, Cornish R, Macleod J, Boyd A, Doerner R, Sissons Joshi M. An evaluation of the impact of 'Lifeskills' training on road safety, substance use and hospital attendance in adolescence. Accident; Analysis and Prevention 2016;86:108-13.

\section{Thein 1993 \{published data only\}}

Thein MM, Lee J. Road safety education for schoolchildren. World Health Forum 1993;14:407-9. 
Toms 1993 \{published data only\}

Toms SA, Neuwelt EA, Avolio AC, Ramsey FL. Evaluation of a program to prevent head and spinal cord injuries: a comparison between middle school and high school. Neurosurgery 1993;32:879-80.

\section{Twisk 2014 \{published data only\}}

Twisk DM, Vlakveld WP, Commandeur JF, Shope JT, Kok G. Five road safety education programmes for young adolescent pedestrians and cyclists: a multi-programme evaluation in a field setting. Accident; Analysis and Prevention 2014;66:55-61.

\section{Zierold 2016 \{published data only\}}

Zierold KM. Safety training for working youth: methods used versus methods wanted. Work (Reading, Mass) 2016;54:149-57.

\section{Additional references}

\section{Bijur 1988}

Bijur PE, Golding J, Kurzon M. Childhood accidents, family size and birth order. Society of Scientific Medicine. 1988;26(8):839-43.

\section{Bruce 2005}

Bruce B, Mcgrath P. Group interventions for the prevention of injuries in young children: a systematic review. Injury Prevention 2005;11:143-7.

\section{Cooper 2004}

Cooper C, Dennison EM, Leufkens HG, Bishop N, van Staa TP. Epidemiology of childhood fractures in Britain: a study using the general practice research database. Journal of Bone Mineral Research 2004;19(12):1976-81.

\section{Donner 2000}

Donner A, Klar N. Design and Aanalysis of Cluster

Randomization Trials in Health Research. London: Arnold, 2000.

\section{Duperrex 2009}

Duperrex O, Blackhall K, Burri M, Jeannot E. Education of children and adolescents for the prevention of dog bite injuries. Cochrane Database of Systematic Reviews 2009, Issue 2. [DOI: 10.1002/14651858.CD004726.pub2; CD004726]

\section{Ekeus 2004}

Ekeus C, Christensson K, Hjern A. Unintentional and violent injuries among pre-school children of teenage mothers in Sweden: a national cohort study. Journal of Epidemiology and Community Health 2004;58(8):680-5.

\section{Faggiano 2005}

Faggiano F, Vigna-Taglianti F, Versino E, Zambon A, Borraccino A, Lemma P. School-based prevention for illicit drugs' use. Cochrane Database of Systematic Reviews 2005, Issue 2. [DOI: 10.1002/14651858.CD003020.pub2; CD003020]

\section{Fishbein 1975}

Fishbein M, Ajzen I. Belief, Attitude, Intention, and Behaviour: an Introduction to Theory and Research. Reading, MA: AddisonWesley Publishing Company, 1975.

\section{Foxcroft 2011}

Foxcroft D, Tsertsvadze A. Universal school-based prevention programs for alcohol misuse in young people. Cochrane Database of Systematic Reviews 2011, Issue 5. [DOI: 10.1002/14651858.CD009113]

\section{Glanz 1997}

Glanz K, Rimer BK, Lewis FM. Health Behaviour and Health Education: Theory, Research and Practice. 2nd Edition. San Francisco: Jossey-Bass, 1997.

\section{GRADE 2004}

GRADE working group. Grading quality of evidence and strength of recommendations. BMJ 2004;328:1490-7.

\section{Grossman 2000}

Grossman DC. The history of injury control and the epidemiology of child and adolescent injuries. The Future of Children 2000;10(1):23-52.

\section{Haagsma 2016}

Haagsma JA, Graetz N, Bolliger I, Naghavi M, Higashi H, Mullany EC, et al. The global burden of injury: incidence, mortality, disability-adjusted life years and time trends from the Global Burden of Disease study 2013. Injury Prevention 2016;22(1):3-18.

\section{Hayes 1999}

Hayes RJ, Bennett S. Simple sample size calculation for clusterrandomized trials. International Journal of Epidemiology 1999;28:319-26.

\section{Higgins 2011}

Higgins JPT, Green S, editor(s). Cochrane Handbook for Systematic Reviews of Interventions Version 5.1.0 (updated March 2011). The Cochrane Collaboration, 2011. Available from handbook.cochrane.org.

\section{Hovell 1986}

Hovell MF, Elder JP, Blanchard J, Sallis JF. Behaviour analysis and public health perspectives: combining paradigms to effect prevention. Education and Treatment in Children 1986;9:287-306.

\section{Jacobs 2008}

Jacobs G, Thomas AA. Astrop A. Estimating global road fatalities, 2008. Crowthorne, Transport Research Laboratory.

\section{Janz 1984}

Janz NK, Becker MH. The health belief model: a decate later. Health Education 1984;11(1):1-47.

\section{Klassen 2000}

Klassen TP, MacKay JM, Moher D, Walker A, Jones AL. Community-based injury prevention interventions. Future Child 2000;10(1):83-110. [MEDLINE: 10911689]

\section{Laflamme 2010}

Laflamme L, Hasselberg M, Burrows S. 20 years of research on socioeconomic inequality and children's unintentional injuries - understanding the cause-specific evidence at hand. 
International Journal of Pediatrics 2010;2010:1-23. [DOI: 10.1155/2010/819687]

\section{Laing 1999}

Laing GJ, Logan S. Patterns of unintentional injury in childhood and their relation to socio-economic factors. Public Health 1999;113(6):291-4.

\section{Lalloo 2003}

Lalloo R, Sheiham A, Nazroo JY. Behavioural characteristics and accidents: findings from the Health Survey for England, 1997. Accidents; Analysis and Prevention 2003;35(5):661-7.

\section{Langford 2014}

Langford R, Bonell CP, Jones HE, Pouliou T, Murphy SM, Waters E, et al. The WHO Health Promoting School framework for improving the health and well-being of students and their academic achievement. Cochrane Database of Systematic Reviews 2014, Issue 4. [DOI: 10.1002/14651858.CD008958.pub2]

\section{Morag 2002}

Morag Mackay DR, David M. Evaluation of the Risk WatchTM injury prevention elementary school curriculum in Ottowa, Canada. 6th World Conference on Injury Prevention and Safety Promotion 2002:1323.

\section{Mulvaney 2012}

Mulvaney C, Watson M, Errington G. Safety education impact and good practice: a review. Health Education 2012;112(1):15-30.

\section{Mytton 2006}

Mytton JA, DiGuiseppi C, Gough D, Taylor RS, Logan S. Schoolbased secondary prevention programmes for preventing violence. Cochrane Database of Systematic Reviews 2006, Issue 3. [DOI: 10.1002/14651858.CD004606.pub2; CD004606]

\section{Mytton 2009}

Mytton J, Towner E, Brussoni M, Gray S. Unintentional injuries in school-aged children and adolescents: lessons from a systematic review of cohort studies. Injury Prevention 2009;15(2):111-24.

\section{Nauta 2014}

Nauta J, van Mechelen W, Otten RH, Verhagen EA. A systematic review on the effectiveness of school and community-based injury prevention programmes on risk behaviour and injury risk in 8-12 year old children. Journal of Science Medicine and Sport 2014;17(2):165-72.

\section{Owen 2011}

Owen R, Kendrick D, Mulvaney C, Coleman T, Royal S. Nonlegislative interventions for the promotion of cycle helmet

\section{CHARACTERISTICS OF STUDIES}

Characteristics of included studies [ordered by study ID] wearing by children. Cochrane Database of Systematic Reviews 2011, Issue 11. [DOI: 10.1002/14651858.CD003985.pub3; CD003985]

\section{Poland 2000}

Poland B, Green L, Rootman I. Settings for Health Promotion. Linking Theory and Practice.. Thousand Oaks: Sage Publications, 2000.

\section{Prochaska 1983}

Prochaska JO, DiClemente CC. Stages and processes of self change of smoking: toward an integrative model of change. Journal of Consultation in Clinical Psychology 1983;51:390-5.

\section{RevMan 2014 [Computer program]}

The Cochrane Collaboration. Review Manager. Version 5.3. Copenhagen: The Cochrane Collaboration, 2014.

\section{Sethi 2008}

Sethi D, Towner E, Vincenten J, Segui-Gomez M, Racioppi F. European report on child injury prevention, 2008. www.who.int/ violence_injury_prevention/child/injury/world_report/ European_report.pdf (accessed 19 December 2016).

\section{Sindelar 2004}

Sindelar HA, Barnett NP, Spirito A. Adolescent alcohol use and injury. A summary and critical review of the literature. Minerva Pediatrica 2004;56(3):291-309.

\section{Thomas 2006}

Thomas RE, Perera R. School-based programmes for preventing smoking. Cochrane Database of Systematic Reviews 2006, Issue 3. [DOI: 10.1002/14651858.CD001293.pub2; CD001293]

\section{Tobler 1986}

Tobler NS. Meta-analysis of 143 adolescent drug prevention programs: quantitative outcome results of program participants compared to a control or comparison group. Journal of Drug Issues 1986;16(4):537-67.

\section{Towner 2002}

Towner E, Dowswell T. Community-based childhood injury prevention interventions: what works?. Health Promotion International 2002;17(3):273-84.

\section{Wazana 1997}

Wazana A. Are there injury-prone children? A critical review of the literature. Canadian Journal of Psychiatry 1997;42(6):602-10.

* Indicates the major publication for the study 
Azeredo 2003

\begin{tabular}{|c|c|}
\hline Methods & CBA \\
\hline \multirow[t]{3}{*}{ Participants } & $\begin{array}{l}\text { School children in grades kindergarten to grade } 5 \text { and their families in Muskogee, Oklahoma from pri- } \\
\text { vate and state schools located in both rural and urban settings. }\end{array}$ \\
\hline & Number of participants: not reported. \\
\hline & $\begin{array}{l}4750 \text { observations of children's behaviour were made and } 6300 \text { pre- and postintervention question- } \\
\text { naires were distributed. }\end{array}$ \\
\hline \multirow[t]{2}{*}{ Interventions } & $\begin{array}{l}\text { Intervention: } 18 \text { or } 27 \text { lesson curricula stratified by grade ( } 30 \text { - to } 45 \text {-minute sessions). Smoke alarm } \\
\text { giveaway. School cycle fairs with helmet giveaways. Safety pen pal letters. Letters to parents. Injury } \\
\text { prevention talks at parent-teacher meetings. }\end{array}$ \\
\hline & Control: no injury prevention curriculum. Opportunity for smoke alarm to be installed. \\
\hline \multirow[t]{3}{*}{ Outcomes } & $\begin{array}{l}\text { Observed seat-belt use of occupants in the front seat of a vehicle and cycle helmet use during and } 2 \\
\text { weeks after the intervention. }\end{array}$ \\
\hline & Self-reported behaviour, including driver and passenger seat-belt use and cycle helmet use. \\
\hline & $\begin{array}{l}\text { Safety knowledge measured using written questions for children in kindergarten to grade } 1 \text {, and true or } \\
\text { false and multiple choice questionnaire for children in grades } 2 \text { and } 3 \text { and grades } 4 \text { and } 5 \text {. }\end{array}$ \\
\hline \multirow[t]{2}{*}{ Injury mechanisms } & $\begin{array}{l}\text { Vehicle safety; smoke alarms and fire; cycle safety helmet use; brain and spinal cord injuries; home } \\
\text { safety; }\end{array}$ \\
\hline & pedestrian safety; first aid; traffic signs and signals; intersections and railroad crossings; water safety. \\
\hline Notes & $\begin{array}{l}\text { Did not present the characteristics of the control and intervention groups. Measurement of observed } \\
\text { seat-belt use } 3 \text { months' post-intervention did not occur as many of the students had emigrated or im- } \\
\text { migrated, leading to a change in the population. }\end{array}$ \\
\hline
\end{tabular}

\section{Risk of bias}

\begin{tabular}{lll}
\hline Bias & Authors' judgement & Support for judgement \\
\hline $\begin{array}{l}\text { Allocation to interven- } \\
\text { tion/control (selection }\end{array}$ & High risk & Schools chose to be in the intervention group. \\
bias) (for non-RCT and & \\
CBA studies) &
\end{tabular}

Blinding of participants High risk $\quad$ No blinding.
and personnel (perfor-
mance bias)
All outcomes

\begin{tabular}{lll}
\hline $\begin{array}{l}\text { Blinding of outcome as- } \\
\text { sessment (detection bias) } \\
\text { All outcomes }\end{array}$ & High risk & Self-reported outcomes. \\
\hline $\begin{array}{l}\text { Incomplete outcome data } \\
\text { (attrition bias) } \\
\text { All outcomes }\end{array}$ & Unclear risk & Number allocated at baseline not reported. \\
\hline $\begin{array}{l}\text { Selective reporting (re- } \\
\text { porting bias) }\end{array}$ & High risk & Seat-belt use outcome reported incompletely. \\
\hline Other bias & Unclear risk & No baseline data presented. \\
\hline
\end{tabular}


Azeredo 2003 (Continued)

Risk of bias due to confounding (for non-RCTs and CBA studies)
High risk

Did not adjust for confounding. Pre-programme, more control school pupils used seat belts.

\section{Buckley 2010}

\begin{tabular}{ll}
\hline Methods & CBA \\
\hline Participants & $\begin{array}{l}\text { Children in year } 9 \text { of high school (95\% were aged } 13 \text { to } 14 \text { years) from schools in an urban deprived are } \\
\text { of Queensland, Australia. }\end{array}$ \\
& $\begin{array}{l}\text { Number of participants: } 360 \text { students in the intervention group ( } 97 \% \text { of all eligible students) and } 180 \\
\text { students ( } 45 \% \text { of all eligible students) in the control group. }\end{array}$
\end{tabular}

Interventions

Intervention: SPIY programme. teacher training, a teacher's manual and student workbook for 8 lessons carried out in the school. Each lesson lasted 50 minutes, and included presentations of risktaking and injury scenarios, introduction to first aid and cognitive behavioural activities to prevent the risk-taking behaviour, including protecting friends.

Control: usual curriculum. The SPIY programme was made available after the study.

\begin{tabular}{ll}
\hline Outcomes & Self-reported risk behaviour measured using the Australian Self-Report Delinquency Scale, 2 weeks \\
postintervention.
\end{tabular}

\begin{tabular}{ll}
\hline Injury mechanisms & Poisoning; \\
& road traffic accidents: cars, cycles, motorbike, pedestrian.
\end{tabular}

\section{Notes}

\section{Risk of bias}

\begin{tabular}{|c|c|c|}
\hline Bias & Authors' judgement & Support for judgement \\
\hline $\begin{array}{l}\text { Allocation to interven- } \\
\text { tion/control (selection } \\
\text { bias) (for non-RCT and } \\
\text { CBA studies) }\end{array}$ & High risk & Schools selected which group they wanted to be in (intervention vs control). \\
\hline $\begin{array}{l}\text { Blinding of participants } \\
\text { and personnel (perfor- } \\
\text { mance bias) } \\
\text { All outcomes }\end{array}$ & High risk & $\begin{array}{l}\text { Parents were sent information that an evaluation of an injury prevention pro- } \\
\text { gramme was taking place. }\end{array}$ \\
\hline $\begin{array}{l}\text { Blinding of outcome as- } \\
\text { sessment (detection bias) } \\
\text { All outcomes }\end{array}$ & High risk & Self-reported outcomes, high risk of allocations being detected. \\
\hline $\begin{array}{l}\text { Incomplete outcome data } \\
\text { (attrition bias) } \\
\text { All outcomes }\end{array}$ & Low risk & $\begin{array}{l}\text { Attrition was }>20 \% \text { as the analyses were only based on children with complete } \\
\text { before-and-after data. }\end{array}$ \\
\hline $\begin{array}{l}\text { Selective reporting (re- } \\
\text { porting bias) }\end{array}$ & Unclear risk & The authors only reported data for children with before-and-after data. \\
\hline
\end{tabular}


Buckley 2010 (Continued)

Other bias High risk

The study did not take into account clustering effects. Only $45 \%$ of control group children were included (197 children) compared to $97 \%$ of the intervention group, indicating a differential selection bias.

\begin{tabular}{|c|c|c|}
\hline $\begin{array}{l}\text { Risk of bias due to con- } \\
\text { founding (for non-RCTs } \\
\text { and CBA studies) }\end{array}$ & Unclear risk & $\begin{array}{l}\text { Although groups had similar sociodemographic factors, because schools self- } \\
\text { selected which groups they were in there could have been some residual con- } \\
\text { founding. }\end{array}$ \\
\hline
\end{tabular}

Campbell 2001

\begin{tabular}{|c|c|}
\hline Methods & $\mathrm{RCT}$ \\
\hline \multirow[t]{2}{*}{ Participants } & $\begin{array}{l}\text { Children aged } 11 \text { to } 16 \text { years and parents with a Hispanic background, attending state-based high } \\
\text { schools in US. }\end{array}$ \\
\hline & Number of participants: 293 students in the intervention group and 367 in the intervention group. \\
\hline \multirow[t]{2}{*}{ Interventions } & $\begin{array}{l}\text { Intervention: first aid and home safety educational programme. Focus was on responding to emer- } \\
\text { gency situations and the prevention of injuries. This included household safety, giving emergency care, } \\
\text { controlling bleeding and treating burns. Involved } 8 \text { sessions over a } 7 \text { - to } 10 \text {-week period, including } \\
\text { homework. Each session lasted } 2 \text { hours. }\end{array}$ \\
\hline & $\begin{array}{l}\text { Control: tobacco and alcohol prevention programme delivered over a } 7 \text { - to } 10 \text {-week period by teachers. } \\
\text { This included refusal skills, health effects of smoking and peer pressure. Each session lasted } 2 \text { hours, } \\
\text { with homework for children to take away. }\end{array}$ \\
\hline Outcomes & $\begin{array}{l}\text { Proportion of adolescents who reported that their household had made home safety behaviour } \\
\text { change, including practicing a fire escape plan, } 1 \text { year after the intervention. }\end{array}$ \\
\hline Injury mechanisms & $\begin{array}{l}\text { First aid; smoke, fire and flames; heat/hot surfaces; sport/physical activity; household safety; poison- } \\
\text { ing. }\end{array}$ \\
\hline Notes & $\begin{array}{l}\text { Sex of children was balanced between groups. } 67 \% \text { of respondents reported low income, } 3 \text { children un- } \\
\text { der the age of } 18 \text { years, and were classified as very Mexican orientated on Acculturation Scale for Mexi- } \\
\text { can Americans (ARSMA) scale. }\end{array}$ \\
\hline
\end{tabular}

\section{Risk of bias}

\begin{tabular}{lll}
\hline Bias & Authors' judgement & Support for judgement \\
\hline $\begin{array}{l}\text { Random sequence genera- } \\
\text { tion (selection bias) }\end{array}$ & Unclear risk & Randomly assigned, but no further information provided. \\
\hline $\begin{array}{l}\text { Allocation concealment } \\
\text { (selection bias) }\end{array}$ & Unclear risk & Not applicable - non-randomised study. \\
\hline $\begin{array}{l}\text { Blinding of participants } \\
\text { and personnel (perfor- } \\
\text { mance bias) } \\
\text { All outcomes }\end{array}$ & High risk & Not possible to blind participants. \\
\hline
\end{tabular}
Blinding of outcome as- 
Campbell 2001 (Continued)

Incomplete outcome data High risk Attrition was $>20 \%$ for the behavioural skills testing outcomes. Intention-to(attrition bias) treat analysis unclear as not mentioned.

All outcomes

\begin{tabular}{lll}
$\begin{array}{l}\text { Selective reporting (re- } \\
\text { porting bias) }\end{array}$ & Unclear risk & $\begin{array}{l}\text { Report most outcomes, but home safety behaviour changes are not all report- } \\
\text { ed. }\end{array}$ \\
\hline Other bias & Low risk & $\begin{array}{l}\text { No baseline data for home safety behaviours, but groups were otherwise simi- } \\
\text { lar. }\end{array}$
\end{tabular}

\section{Carmel 1991}

\begin{tabular}{ll}
\hline Methods & RCT \\
\hline Participants & School children aged 10 to 14 years in state-based primary schools in a city in Israel. \\
& Number of participants: 308 students in the intervention group and 254 students in the control group.
\end{tabular}

Interventions

Intervention: schools delivered a targeted burn prevention programme developed by a plastic surgery research unit in Beer-Sheva, Israel. The programme aimed to raise awareness, increase knowledge, and change attitudes and behaviour related to burn prevention. Multi-methods of teaching were used including: a slide set, home checklist, set of photographs and colouring book.

Control: no intervention.

Outcomes Safety knowledge was tested using a questionnaire immediately post and 10 weeks following the inter-
vention.

\begin{tabular}{ll}
\hline Injury mechanisms & Burn injuries. \\
\hline Notes & Groups appeared balanced for baseline characteristics following randomisation.
\end{tabular}

\section{Risk of bias}

\begin{tabular}{lll}
\hline Bias & Authors' judgement & Support for judgement \\
\hline $\begin{array}{l}\text { Random sequence genera- } \\
\text { tion (selection bias) }\end{array}$ & Unclear risk & Randomly assigned, but no further information about how it was done. \\
\hline $\begin{array}{l}\text { Allocation concealment } \\
\text { (selection bias) }\end{array}$ & Unclear risk & Insufficient information to make a judgement. \\
\hline $\begin{array}{l}\text { Blinding of participants } \\
\text { and personnel (perfor- } \\
\text { mance bias) }\end{array}$ & High risk & No blinding or any attempt to conceal allocation (not possible to blind partici- \\
All outcomes & pants). \\
\hline $\begin{array}{l}\text { Blinding of outcome as- } \\
\text { sessment (detection bias) } \\
\text { All outcomes }\end{array}$ & Unclear risk & Not clear how test results were marked. \\
\hline $\begin{array}{l}\text { Incomplete outcome data } \\
\text { (attrition bias) } \\
\text { All outcomes }\end{array}$ & High risk & High attrition bias as outcome data were based on < 80\% of original sample. \\
\hline
\end{tabular}


Carmel 1991 (Continued)

Selective reporting (re- High risk Did not report parents' outcomes, which was 1 of the study objectives. porting bias)

Other bias

Unclear risk

Did not use cluster level analyses. Did not adequately explain scoring system.

Chapman 2013

\begin{tabular}{ll}
\hline Methods & RCT \\
\hline Participants & Boys and girls aged 13 to 14 years attending school in Australia. \\
& Number of participants: 77 students in the intervention group and 196 students in the control group.
\end{tabular}

\begin{tabular}{|c|c|}
\hline Interventions & $\begin{array}{l}\text { Intervention: a risk and injury prevention curriculum for adolescents, involving } 8 \text { sessions lasting } 50 \\
\text { minutes, delivered weekly. Students were presented with risk-taking injury scenarios, incorporating } \\
\text { multiple activities including role plays and discussion. The sessions utilised cognitive behavioural } \\
\text { change principles. }\end{array}$ \\
\hline & Control: no intervention. \\
\hline
\end{tabular}

Outcomes

Proportion of children with a self-reported transport injury over a 3-month period was measured using the Extended Adolescent Injury Checklist (Chapman 2011) 6 months following the intervention.

\begin{tabular}{ll}
\hline Injury mechanisms & Cycle, \\
& motor cycle, \\
& motor vehicle. \\
\hline Notes & $\begin{array}{l}\text { Sex of children differed slightly between groups at baseline (46\% male in control group, } 56 \% \text { male in in- } \\
\text { tervention group), but were similar at follow-up ( } 50 \% \text { male in control group, } 51 \% \text { male in intervention } \\
\text { group). }\end{array}$ \\
\hline
\end{tabular}

\section{Risk of bias}

\begin{tabular}{lll}
\hline Bias & Authors' judgement & Support for judgement \\
\hline $\begin{array}{l}\text { Random sequence genera- } \\
\text { tion (selection bias) }\end{array}$ & Unclear risk & States 'randomly assigned' but no detail of randomisation method given. \\
\hline $\begin{array}{l}\text { Allocation concealment } \\
\text { (selection bias) }\end{array}$ & Unclear risk & Insufficient information given about allocation process. \\
\hline $\begin{array}{l}\text { Blinding of participants } \\
\text { and personnel (perfor- } \\
\text { mance bias) } \\
\text { All outcomes }\end{array}$ & High risk & $\begin{array}{l}\text { Not possible to conceal allocation due to study design. Participants aware that } \\
\text { they were in intervention group. }\end{array}$ \\
\hline $\begin{array}{l}\text { Blinding of outcome as- } \\
\text { sessment (detection bias) } \\
\text { All outcomes }\end{array}$ & Unclear risk & $\begin{array}{l}\text { No details given regarding how the questionnaires used to collect self-report- } \\
\text { ed outcomes were assessed, or if those marking were masked. }\end{array}$ \\
\hline $\begin{array}{l}\text { Incomplete outcome data } \\
\text { (attrition bias) } \\
\text { All outcomes }\end{array}$ & Unclear risk & $\begin{array}{l}\text { Study did not address incomplete outcome data. Response rate with active } \\
\text { parental consent was similar across baseline and follow-up groups. Inten- } \\
\text { tion-to-treat analysis was not mentioned. }\end{array}$ \\
\hline
\end{tabular}


Chapman 2013 (Continued)

Selective reporting (re- $\quad$ Unclear risk No protocol described.
porting bias)

\begin{tabular}{ll}
\hline Other bias $\quad$ High risk & $\begin{array}{l}\text { Only students whose parents signed consent forms for children to participate } \\
\text { in the programme were included. }\end{array}$
\end{tabular}

Collard 2010

\begin{tabular}{ll}
\hline Methods & RCT (clustered) \\
\hline Participants & $\begin{array}{l}\text { Primary school children aged } 10 \text { to } 12 \text { years from state-based schools in urban and suburban areas } \\
\text { the Netherlands. }\end{array}$ \\
& $\begin{array}{l}\text { Number of participants: } 1117 \text { students in the intervention group and } 1091 \text { students in the control } \\
\text { group. }\end{array}$
\end{tabular}

Interventions
ered by a teacher. Children received 5 minutes of exercises at the beginning and end of lessons. Parents
and children received monthly newsletters for 8 months and were offered access to a website devel-
oped by the programme.
Control: received usual PE classes.

Outcomes Rate of physical activity injury measured by weekly self-reporting.

Self-reported behaviour and safety practices (wearing protective equipment during organised sport and leisure activities and appropriate footwear during PE) measured by 5-point Likert scale at 8 months.

Safety knowledge of injury prevention measured by multiple choice questions at the 8-month follow-up only.

\begin{tabular}{ll}
\hline Injury mechanisms & Sports/physical activity injuries. \\
\hline Notes & $\begin{array}{l}\text { Age and sex of children were balanced at baseline. BMI higher in the control group. Number of children } \\
\text { from low socioeconomic group was higher in the intervention group. }\end{array}$ \\
\hline
\end{tabular}

\section{Risk of bias}

\begin{tabular}{|c|c|c|}
\hline Bias & Authors' judgement & Support for judgement \\
\hline $\begin{array}{l}\text { Random sequence genera- } \\
\text { tion (selection bias) }\end{array}$ & Unclear risk & Insufficient information given to make a judgement. \\
\hline $\begin{array}{l}\text { Allocation concealment } \\
\text { (selection bias) }\end{array}$ & Unclear risk & Insufficient information given to make a judgement. \\
\hline $\begin{array}{l}\text { Blinding of participants } \\
\text { and personnel (perfor- } \\
\text { mance bias) } \\
\text { All outcomes }\end{array}$ & High risk & Not possible to blind participants or people delivering the intervention. \\
\hline $\begin{array}{l}\text { Blinding of outcome as- } \\
\text { sessment (detection bias) } \\
\text { All outcomes }\end{array}$ & Unclear risk & No detail of who assessed or marked test papers. \\
\hline
\end{tabular}


Collard 2010 (Continued) Incomplete outcome data Low risk
(attrition bias)

All outcomes

\begin{tabular}{lll}
\hline $\begin{array}{l}\text { Selective reporting (re- } \\
\text { porting bias) }\end{array}$ & Low risk & Appeared to report all outcomes measured, but no protocol available. \\
\hline Other bias & Low risk & $\begin{array}{l}\text { No sample size calculation available, did not report intraclass correlation coef- } \\
\text { ficient. }\end{array}$
\end{tabular}

Good retention of participants. Potential bias due to exclusion of social modelling from analysis (but not included in this review). Intention-to-treat analysis was carried out.

\section{Cook 2006}

\begin{tabular}{ll}
\hline Methods & Non-RCT \\
\hline Participants & $\begin{array}{l}\text { Boys and girls in grades } 3 \text { to } 6 \text { (aged } 8 \text { to } 12 \text { years). Participants were classmates of } 1 \text { of } 6 \text { injured chil- } \\
\text { dren who had been admitted into hospital. } \\
\text { Number of participants: } 206 \text { students in the intervention group and } 306 \text { students in the control group. }\end{array}$ \\
\hline
\end{tabular}

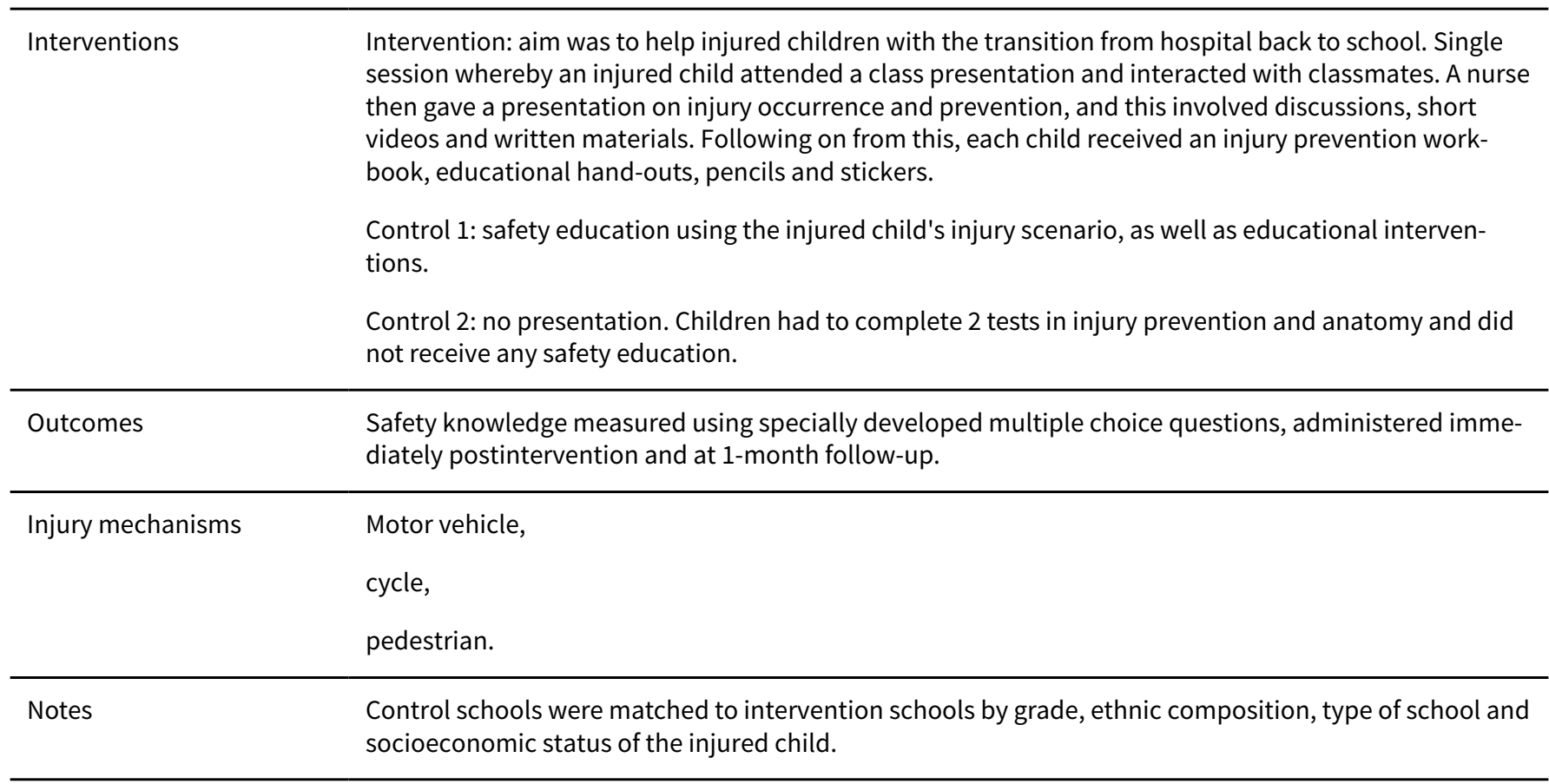

\section{Risk of bias}

\begin{tabular}{lll}
\hline Bias & Authors' judgement & Support for judgement \\
\hline $\begin{array}{l}\text { Allocation to interven- } \\
\text { tion/control (selection } \\
\text { bias) (for non-RCT and } \\
\text { CBA studies) }\end{array}$ & High risk & $\begin{array}{l}\text { Intervention schools were selected by identifying injured children. There was } \\
\text { no mention of how control schools were identified. }\end{array}$ \\
\hline $\begin{array}{l}\text { Blinding of participants } \\
\begin{array}{l}\text { and personnel (perfor- } \\
\text { mance bias) } \\
\text { All outcomes }\end{array}\end{array}$ & High risk & No blinding. \\
\hline
\end{tabular}


Cook 2006 (Continued)

$\begin{array}{lll}\text { Blinding of outcome as- } & \text { High risk } & \text { Teachers read out the questions. } \\ \text { sessment (detection bias) }\end{array}$

All outcomes

\begin{tabular}{lll}
\hline $\begin{array}{l}\text { Incomplete outcome data } \\
\text { (attrition bias) } \\
\text { All outcomes }\end{array}$ & Unclear risk & No numbers provided at baseline. \\
\hline $\begin{array}{l}\text { Selective reporting (re- } \\
\text { porting bias) }\end{array}$ & Unclear risk & Unclear how the outcomes reported in conclusion section were ascertained. \\
\hline Other bias & Unclear risk & No baseline data presented. \\
\hline $\begin{array}{l}\text { Risk of bias due to con- } \\
\text { founding (for non-RCTs } \\
\text { and CBA studies) }\end{array}$ & Low risk & $\begin{array}{l}\text { Control schools were matched to intervention schools by grade, ethnic com- } \\
\text { position, type of school and socioeconomic status of the injured child. }\end{array}$ \\
\hline
\end{tabular}

\section{Falavigna 2012}

\begin{tabular}{ll}
\hline Methods & RCT \\
\hline Participants & $\begin{array}{l}1049 \text { children from state and public schools who were in the second year of high school (mean age } 16 \\
\text { years) from an urban area in Brazil. } \\
\text { Number of participants: } 572 \text { students in the intervention group and } 477 \text { students in the control group. }\end{array}$ \\
\hline
\end{tabular}

\begin{tabular}{ll}
\hline Interventions & Intervention: 'Think Well' (English translation) project, inspired by 'Think First'. Intervention lasted \\
60 minutes and was conducted by researchers trained by the research co-ordinator, and included a \\
video of injured young people discussing their accident and its impact and a brain and spinal cord trau- \\
ma prevention lecture (basic neuroanatomy, age-related risks, main causes of neurotrauma, general \\
guidelines to prevent neurotrauma). \\
Control: no intervention.
\end{tabular}

Control: no intervention.

\begin{tabular}{ll}
\hline Outcomes & Self-reported behaviour and practices, plus safety knowledge assessed using a test instrument special- \\
ly developed by the Neurology and Neurosurgery Multidisciplinary Academic League at the University \\
of Caxias do Sul, administered 1 week and 5 months following intervention.
\end{tabular}

Injury mechanisms
swaumatic brain and spinal cord injuries:
cycle,
motorcycle,
falls.
Sex and age of children did not differ between groups at baseline. Significantly more children in the in-
tervention group had ridden a cycle and had skateboarded/rollerbladed (75.8\% had ridden a cycle vs
$\begin{aligned} & 40.6 \% \text { had skateboarded/rollerbladed) than in the control group }(66.8 \% \text { had ridden a cycle and } 27 \% \\ & \text { had skateboarded/rollerbladed). }\end{aligned}$

\section{Risk of bias}

Bias Authors' judgement Support for judgement


Falavigna 2012 (Continued)

Random sequence genera- Unclear risk Not described. States "controlled and randomised study" only. tion (selection bias)

Allocation concealment Unclear risk Insufficient information given to make a judgement.
(selection bias)

(selection bias)

Blinding of participants High risk It was not possible to blind participants.

and personnel (perfor-

mance bias)

All outcomes

Blinding of outcome as-
sessment (detection bias) $\quad$ Unclear risk Does not describe how tests were marked.

All outcomes

\section{Incomplete outcome data High risk}

(attrition bias)

All outcomes
Only students who gave consent and with complete data at baseline where included. Attrition was high in both the intervention and control group.

Intervention: 1053 number allocated, at baseline $=572,1$ week $=547,5$ months $=513$.

Control: 1051 number allocated, at baseline $=477,1$ week $=436,5$ months $=$ 416.

Intention-to-treat analysis unclear as not mentioned.
Selective reporting (re- High risk porting bias) $\geq 1$ outcomes of interest in the review were reported incompletely so they could not be entered in a meta-analysis: knowledge scores were presented in a graph with no specific data provided.

Other bias Low risk Did not appear to be at risk of other bias.

\section{Frederick 2000}

\begin{tabular}{ll}
\hline Methods & CBA \\
\hline Participants & 1292 children aged between 10 and 11 years from Oxfordshire UK. \\
& Number of participants: 657 students in the intervention group and 635 students in the control group.
\end{tabular}

Interventions

Intervention: IMPS. Teachers were given a resource pack, available for 1 academic year, which covered basic life support training, interactional videos illustrating a range of accidents such as burns and how to respond. This was then followed by a hospital visit, whereby children were given a tour of the accident and emergency department by IMPS trainers.

Control: schools with no prior exposure to IMPS. Normal curriculum.

Outcomes Safety knowledge assessed using a specially developed quiz 5 months after the intervention.

A hypothetical basic life support scenario was used to measure observed safety skills and behaviour retained after the intervention.

Self-reported behaviour and safety practices assessed using a validated 'draw and write' test.

Injury mechanisms Road safety, accidents in the home, fire, electricity, poisons, waterways.


Frederick 2000 (Continued)

Notes

Control schools were matched on location, size and Standard Assessment Test results. Intervention schools were those that were already enrolled in the IMPS programme.

\section{Risk of bias}

\begin{tabular}{|c|c|c|}
\hline Bias & Authors' judgement & Support for judgement \\
\hline $\begin{array}{l}\text { Allocation to interven- } \\
\text { tion/control (selection } \\
\text { bias) (for non-RCT and } \\
\text { CBA studies) }\end{array}$ & High risk & Schools self-selected an intervention. \\
\hline $\begin{array}{l}\text { Blinding of participants } \\
\text { and personnel (perfor- } \\
\text { mance bias) } \\
\text { All outcomes }\end{array}$ & High risk & No blinding. \\
\hline $\begin{array}{l}\text { Blinding of outcome as- } \\
\text { sessment (detection bias) } \\
\text { All outcomes }\end{array}$ & High risk & For observed outcomes, the trainers were unblinded. \\
\hline $\begin{array}{l}\text { Incomplete outcome data } \\
\text { (attrition bias) } \\
\text { All outcomes }\end{array}$ & Low risk & $\begin{array}{l}\text { Attrition was }<20 \% \text { for all outcomes and in both intervention and control } \\
\text { groups. }\end{array}$ \\
\hline $\begin{array}{l}\text { Selective reporting (re- } \\
\text { porting bias) }\end{array}$ & Unclear risk & $\begin{array}{l}\text { Some inconsistencies in the reporting of findings (e.g. between tables and the } \\
\text { text). }\end{array}$ \\
\hline Other bias & Unclear risk & Tables comparing the characteristics of schools were not included. \\
\hline $\begin{array}{l}\text { Risk of bias due to con- } \\
\text { founding (for non-RCTs } \\
\text { and CBA studies) }\end{array}$ & Low risk & $\begin{array}{l}\text { Control schools were matched on location, size and Standard Assessment Test } \\
\text { results. }\end{array}$ \\
\hline
\end{tabular}

\section{Grant 1992}

\begin{tabular}{ll}
\hline Methods & RCT \\
\hline Participants & $\begin{array}{l}\text { School children in grade } 3 \text { and } 4 \text { in state-based primary schools in the US. } \\
\text { Number of participants: } 1187 \text { students in the intervention group and } 730 \text { students in the control group. }\end{array}$ \\
\hline Interventions & $\begin{array}{l}\text { Intervention: schools delivered the 'Learn Not to Burn' curriculum, which was developed by a collabo- } \\
\text { ration of fire protection organisations and a burn centre in North Carolina. The programme was based } \\
\text { upon } 22 \text { key behaviours for burn prevention, but no other details of the programme or teaching meth- } \\
\text { ods were described. } \\
\text { Control: schools used "other methods of fire safety education" (not described) or "no established fire } \\
\text { safety curriculum". }\end{array}$ \\
\hline Outcomes & $\begin{array}{l}\text { Students' knowledge of burn prevention assessed using a test administered at the end of the academic } \\
\text { year following intervention. }\end{array}$ \\
\hline Injury mechanisms & Burn-related injuries and deaths. \\
\hline Notes & No characteristics of participants presented to enable judgement on how well balanced groups were. \\
\hline \hline
\end{tabular}

School-based education programmes for the prevention of unintentional injuries in children and young people (Review) 
Grant 1992 (Continued)

Risk of bias

\begin{tabular}{|c|c|c|}
\hline Bias & Authors' judgement & Support for judgement \\
\hline $\begin{array}{l}\text { Random sequence genera- } \\
\text { tion (selection bias) }\end{array}$ & High risk & $\begin{array}{l}\text { States 'randomly drawn' and 'stratified random sample' but no description of } \\
\text { sequence generation or process. No baseline characteristics presented to en- } \\
\text { able judgement regarding success of randomisation. } 1 \text { set of analyses included } \\
\text { data volunteered by schools not included in randomisation process. }\end{array}$ \\
\hline $\begin{array}{l}\text { Allocation concealment } \\
\text { (selection bias) }\end{array}$ & Unclear risk & $\begin{array}{l}\text { Insufficient information about allocation process given. No mention of alloca- } \\
\text { tion concealment. }\end{array}$ \\
\hline $\begin{array}{l}\text { Blinding of participants } \\
\text { and personnel (perfor- } \\
\text { mance bias) } \\
\text { All outcomes }\end{array}$ & High risk & $\begin{array}{l}\text { No blinding or any attempt to conceal allocation (not possible to blind partici- } \\
\text { pants). }\end{array}$ \\
\hline $\begin{array}{l}\text { Blinding of outcome as- } \\
\text { sessment (detection bias) } \\
\text { All outcomes }\end{array}$ & High risk & $\begin{array}{l}\text { Stated "tests were graded by the teachers in the study schools". Possible that } \\
\text { marking could have been biased. }\end{array}$ \\
\hline $\begin{array}{l}\text { Incomplete outcome data } \\
\text { (attrition bias) } \\
\text { All outcomes }\end{array}$ & High risk & $\begin{array}{l}\text { Incomplete data occurred due to test scores not received from schools (higher } \\
\text { in control group), and incorrect tests used. Districts that changed group were } \\
\text { correctly excluded. }\end{array}$ \\
\hline $\begin{array}{l}\text { Selective reporting (re- } \\
\text { porting bias) }\end{array}$ & High risk & No protocol described. Outcomes not reported completely. \\
\hline Other bias & High risk & $\begin{array}{l}\text { Misclassification bias is possible due to control districts using similar burn pre- } \\
\text { vention curriculum to the Learn Not to Burn. Additional data were included } \\
\text { from schools not originally included in the study sample, although these are } \\
\text { reported separately. }\end{array}$ \\
\hline
\end{tabular}

Greene 2002

\begin{tabular}{ll}
\hline Methods & CBA \\
\hline Participants & 1400 children from 64 classrooms (grades 1 to 3 ) in the US. \\
& Number of participants: 735 students in the intervention group and 665 students in the control group.
\end{tabular}

Interventions

Reporting Phase III of the Think First For Kids curriculum. Only children were the recipients of the intervention, which was carried out by teachers within schools.

Intervention: Think First For Kids programme. 6-week, 6-subject curriculum was integrated into the usual school curriculum. The units looked at the structure and function of the brain and spinal cord; road traffic safety (e.g. motor vehicle safety); conflict resolution; and water, sports, playground and recreational safety. There were 3 intervention groups (for the 3 grades).

Control: no intervention.

Outcomes

Safety knowledge (brain and spinal cord injury, water safety, cycle safety, motor vehicle/pedestrian safety and playground/sports safety) assessed using questions designed to measure the effectiveness of the programme 1 week after the intervention. 
Greene 2002 (Continued)

$$
\begin{aligned}
& \text { motorcycle injuries; } \\
& \text { pedestrian injuries; } \\
& \text { cycle safety; } \\
& \text { conflict resolution and weapon's safety; } \\
& \text { water safety; } \\
& \text { playground, recreation and sports safety. }
\end{aligned}
$$

\begin{tabular}{|c|c|c|}
\hline Bias & Authors' judgement & Support for judgement \\
\hline $\begin{array}{l}\text { Allocation to interven- } \\
\text { tion/control (selection } \\
\text { bias) (for non-RCT and } \\
\text { CBA studies) }\end{array}$ & Unclear risk & Not report. \\
\hline $\begin{array}{l}\text { Blinding of participants } \\
\text { and personnel (perfor- } \\
\text { mance bias) } \\
\text { All outcomes }\end{array}$ & High risk & $\begin{array}{l}\text { Insufficient information provided about the blinding process. Participants } \\
\text { were likely to know that they received the intervention. }\end{array}$ \\
\hline $\begin{array}{l}\text { Blinding of outcome as- } \\
\text { sessment (detection bias) } \\
\text { All outcomes }\end{array}$ & Unclear risk & Insufficient information provided about the blinding process. \\
\hline $\begin{array}{l}\text { Incomplete outcome data } \\
\text { (attrition bias) } \\
\text { All outcomes }\end{array}$ & Unclear risk & Insufficient information about the missing outcome data. \\
\hline $\begin{array}{l}\text { Selective reporting (re- } \\
\text { porting bias) }\end{array}$ & Unclear risk & Insufficient information about the outcome reporting to determine risk. \\
\hline Other bias & Unclear risk & $\begin{array}{l}\text { May be risk of bias but there was insufficient information to assess whether an } \\
\text { important risk of bias existed. }\end{array}$ \\
\hline $\begin{array}{l}\text { Risk of bias due to con- } \\
\text { founding (for non-RCTs } \\
\text { and CBA studies) }\end{array}$ & Unclear risk & No baseline data provided to enable a comparison of the groups. \\
\hline
\end{tabular}

\section{Notes}

\section{Risk of bias}

Gresham 2001

\begin{tabular}{ll}
\hline Methods & RCT \\
\hline Participants & $\begin{array}{l}\text { Participants were elementary children in grades } 1,2 \text { and } 3 \text { and their parents, from } 2 \text { urban areas in San } \\
\text { Diego County (US). } \\
\text { Number of participants: } 1126 \text { students in the intervention group and } 851 \text { students in the control group. }\end{array}$ \\
\hline Interventions & $\begin{array}{l}\text { Intervention: Think First For Kids programme. Children had } 6 \text { contacts, each lasting 35-40 minutes, } \\
\text { over a 6-week period. There were } 6 \text { modules involving a range of video, a spinal cord speaker, hands } \\
\text { on interactive teaching, maths, visual reinforcement and discussion. The intervention was delivered by }\end{array}$ \\
\hline
\end{tabular}


teachers, district nurse, life skills educators as well as an external speaker/brain and spinal cord patient as well as input from parents in the form of parental support with a homework component.

Control: unclear.

\section{Outcomes}

Self-reported behaviour and safety skills and safety knowledge assessed using forced choice format questionnaires, 10 days following intervention.

\begin{tabular}{ll}
\hline Injury mechanisms & Brain and spinal cord injuries: \\
& violence and weapons safety; \\
& playground, recreation and sports safety; \\
& cycle safety; \\
& water safety; \\
& vehicle safety.
\end{tabular}

\section{Risk of bias}

\begin{tabular}{|c|c|c|}
\hline Bias & Authors' judgement & Support for judgement \\
\hline $\begin{array}{l}\text { Random sequence genera- } \\
\text { tion (selection bias) }\end{array}$ & Unclear risk & No information provided about the randomisation process. \\
\hline $\begin{array}{l}\text { Allocation concealment } \\
\text { (selection bias) }\end{array}$ & Unclear risk & $\begin{array}{l}\text { No information provided about the allocation process to determine if low or } \\
\text { high risk, although children were matched on district, socioeconomic status, } \\
\text { reading scores and ethnicity in the school. }\end{array}$ \\
\hline $\begin{array}{l}\text { Blinding of participants } \\
\text { and personnel (perfor- } \\
\text { mance bias) } \\
\text { All outcomes }\end{array}$ & High risk & $\begin{array}{l}\text { Not described. Participants were likely to know that they had received the in- } \\
\text { tervention. }\end{array}$ \\
\hline $\begin{array}{l}\text { Blinding of outcome as- } \\
\text { sessment (detection bias) } \\
\text { All outcomes }\end{array}$ & Unclear risk & Insufficient information provided about the blinding process. \\
\hline $\begin{array}{l}\text { Incomplete outcome data } \\
\text { (attrition bias) } \\
\text { All outcomes }\end{array}$ & Unclear risk & $\begin{array}{l}\text { Post-test results could not be matched for } 20 \% \text { of students, though the pa- } \\
\text { per did not report whether these were control or intervention students. Inten- } \\
\text { tion-to-treat analysis not mentioned. }\end{array}$ \\
\hline $\begin{array}{l}\text { Selective reporting (re- } \\
\text { porting bias) }\end{array}$ & High risk & $\begin{array}{l}\text { The authors did not separate out behaviour and knowledge outcomes and did } \\
\text { not report the module scores. }\end{array}$ \\
\hline Other bias & Low risk & Did not appear to be at risk of other bias. \\
\hline
\end{tabular}

Kendrick 2007

Methods RCT (clustered)


Kendrick 2007 (Continued)

Allocation occurred at the school level, with schools divided into 3 groups based on the proportion of children who were receiving free meals (representing deprivation). Using these 3 groups, schools were then randomly allocated to the intervention and control groups.

Participants Children were aged 7 to 10 years (in years 3, 4 and 5) and were from state-funded primary schools in the UK.

Number of participants: 240 students in the intervention group and 219 students in the control group.

Interventions

Intervention: 'Risk Watch' programme. Teachers were trained by fire service personnel and received 'Risky boxes' containing background information, lesson plans and activities for pupils. The boxes were age-specific ( 1 box for years 3 and 4 , and 1 box for year 5). Participating schools had to teach at least 1 of 4 injury topics (cycle and pedestrian, falls, poisoning, fire and burns).

Control: usual curriculum. Control schools agreed to teach at least 1 'Risk Watch' topic once the evaluation had been completed.

Outcomes

Observed safety skills assessed by observation and role play in age-appropriate injury scenarios ('stop, drop and roll', road safety and poisoning secondary intervention skills in years 3 and 4, fire and road safety skills and appropriate use of cycle helmets in year 5).

Self-reported behaviour and safety practices (fire and burn prevention, poisoning prevention, falls prevention, and cycle and pedestrian safety) measured using age-appropriate pencil and paper questionnaires. Safety knowledge (fire and burn prevention, poisoning prevention, falls prevention and cycle and pedestrian safety) measured using age-appropriate questionnaires, with questions illustrated pictorially.
Injury mechanisms Cycle and pedestrian; falls, fire and burns, poisoning.

Notes Children in the intervention group were more likely to be younger and to come from families without access to a car than children in the control group.

Outcome data obtained from published and unpublished data.

\section{Risk of bias}

\begin{tabular}{|c|c|c|}
\hline Bias & Authors' judgement & Support for judgement \\
\hline $\begin{array}{l}\text { Random sequence genera- } \\
\text { tion (selection bias) }\end{array}$ & High risk & $\begin{array}{l}\text { Although the allocation schedule was generated by computer, all schools in- } \\
\text { cluded in the study were those who had agreed to undertake the programme. }\end{array}$ \\
\hline $\begin{array}{l}\text { Allocation concealment } \\
\text { (selection bias) }\end{array}$ & Unclear risk & $\begin{array}{l}\text { Unclear how the independent researcher allocated schools to the treatment } \\
\text { groups. }\end{array}$ \\
\hline $\begin{array}{l}\text { Blinding of participants } \\
\text { and personnel (perfor- } \\
\text { mance bias) } \\
\text { All outcomes }\end{array}$ & High risk & $\begin{array}{l}\text { "It was not possible to blind participants or teachers to treatment group allo- } \\
\text { cation". }\end{array}$ \\
\hline $\begin{array}{l}\text { Blinding of outcome as- } \\
\text { sessment (detection bias) } \\
\text { All outcomes }\end{array}$ & High risk & Blinding was attempted, but it is likely that this was broken. \\
\hline $\begin{array}{l}\text { Incomplete outcome data } \\
\text { (attrition bias) } \\
\text { All outcomes }\end{array}$ & Low risk & $\begin{array}{l}\text { Attrition }<20 \% \text { in both treatment arms. Intention-to-treat analysis not men- } \\
\text { tioned. }\end{array}$ \\
\hline $\begin{array}{l}\text { Selective reporting (re- } \\
\text { porting bias) }\end{array}$ & Low risk & $\begin{array}{l}\text { The study's prespecified outcomes of interest were reported in the prespeci- } \\
\text { fied way. }\end{array}$ \\
\hline
\end{tabular}


Kendrick 2007 (Continued)

Other bias Unclear risk Unclear if there were any difference between schools who agreed to carry out the programme and those who did not, and if this could have introduced bias.

Lee 2004

\begin{tabular}{ll}
\hline Methods & RCT (clustered) \\
\hline Participants & High-school children aged 13 to 18 years from 123 rural-based schools across 10 states in the US. \\
& Number of participants: 5113 students in the intervention group and 2955 students in the control \\
group.
\end{tabular}

Outcomes All outcomes were measured immediately and 1 year postintervention using the specially developed student instrument including:

Self-reported injury incidence proportion in the last 3 months;

Safety knowledge (self-reported learning);

Self-reported behaviour and safety practices including: safety consciousness and dangerous risk taking.

\begin{tabular}{ll} 
Injury mechanisms & Agricultural injuries. \\
\hline Notes & $\begin{array}{l}\text { Pre-intervention sample consisted of } 48 \% \text { farm residents and } 68 \% \text { males. Postintervention groups } \\
\text { (who had matched data) were balanced across sexes and age groups, with approximately } 68 \% \text { male } \\
\text { and } 42 \% \text { farm residents. }\end{array}$
\end{tabular}

\section{Risk of bias}

\begin{tabular}{lll}
\hline Bias & Authors' judgement & Support for judgement \\
\hline $\begin{array}{l}\text { Random sequence genera- } \\
\text { tion (selection bias) }\end{array}$ & Unclear risk & Method of randomisation not described. \\
\hline $\begin{array}{l}\text { Allocation concealment } \\
\text { (selection bias) }\end{array}$ & Unclear risk & No information provided regarding allocation concealment. \\
\hline $\begin{array}{l}\text { Blinding of participants } \\
\begin{array}{l}\text { and personnel (perfor- } \\
\text { mance bias) }\end{array}\end{array}$ & High risk & Not possible to blind participants or those delivering intervention. \\
$\begin{array}{l}\text { All outcomes } \\
\text { Blinding of outcome as- } \\
\text { sessment (detection bias) }\end{array}$ & High risk & $\begin{array}{l}\text { Stated that "Data entry was conducted by trained staff who used a glossary to } \\
\text { deal with aberrant responses" - no mention of blinding. }\end{array}$
\end{tabular}


Lee 2004 (Continued)

All outcomes

Incomplete outcome data High risk (attrition bias)

All outcomes
Started with 8068 children in 111 schools, but only analysed matched data for 3081 children (92 schools). No discussion regarding possible differences in children for whom both sets of data were not available. May have become underpowered. No sensitivity analyses. Intention-to-treat analysis was unclear as not mentioned.

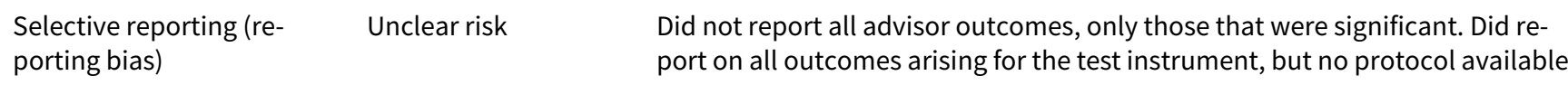

Other bias High risk Risk of being underpowered; no discussion regarding sample size achieved. Adjusted analyses for clustering effect not reported.

\section{Lu 2000}

Methods CBA

Participants School children aged 6 to 16 years in state-based primary and middle schools in Guangdong province, China.

Number of participants: 3988 students in the intervention group and 651 students in the control group.

Interventions Intervention: a multi-component prevention programme delivered through schools. The programme aimed to raise awareness, increase knowledge and reduce the incidence of injuries to students.

At least 2 classes on injury prevention per term were delivered to students, with a booklet on injury prevention provided for each student. A letter was also sent to families of children asking them to collaborate with health and safety education. A mass media campaign was used to promote public awareness regarding injury prevention.

Teachers selected from each school were trained to take part in a rota to watch over the safety of students during physical activity classes, and during peak hours (morning, noon and afternoon) when parents dropped or collected their children. A school injury reporting system to the municipal Centre for Disease Control and Prevention was also set up. Meetings were held between healthcare teachers and school doctors to evaluate progress and gather feedback every 2 months.

Control: no intervention.

Outcomes

Injury incidence rates (mild/moderate/severe) reported through surveys at baseline and postintervention.

Safety knowledge tested by questions on injury prevention and safety.

Cost:benefit analysis using cost per unit of injury.

Injury mechanisms Pedestrian, cycle, motorcycle, vehicle (non-specific), falls, heat and hot surfaces, sport/physical activity.

Notes Translated from Chinese.

\section{Risk of bias}

\begin{tabular}{lll}
\hline Bias & Authors' judgement & Support for judgement \\
\hline Allocation to interven- & Unclear risk & No allocation concealment mentioned.
\end{tabular}

tion/control (selection 
Lu 2000 (Continued)

bias) (for non-RCT and

CBA studies)

\begin{tabular}{|c|c|c|}
\hline $\begin{array}{l}\text { Blinding of participants } \\
\text { and personnel (perfor- } \\
\text { mance bias) } \\
\text { All outcomes }\end{array}$ & High risk & $\begin{array}{l}\text { No mention of blinding. Participants were likely to know that they had re- } \\
\text { ceived the intervention. }\end{array}$ \\
\hline
\end{tabular}

Blinding of outcome as- Unclear risk No mention of blinding of outcome assessment.

sessment (detection bias)

All outcomes

Incomplete outcome data $\quad$ Unclear risk $\quad$ Attrition 2.3\% in intervention group; not reported for control group.
(attrition bias)

(attritic

All outcomes

\begin{tabular}{lll}
\hline $\begin{array}{l}\text { Selective reporting (re- } \\
\text { porting bias) }\end{array}$ & Low risk & All outcomes were reported in prespecified ways. \\
\hline Other bias & Unclear risk & $\begin{array}{l}\text { No baseline data available to compare demographics of intervention and con- } \\
\text { trol groups. }\end{array}$ \\
\hline $\begin{array}{l}\text { Risk of bias due to con- } \\
\text { founding (for non-RCTs } \\
\text { and CBA studies) }\end{array}$ & High risk & $\begin{array}{l}\text { Did not adjust for confounding. Cluster analyses were presented by injury } \\
\text { severity rather than by school. }\end{array}$ \\
\hline
\end{tabular}

\title{
Martinez 1996
}

\begin{tabular}{ll}
\hline Methods & Non-RCT \\
\hline Participants & $\begin{array}{l}\text { Participants were from } 2 \text { high schools (grades 10, } 11 \text { and 12) in the US, matched for socioeconomic fac- } \\
\text { tors but geographically separated, with enrolment of participants occurring in } 4 \text { sections of a physics } \\
\text { class. }\end{array}$
\end{tabular}

Number of participants: 129 students in the intervention group and 74 students in the control group.

Intervention: a 5-component course consisting of audio-visual aids, physical demonstration and a di-
dactic lecture. A researcher delivered the course over 1 week, with each contact lasting 1 hour. The
5 components were basic energy lesson; safety features of vehicles including seat belts; occupant
kinematics and forces/crash prevention, e.g. airbags; review of days 1 to 3 and a demonstration of a
rollover, students then designed crash vehicles; the students tested their crash design.

Control: usual physics lesson.

\begin{abstract}
Outcomes All outcomes measured by questionnaire 2 weeks, and 6 months after intervention.
Self-reported behaviour and practices (seat-belt use, speeding and drink driving).

Safety knowledge (physics of crashes, demographics of people involved in crashes and characteristics of automobiles).
\end{abstract}

\begin{tabular}{ll}
\hline Injury mechanisms & Pedestrian, cycle, motorcycle, vehicle (non-specific). \\
\hline Notes & $\begin{array}{l}\text { No sample size calculation; non-significant results may have occurred due to lack of power. There was } \\
\text { a difference in the school grade of control and intervention groups at baseline. }\end{array}$
\end{tabular}

\section{Risk of bias}

School-based education programmes for the prevention of unintentional injuries in children and young people (Review) 
Martinez 1996 (Continued)

\begin{tabular}{lll} 
Bias & Authors' judgement & Support for judgement \\
\hline $\begin{array}{l}\text { Allocation to interven- } \\
\text { tion/control (selection } \\
\text { bias) (for non-RCT and } \\
\text { CBA studies) }\end{array}$ & Unclear risk & Allocation was not described, except that they were 'chosen'. \\
\hline $\begin{array}{l}\text { Blinding of participants } \\
\text { and personnel (perfor- } \\
\text { mance bias) }\end{array}$ & High risk & $\begin{array}{l}\text { It was clear which group the participants were in as the intervention group re- } \\
\text { ceived the lessons and the control group had lessons as normal - blinding not } \\
\text { possible. }\end{array}$
\end{tabular}

\begin{tabular}{|c|c|c|}
\hline $\begin{array}{l}\text { Blinding of outcome as- } \\
\text { sessment (detection bias) } \\
\text { All outcomes }\end{array}$ & Unclear risk & Paper did not report who analysed the data. \\
\hline $\begin{array}{l}\text { Incomplete outcome data } \\
\text { (attrition bias) } \\
\text { All outcomes }\end{array}$ & High risk & $\begin{array}{l}\text { Only results for students with scores for before instruction (time T1), and at } 2 \\
\text { weeks (T2) and then T1 and T3 scores ( } 6 \text { months after instruction was complet- } \\
\text { ed) were included. No imputation for the missing data was carried out. There } \\
\text { was also a large dropout rate in the control group at T3 (differential). }\end{array}$ \\
\hline $\begin{array}{l}\text { Selective reporting (re- } \\
\text { porting bias) }\end{array}$ & Unclear risk & $\begin{array}{l}\text { Unclear how many children were in each group for the analyses and the au- } \\
\text { thors did not mention removing outliers. }\end{array}$ \\
\hline Other bias & Unclear risk & Methods of adjustment used in the regression modelling not described. \\
\hline $\begin{array}{l}\text { Risk of bias due to con- } \\
\text { founding (for non-RCTs } \\
\text { and CBA studies) }\end{array}$ & High risk & $\begin{array}{l}\text { There were slightly more males in the intervention group, and a difference of } \\
1 \text { school grade between most of the intervention and control group. Schools } \\
\text { were matched on socioeconomic status. }\end{array}$ \\
\hline
\end{tabular}

\section{Morrongiello 1998}

\begin{tabular}{ll}
\hline Methods & CBA \\
\hline Participants & Primary school children aged 7.5 to 10 years from 4 schools in Toronto, Canada. \\
& Number of participants: 96 students in the intervention group and 36 students in the control group. \\
\hline
\end{tabular}

Interventions

Intervention: Go AHEAD programme. single sessions delivered by teacher in the presence of a project co-ordinator/trained facilitator. Activity-based stations that looked at 4 safety topics: cycling and road use; reducing sports injury; creating a safety banner as a group; vehicle and road safety.

Control: no intervention.

Outcomes measured using questionnaire administered prior to and 4 months following intervention,
including:

Self-reported behaviour and safety practices (helmet wearing, seat-belt use).

Safety knowledge (correct use of safety equipment).

Injury mechanisms Cycle, vehicle (non-specific), sport/physical activity, sun.

Notes Intervention and controls were from the same class.

\section{Risk of bias}

School-based education programmes for the prevention of unintentional injuries in children and young people (Review) 
Morrongiello 1998 (Continued)

\begin{tabular}{|c|c|c|}
\hline Bias & Authors' judgement & Support for judgement \\
\hline $\begin{array}{l}\text { Allocation to interven- } \\
\text { tion/control (selection } \\
\text { bias) (for non-RCT and } \\
\text { CBA studies) }\end{array}$ & Unclear risk & Allocation of schools to groups not described. \\
\hline $\begin{array}{l}\text { Blinding of participants } \\
\text { and personnel (perfor- } \\
\text { mance bias) } \\
\text { All outcomes }\end{array}$ & High risk & $\begin{array}{l}\text { Intervention group participants taught separately in the gym, so not possible } \\
\text { to conceal allocation to teachers. }\end{array}$ \\
\hline $\begin{array}{l}\text { Blinding of outcome as- } \\
\text { sessment (detection bias) } \\
\text { All outcomes }\end{array}$ & Unclear risk & No detail of who assessed or marked test papers. \\
\hline $\begin{array}{l}\text { Incomplete outcome data } \\
\text { (attrition bias) } \\
\text { All outcomes }\end{array}$ & Unclear risk & Number followed up for secondary outcomes not reported. \\
\hline $\begin{array}{l}\text { Selective reporting (re- } \\
\text { porting bias) }\end{array}$ & Unclear risk & No protocol available; primary and secondary outcomes not prespecified. \\
\hline Other bias & Unclear risk & No baseline data. \\
\hline $\begin{array}{l}\text { Risk of bias due to con- } \\
\text { founding (for non-RCTs } \\
\text { and CBA studies) }\end{array}$ & Unclear risk & $\begin{array}{l}\text { Intervention and controls were from the same class. No table of characteristics } \\
\text { provided. }\end{array}$ \\
\hline
\end{tabular}

Reed 2001

\begin{tabular}{ll}
\hline Methods & RCT \\
\hline Participants & Participants were high-school agriculture students in the 9th and 10th grades from Kentucky, US. \\
& Number of participants: 373 students in the intervention group and 417 students in the control group.
\end{tabular}

Interventions Intervention: Agricultural Disability Awareness and Risk Education (AgDARE) programme utilised 2 simulation exercise modules: narrative and physical. Narrative (cognitive) simulations which involved problem-solving activities, whereby students were told a story and used pencil and paper to make decisions about work behaviours. Students received instant feedback about their choices, which helped to reinforce the realities of the story being told. In the physical simulations, students had to pretend to have a disability while different farm tasks were simulated. The 2 simulation exercise modules were carried out for each of the 4 topics. The intervention was delivered by 2 research assistants and 2 public health nurses. Due to students' often conflicting commitments, not all students could complete the whole curriculum.

Control: no intervention.

Outcomes

Observed safety behaviour (during farm work) measured by visits 1 year after the intervention.

Self-reported behaviour and safety practices measured by Stages of Change questionnaire pre- and postintervention.

Injury mechanisms Agricultural injuries.


Reed 2001 (Continued)

Notes

Control group students were more likely to be older than students in the intervention group. There were no significant differences between the groups in the number of years they had lived or worked on a farm.

\section{Risk of bias}

\begin{tabular}{lll}
\hline Bias & Authors' judgement & Support for judgement \\
\hline $\begin{array}{l}\text { Random sequence genera- } \\
\text { tion (selection bias) }\end{array}$ & Unclear risk & $\begin{array}{l}\text { Authors reported that the schools were randomly assigned. But there was no } \\
\text { further information provided. In addition, initial schools were selected based } \\
\text { on the strength of their agricultural programmes. }\end{array}$ \\
& &
\end{tabular}

\begin{tabular}{|c|c|c|}
\hline $\begin{array}{l}\text { Allocation concealment } \\
\text { (selection bias) }\end{array}$ & Unclear risk & $\begin{array}{l}\text { Insufficient information about the allocation process to determine if high or } \\
\text { low risk. }\end{array}$ \\
\hline
\end{tabular}

\begin{tabular}{lll}
\hline $\begin{array}{l}\text { Blinding of participants } \\
\text { and personnel (perfor- }\end{array}$ & High risk & $\begin{array}{l}\text { Study did not address blinding of participants and personnel. Participants are } \\
\text { likely to know that they have received the intervention. }\end{array}$
\end{tabular}

mance bias)

All outcomes

Blinding of outcome as- High risk sessment (detection bias)

All outcomes
The people who conducted the interventions were the same ones who assessed the outcomes, particularly the observed behaviours.

\begin{tabular}{|c|c|c|}
\hline $\begin{array}{l}\text { Incomplete outcome data } \\
\text { (attrition bias) } \\
\text { All outcomes }\end{array}$ & High risk & $\begin{array}{l}\text { Only students who completed at least } 2 \text { out of the } 4 \text { units of instruction were } \\
\text { included. There was no mention of missing data points as a result of this. In- } \\
\text { tention-to-treat analysis not mentioned. }\end{array}$ \\
\hline
\end{tabular}

Selective reporting (re- High risk No clear description of the method of scoring for the assessment tools used. porting bias)

Other bias Unclear risk Insufficient information to assess whether an important risk of bias existed.

\section{Richards 1991}

\begin{tabular}{|c|c|}
\hline Methods & Non-RCT \\
\hline Participants & $\begin{array}{l}\text { Children and their teachers in state-based preschool and grades } 1,3 \text { and } 5 \text { from urban and rural areas } \\
\text { of Birmingham, US. Intervention and control group participants were enrolled in the same } 3 \text { schools. } \\
\text { There were } 4 \text { intervention groups (by grade level). }\end{array}$ \\
\hline & Number of participants: 266 students in the intervention group and 229 students in the control group. \\
\hline
\end{tabular}

Interventions Intervention: special injury prevention curriculum delivered over 3 months by a teacher. An 8-component curriculum was developed for each grade level. This included spinal cord awareness and water safety. Teachers had a choice of at least 3 activities to teach each concept. A cartoon character was used to represent behaviours presented in the curriculum (e.g. Alli cat for falls, as cats always land on their feet).

Control: unclear - not reported.

Outcomes Outcomes were assessed by questionnaire, 4 months following the intervention.

Self-reported behaviour and practices (seat-belt use).

Safety knowledge (relating to a range of injury mechanisms). 
Richards 1991 (Continued)

Injury mechanisms Pedestrian, cycle, vehicle (non-specific), falls, swimming/drowning, sport/physical activity.

\begin{tabular}{ll}
\hline Notes & No baseline characteristics were presented, although study reported that intervention and control \\
group participants were taken from the same 3 schools (with students from a range of socioeconomic \\
backgrounds).
\end{tabular}

\section{Risk of bias}

\begin{tabular}{|c|c|c|}
\hline Bias & Authors' judgement & Support for judgement \\
\hline $\begin{array}{l}\text { Allocation to interven- } \\
\text { tion/control (selection } \\
\text { bias) (for non-RCT and } \\
\text { CBA studies) }\end{array}$ & Unclear risk & Allocation method not reported. \\
\hline $\begin{array}{l}\text { Blinding of participants } \\
\text { and personnel (perfor- } \\
\text { mance bias) } \\
\text { All outcomes }\end{array}$ & High risk & No blinding - teachers were aware of the group allocations. \\
\hline $\begin{array}{l}\text { Blinding of outcome as- } \\
\text { sessment (detection bias) } \\
\text { All outcomes }\end{array}$ & High risk & Teachers were aware of group allocations and assessed the outcomes. \\
\hline $\begin{array}{l}\text { Incomplete outcome data } \\
\text { (attrition bias) } \\
\text { All outcomes }\end{array}$ & Unclear risk & $\begin{array}{l}\text { Number allocated to each of the groups at baseline not reported. No mention } \\
\text { of any missing data, or the number of children absent and pre- and post-test- } \\
\text { ing. }\end{array}$ \\
\hline $\begin{array}{l}\text { Selective reporting (re- } \\
\text { porting bias) }\end{array}$ & Unclear risk & $\begin{array}{l}\text { The seat-belt use outcome was reported incompletely (missing exact figures), } \\
\text { so that it could not be entered in a meta-analysis. }\end{array}$ \\
\hline Other bias & Unclear risk & $\begin{array}{l}\text { There may be risk of bias, but there was insufficient information to assess } \\
\text { whether an important risk of bias existed. }\end{array}$ \\
\hline $\begin{array}{l}\text { Risk of bias due to con- } \\
\text { founding (for non-RCTs } \\
\text { and CBA studies) }\end{array}$ & Unclear risk & $\begin{array}{l}\text { Intervention and control group participants were taken from the same } 3 \\
\text { schools (from low, middle and upper socioeconomic backgrounds), but no } \\
\text { baseline characteristics presented. }\end{array}$ \\
\hline
\end{tabular}

Sun 2004

\begin{tabular}{ll}
\hline Methods & RCT(clustered) \\
\hline Participants & $\begin{array}{l}\text { Primary- and middle-school aged children from } 10 \text { state schools (approximately 10,000 students) in a } \\
\text { city setting in China. In each arm, there were } 3 \text { primary schools and } 2 \text { middle schools. Analyses were } \\
\text { not carried out in the oldest children as they left school before outcomes were ascertained. Sex and } \\
\text { ages not specified. } \\
\text { Number of participants: } 8305 \text { children remained and outcomes were analysed for } 7605 \text { students. }\end{array}$ \\
\hline
\end{tabular}

Interventions Intervention: aimed mainly at children but also included parents.

Mainly delivered in schools but some information materials did go home to parents.

Intervention consisted of multiple components:

distributing booklets and leaflets with information on injury prevention to students and parents; 
Sun 2004 (Continued)

helping students to publish "blackboard bulletins" by offering them relevant materials;

offering posters on safety education to schools.

Unclear who delivered the intervention. Frequency and duration of contacts not specified. Intervention ran over an 11-month period.

Control: general information on food hygiene and disease prevention. Method of delivery not specified.

\begin{tabular}{ll}
\hline Outcomes & $\begin{array}{l}\text { Outcomes measured } 1 \text { year after intervention, including: } \\
\text { Self-reported injury incidence rate (overall, at school, at home, travelling to school, falls, road transport } \\
\text { and recurrent injuries). } \\
\text { Injury-related behaviour, assessed by questionnaire. }\end{array}$ \\
\hline Injury mechanisms & Fall injuries. \\
\hline Notes & $\begin{array}{l}\text { Only available as an English abstract. This was a PhD thesis and the full thesis could not be obtained } \\
\text { through inter-library loans. }\end{array}$ \\
\hline
\end{tabular}

\section{Risk of bias}

\begin{tabular}{|c|c|c|}
\hline Bias & Authors' judgement & Support for judgement \\
\hline $\begin{array}{l}\text { Random sequence genera- } \\
\text { tion (selection bias) }\end{array}$ & Unclear risk & No details given. Just says "randomly assigned". \\
\hline $\begin{array}{l}\text { Allocation concealment } \\
\text { (selection bias) }\end{array}$ & Unclear risk & No details given. \\
\hline $\begin{array}{l}\text { Blinding of participants } \\
\text { and personnel (perfor- } \\
\text { mance bias) } \\
\text { All outcomes }\end{array}$ & High risk & $\begin{array}{l}\text { No details given. Participants are likely to have known that they received the } \\
\text { intervention. }\end{array}$ \\
\hline $\begin{array}{l}\text { Blinding of outcome as- } \\
\text { sessment (detection bias) } \\
\text { All outcomes }\end{array}$ & Unclear risk & No details given. \\
\hline $\begin{array}{l}\text { Incomplete outcome data } \\
\text { (attrition bias) } \\
\text { All outcomes }\end{array}$ & Unclear risk & No details given. Unclear if intention-to-treat analysis used. \\
\hline $\begin{array}{l}\text { Selective reporting (re- } \\
\text { porting bias) }\end{array}$ & Low risk & $\begin{array}{l}\text { Only analysed data for students that had complete follow-up data but this was } \\
91.57 \% \text { of all children. Unclear how the } 8.43 \% \text { of children not followed up dif- } \\
\text { fered. }\end{array}$ \\
\hline Other bias & Unclear risk & $\begin{array}{l}\text { Only the abstract was available in English and a full copy of the thesis could } \\
\text { not be obtained. It was unclear, therefore, whether there was selective report- } \\
\text { ing in the full document. Only a subset of data were reported in the abstract. } \\
\text { Did not appear to have taken clustering into account but without the full thesis } \\
\text { it is difficult to know for sure. }\end{array}$ \\
\hline
\end{tabular}

\section{Terzidis 2007}

Methods CBA


Terzidis 2007 (Continued)

Participants
Children were grouped by grade level: kindergarten and grade 1; elementary school; and the first 3 grades of high school. The schools were from an urban area in Greece.

Number of participants: 1400 children included in the evaluation. 641 children in the intervention group (693 minus 28 (pupils who did not receive the intervention) - 24 (pupils absent during the evaluation)) and 759 control group children.
Intervention: special day event. Presentation of age-adjusted educational materials by health professionals in collaboration with teachers. Comprised a short audio-visual presentation, a discussion about pupils' personal experiences, comments on how relevant events could have been averted, drama plays or a combination of these. Take home materials were also provided (e.g. leaflets, crosswords, stickers, badges with water safety messages).

Control: no intervention.

\begin{tabular}{ll}
\hline Outcomes & Safety knowledge (water safety), assessed by multiple choice and open-ended questions. \\
\hline Injury mechanisms & Water safety, swimming/drowning. \\
\hline Notes & \\
\hline
\end{tabular}

\section{Risk of bias}

\begin{tabular}{|c|c|c|}
\hline Bias & Authors' judgement & Support for judgement \\
\hline $\begin{array}{l}\text { Allocation to interven- } \\
\text { tion/control (selection } \\
\text { bias) (for non-RCT and } \\
\text { CBA studies) }\end{array}$ & Unclear risk & $\begin{array}{l}\text { No mention of how schools were allocated to the intervention and control } \\
\text { groups. }\end{array}$ \\
\hline $\begin{array}{l}\text { Blinding of participants } \\
\text { and personnel (perfor- } \\
\text { mance bias) } \\
\text { All outcomes }\end{array}$ & High risk & $\begin{array}{l}\text { Study did not address blinding of participants and personnel. Participants } \\
\text { were likely to know that they have received the intervention. }\end{array}$ \\
\hline $\begin{array}{l}\text { Blinding of outcome as- } \\
\text { sessment (detection bias) } \\
\text { All outcomes }\end{array}$ & Unclear risk & Study did not address blinding of outcome assessor. \\
\hline $\begin{array}{l}\text { Incomplete outcome data } \\
\text { (attrition bias) } \\
\text { All outcomes }\end{array}$ & Low risk & $\begin{array}{l}\text { Reasons for missing outcome data were unlikely to be related to the true out- } \\
\text { come. }\end{array}$ \\
\hline $\begin{array}{l}\text { Selective reporting (re- } \\
\text { porting bias) }\end{array}$ & Low risk & All the study's prespecified outcomes reported in the specified ways. \\
\hline Other bias & Low risk & Study appeared to be free of other sources of bias. \\
\hline $\begin{array}{l}\text { Risk of bias due to con- } \\
\text { founding (for non-RCTs } \\
\text { and CBA studies) }\end{array}$ & Unclear risk & $\begin{array}{l}\text { There were some differences between the baseline characterises of interven- } \\
\text { tion and control groups. No matching. }\end{array}$ \\
\hline
\end{tabular}

Twisk 2013

Methods Non-RCT


Twisk 2013 (Continued)

Participants

School children aged 10 to 13 years from 4 primary schools in Netherlands.

Number of participants: 31 students in the intervention group and 32 students in the control group.

Interventions

Intervention: pedestrian and cyclist safety instruction was given using a real lorry placed in the school yard. Limitations in the driver's field of view were demonstrated, and information on safe behaviour was provided. Blind spots were further illustrated through graphic representations and videos. Each intervention group assessed 1 of 2 blind spot programmes: awareness (addressing carelessness) and competency (addressing blind spot hazards only).

Control: no intervention.

Outcomes Self-reported behaviour and safety practices (correct positioning of cycle or self as pedestrian) 1 month
after intervention.

\begin{tabular}{ll}
\hline Injury mechanisms $\quad$ Pedestrian and cycle. \\
\hline Notes
\end{tabular}

\section{Risk of bias}

\begin{tabular}{lll}
\hline Bias & Authors' judgement & Support for judgement \\
\hline $\begin{array}{l}\text { Allocation to interven- } \\
\text { tion/control (selection } \\
\text { bias) (for non-RCT and } \\
\text { CBA studies) }\end{array}$ & High risk & Selected schools that "already used the programmes on a regular basis". \\
\hline $\begin{array}{l}\text { Blinding of participants } \\
\text { and personnel (perfor- } \\
\text { mance bias) }\end{array}$ & High risk & \\
All outcomes & $\begin{array}{l}\text { Stated that "At the intervention schools... participants, instructors and school } \\
\text { staff were informed about the purpose of the evaluation". Not clear whether } \\
\text { control groups were informed about participation in the study, and their sta- } \\
\text { tus within it. }\end{array}$ \\
\hline
\end{tabular}

\begin{tabular}{|c|c|c|}
\hline $\begin{array}{l}\text { Blinding of outcome as- } \\
\text { sessment (detection bias) } \\
\text { All outcomes }\end{array}$ & High risk & Staff and students were aware of the purpose of the evaluation. \\
\hline $\begin{array}{l}\text { Incomplete outcome data } \\
\text { (attrition bias) } \\
\text { All outcomes }\end{array}$ & Low risk & $\begin{array}{l}\text { No discussion regarding any missing participants at post-test. Numbers indi- } \\
\text { cated that } 100 \% \text { of sample completed post-test in all groups. }\end{array}$ \\
\hline $\begin{array}{l}\text { Selective reporting (re- } \\
\text { porting bias) }\end{array}$ & Low risk & $\begin{array}{l}\text { Protocol not available, but complexity levels stated a priori, and were related } \\
\text { to hypotheses which are clearly stated in the introduction. }\end{array}$ \\
\hline Other bias & Low risk & Appeared to be free of other bias. \\
\hline $\begin{array}{l}\text { Risk of bias due to con- } \\
\text { founding (for non-RCTs } \\
\text { and CBA studies) }\end{array}$ & Unclear risk & $\begin{array}{l}\text { Although schools matched for geographical location, characteristics of the } \\
\text { schools not reported. }\end{array}$ \\
\hline
\end{tabular}

Wang 2009

\begin{tabular}{ll}
\hline Methods & RCT \\
\hline Participants & School children in grades 1-6 in state-based middle schools in Jiujang province, China.
\end{tabular}


Wang 2009 (Continued)

Number of participants: 1200 students in the intervention group and 1268 students in the control group.

\begin{tabular}{|c|c|}
\hline Interventions & $\begin{array}{l}\text { Intervention: peer educators trained to deliver weekly sessions to students. The session could be an ac- } \\
\text { tivity, presentation, game or themed discussion on injury prevention. The peer educators also passed } \\
\text { on health and safety information. }\end{array}$ \\
\hline & Control: no intervention. \\
\hline
\end{tabular}

Outcomes

Outcomes measured by questionnaire over 2 years following intervention.

Self-reported injury incidence rates (sports, falls, traffic, burns, other type).

Safety knowledge (sports, falls, traffic, burn, health, other).

\begin{tabular}{ll}
\hline Injury mechanisms & Common injuries (non-specific). \\
\hline Notes & Original paper in Chinese. \\
\hline
\end{tabular}

\section{Risk of bias}

\begin{tabular}{lll}
\hline Bias & Authors' judgement & Support for judgement \\
\hline $\begin{array}{l}\text { Random sequence genera- } \\
\text { tion (selection bias) }\end{array}$ & Unclear risk & Randomisation was mentioned, but no detail reported. \\
\hline $\begin{array}{l}\text { Allocation concealment } \\
\text { (selection bias) }\end{array}$ & Unclear risk & No details reported. \\
\hline $\begin{array}{l}\text { Blinding of participants } \\
\text { and personnel (perfor- } \\
\text { mance bias) } \\
\text { All outcomes }\end{array}$ & Unclear risk & $\begin{array}{l}\text { Stated that double-blind method was used but there was insufficient detail } \\
\text { about what this meant. }\end{array}$ \\
\hline $\begin{array}{l}\text { Blinding of outcome as- } \\
\text { sessment (detection bias) }\end{array}$ & Unclear risk & $\begin{array}{l}\text { People were trained to deploy the questionnaires. Data entry was quality con- } \\
\text { trolled. However, unclear whether data entry was blinded. }\end{array}$ \\
\hline $\begin{array}{l}\text { Incomplete outcome data } \\
\text { (attrition bias) } \\
\text { All outcomes }\end{array}$ & Low risk & $\begin{array}{l}\text { Outcomes reported on 87\% of participants at follow-up in the intervention } \\
\text { arm and on 96\% in the control arm. }\end{array}$ \\
\hline $\begin{array}{l}\text { Selective reporting (re- } \\
\text { porting bias) }\end{array}$ & Low risk & \begin{tabular}{l} 
Injury and knowledge outcomes reported as described in methods. \\
\hline \begin{tabular}{l} 
Other bias \\
\hline
\end{tabular}
\end{tabular} \\
\hline
\end{tabular}

Wesner 2003

\begin{tabular}{|c|c|}
\hline Methods & CBA \\
\hline \multirow[t]{2}{*}{ Participants } & $\begin{array}{l}\text { Participants were children from } 2 \text { regions in Canada. Intervention group children were from } 24 \text { class- } \\
\text { es ( } 15 \text { schools) in Regina and the control group were from Saskatoon ( } 20 \text { classes). The } 2 \text { groups were } \\
\text { matched for ages, grade and socioeconomic status. }\end{array}$ \\
\hline & Number of participants: 350 students in the intervention group and 313 students in the control group. \\
\hline
\end{tabular}


Wesner 2003 (Continued)

Interventions
Intervention: $1 \times 1$-hour duration Think First programme presentation involving: video of teenagers with brain and spinal cord injuries; educational session with audio-visual aids; description of brain anatomy and pathophysiology; account of experience from person with a brain/spinal cord injury.

Control: usual curriculum.

\begin{tabular}{ll} 
Outcomes & Outcomes were measured over a 4-month period using questionnaire. \\
& Self-reported behaviour and safety practices. \\
& Safety knowledge. \\
\hline Injury mechanisms & Cycle, vehicle (non-specific), swimming/drowning. \\
\hline Notes &
\end{tabular}

\section{Risk of bias}

\begin{tabular}{|c|c|c|}
\hline Bias & Authors' judgement & Support for judgement \\
\hline $\begin{array}{l}\text { Allocation to interven- } \\
\text { tion/control (selection } \\
\text { bias) (for non-RCT and } \\
\text { CBA studies) }\end{array}$ & High risk & $\begin{array}{l}\text { Intervention schools selected from those already scheduled to receive the } \\
\text { Think First programme. }\end{array}$ \\
\hline $\begin{array}{l}\text { Blinding of participants } \\
\text { and personnel (perfor- } \\
\text { mance bias) } \\
\text { All outcomes }\end{array}$ & High risk & $\begin{array}{l}\text { As there was a first aid component to the intervention, participants would } \\
\text { have been aware that they were receiving some training. }\end{array}$ \\
\hline $\begin{array}{l}\text { Blinding of outcome as- } \\
\text { sessment (detection bias) } \\
\text { All outcomes }\end{array}$ & High risk & Self-reported outcomes. \\
\hline $\begin{array}{l}\text { Incomplete outcome data } \\
\text { (attrition bias) } \\
\text { All outcomes }\end{array}$ & High risk & $\begin{array}{l}\text { Attrition was }>20 \% \text { in the intervention group and was } 0 \% \text { in the control group. } \\
\text { In addition, as } 600 \text { responses were discarded due to characteristics such as } \\
\text { age and education, this could have introduced further bias. }\end{array}$ \\
\hline $\begin{array}{l}\text { Selective reporting (re- } \\
\text { porting bias) }\end{array}$ & Low risk & All outcomes appeared to be reported in the prespecified ways. \\
\hline Other bias & Low risk & Study appeared to be free of other sources of bias. \\
\hline $\begin{array}{l}\text { Risk of bias due to con- } \\
\text { founding (for non-RCTs } \\
\text { and CBA studies) }\end{array}$ & Low risk & $\begin{array}{l}\text { Control schools were matched to intervention schools for age, grade and so- } \\
\text { cioeconomic background. }\end{array}$ \\
\hline
\end{tabular}

\section{Wright 1995}

\begin{tabular}{ll}
\hline Methods & CBA \\
\hline Participants & $\begin{array}{l}\text { Participants were boys and girls aged } 11 \text { and } 15 \text { years (3 middle schools and } 3 \text { high schools) from state } \\
\text { schools in the US, located in rural, urban and suburban settings. }\end{array}$ \\
& $\begin{array}{l}\text { Number of participants: } 663 \text { (372 middle school and } 249 \text { high school) in the intervention group and } 78 \\
\text { children in the control group. }\end{array}$
\end{tabular}


Wright 1995 (Continued)

Interventions
Intervention: Think First programme. Intervention was delivered by Think First project staff and a victim of injury. Children were presented with a short film, were given a lecture and a talk by a victim of a traumatic brain or spinal cord injury, which was followed by a question and answer session. The focus of the talks was on action regarding seat-belt use, use of motorcycle helmets, cycle helmets, as well as the avoidance of drugs and alcohol while driving or participating in sports. Also included was the importance of checking for the depth of water when swimming or diving.

Control: received the same intervention, although delayed until after data collection.

\begin{tabular}{ll} 
Outcomes & Observed behaviour (seat belt and helmet wearing on leaving school). \\
& Self-reported behaviour and practices assessed by questionnaire. \\
Safety knowledge assessed by questionnaire. \\
All outcomes were measured at 2 weeks' and 3 months' post-intervention. \\
\hline Injury mechanisms & Pedestrian, cycle, motorcycle, vehicle (non-specific) \\
\hline Notes &
\end{tabular}

\section{Risk of bias}

\begin{tabular}{|c|c|c|}
\hline Bias & Authors' judgement & Support for judgement \\
\hline $\begin{array}{l}\text { Allocation to interven- } \\
\text { tion/control (selection } \\
\text { bias) (for non-RCT and } \\
\text { CBA studies) }\end{array}$ & High risk & $\begin{array}{l}\text { Intervention schools were a convenience sample. In addition, the baseline } \\
\text { characteristics of the } 2 \text { groups were different - participants in the control } \\
\text { group were older. }\end{array}$ \\
\hline $\begin{array}{l}\text { Blinding of participants } \\
\text { and personnel (perfor- } \\
\text { mance bias) } \\
\text { All outcomes }\end{array}$ & High risk & Participants and people delivering the intervention not blinded. \\
\hline $\begin{array}{l}\text { Blinding of outcome as- } \\
\text { sessment (detection bias) } \\
\text { All outcomes }\end{array}$ & Unclear risk & $\begin{array}{l}\text { Students aware of group allocations when they completed the questionnaires. } \\
\text { Not reported whether people assessing the behaviour outcomes were blinded } \\
\text { to the group allocations. }\end{array}$ \\
\hline $\begin{array}{l}\text { Incomplete outcome data } \\
\text { (attrition bias) } \\
\text { All outcomes }\end{array}$ & High risk & $\begin{array}{l}\text { High attrition at } 3 \text { months in the intervention group. Only } 37.4 \% \text { of the total } \\
\text { number of children allocated to the intervention group at baseline were fol- } \\
\text { lowed up. }\end{array}$ \\
\hline $\begin{array}{l}\text { Selective reporting (re- } \\
\text { porting bias) }\end{array}$ & High risk & For behavioural outcomes, only selected items reported. \\
\hline Other bias & High risk & Control group used a shortened questionnaire. \\
\hline $\begin{array}{l}\text { Risk of bias due to con- } \\
\text { founding (for non-RCTs } \\
\text { and CBA studies) }\end{array}$ & High risk & $\begin{array}{l}\text { Control and intervention groups not matched, no adjustment for confounding } \\
\text { mentioned. }\end{array}$ \\
\hline
\end{tabular}

Zhao 2006

Methods RCT


Zhao 2006 (Continued)

Participants
Primary school children aged 7 to 13 years and their parents from schools in urban and rural areas of China.

Number of participants: 3172 students in the intervention group and 2698 students in the control group.

Interventions

Intervention: 1 lecture, plus leaflets on injury prevention given each semester ( 2 per year) to teachers and parents. Teachers gave 2 lectures on injury prevention each semester to students. Safety practice posters were also given to children during classes. A safety course was given to children before their summer and winter school holidays.

Control: health education and promotion on prevention of pneumonia, iron-deficiency anaemia, rickets and common communicable diseases were given to teachers, parents and children using the same schedule as the intervention group.

\begin{tabular}{ll}
\hline Outcomes & Medically attended injury incidence rates measured by injury surveillance system over 2 years. \\
\hline Injury mechanisms & Pedestrian, motorcycle, vehicle (non-specific), swimming/drowning, household safety, poisoning. \\
\hline Notes & $\begin{array}{l}\text { Location, facilities, situation of sports fields, faculties and socioeconomic status were reported as simi- } \\
\text { lar in rural and urban schools prior to randomisation. Translated from Chinese. }\end{array}$ \\
\hline
\end{tabular}

\section{Risk of bias}

\begin{tabular}{|c|c|c|}
\hline Bias & Authors' judgement & Support for judgement \\
\hline $\begin{array}{l}\text { Random sequence genera- } \\
\text { tion (selection bias) }\end{array}$ & Unclear risk & Paper stated "randomly allocated". No further information given. \\
\hline $\begin{array}{l}\text { Allocation concealment } \\
\text { (selection bias) }\end{array}$ & Unclear risk & $\begin{array}{l}\text { Only stated "randomly allocated". Did not report who performed allocation or } \\
\text { if allocation was concealed. }\end{array}$ \\
\hline $\begin{array}{l}\text { Blinding of participants } \\
\text { and personnel (perfor- } \\
\text { mance bias) } \\
\text { All outcomes }\end{array}$ & Low risk & $\begin{array}{l}\text { No mention of blinding; but injury outcome measured by records of hospital } \\
\text { attendance/insurance claims, therefore, unlikely to have introduced differen- } \\
\text { tial bias. }\end{array}$ \\
\hline $\begin{array}{l}\text { Blinding of outcome as- } \\
\text { sessment (detection bias) } \\
\text { All outcomes }\end{array}$ & Unclear risk & $\begin{array}{l}\text { Stated "trained health personnel kept records of child injuries based on copies } \\
\text { of hospital records", but no mention of personnel being blinded to allocation }\end{array}$ \\
\hline $\begin{array}{l}\text { Incomplete outcome data } \\
\text { (attrition bias) } \\
\text { All outcomes }\end{array}$ & Low risk & $\begin{array}{l}\text { Appeared that there was no loss to follow-up from initial questionnaires sent } \\
\text { through to injury outcome recording. No mention of any missing data. Not } \\
\text { specified, but appeared to use intention-to-treat analysis. }\end{array}$ \\
\hline $\begin{array}{l}\text { Selective reporting (re- } \\
\text { porting bias) }\end{array}$ & Unclear risk & $\begin{array}{l}\text { No protocol available. Insufficient information to judge if all prespecified out- } \\
\text { comes were included. }\end{array}$ \\
\hline Other bias & Low risk & Did not appear to be at risk of other bias. \\
\hline
\end{tabular}

Zirkle 2005

\begin{tabular}{ll}
\hline Methods & CBA \\
\hline Participants & $\begin{array}{l}\text { Primary school children in grades } 1 \text { to } 5, \text { from } 19 \text { elementary schools from a mixture of socioeconomic } \\
\text { backgrounds. }\end{array}$
\end{tabular}


Zirkle 2005 (Continued)

Number of participants: 18,876 . The number in the control and intervention arms was not stated.

$\begin{array}{ll}\text { Interventions } & \begin{array}{l}\text { Information not provided - but named as 'Think First For Kids' programme which is described in other } \\ \text { studies. }\end{array}\end{array}$

Outcomes Observed behaviour, made by parent or guardian (pedestrian, sport, interpersonal and car safety behaviours).

Self-reported behaviour and safety practices.

Safety knowledge.

Injury mechanisms Pedestrian, cycle, motorcycle, vehicle (non-specific).

\section{Notes}

\section{Risk of bias}

\begin{tabular}{|c|c|c|}
\hline Bias & Authors' judgement & Support for judgement \\
\hline $\begin{array}{l}\text { Allocation to interven- } \\
\text { tion/control (selection } \\
\text { bias) (for non-RCT and } \\
\text { CBA studies) }\end{array}$ & Unclear risk & $\begin{array}{l}\text { Did not report the number of schools in intervention and control groups or } \\
\text { how school were selected to receive Think First For Kids programme. }\end{array}$ \\
\hline $\begin{array}{l}\text { Blinding of participants } \\
\text { and personnel (perfor- } \\
\text { mance bias) } \\
\text { All outcomes }\end{array}$ & High risk & $\begin{array}{l}\text { Insufficient information about the blinding process. Participants were likely to } \\
\text { know that they received the intervention. }\end{array}$ \\
\hline $\begin{array}{l}\text { Blinding of outcome as- } \\
\text { sessment (detection bias) } \\
\text { All outcomes }\end{array}$ & High risk & $\begin{array}{l}\text { Parents/guardians assessed their own children's observed behaviours, though } \\
\text { it was unclear if they were informed as to whether their child was in a control } \\
\text { or intervention group. }\end{array}$ \\
\hline $\begin{array}{l}\text { Incomplete outcome data } \\
\text { (attrition bias) } \\
\text { All outcomes }\end{array}$ & Unclear risk & $\begin{array}{l}\text { Insufficient information provided to know how incomplete data were ad- } \\
\text { dressed. }\end{array}$ \\
\hline $\begin{array}{l}\text { Selective reporting (re- } \\
\text { porting bias) }\end{array}$ & Unclear risk & $\begin{array}{l}\text { Numbers not reported. A graph was included but there were no data points } \\
\text { and the multi-variate analysis only included the confidence interval and not } \\
\text { the point estimate. }\end{array}$ \\
\hline Other bias & Unclear risk & Insufficient detail in the summary. \\
\hline $\begin{array}{l}\text { Risk of bias due to con- } \\
\text { founding (for non-RCTs } \\
\text { and CBA studies) }\end{array}$ & Low risk & $\begin{array}{l}\text { Schools were matched on socioeconomic status, reading scores, ethnicity and } \\
\text { school district. No information provided to enable assessment of the balance } \\
\text { of characteristics between groups. }\end{array}$ \\
\hline
\end{tabular}

BMI: body mass index; CBA: controlled before-and-after; IMPS: Injury Minimization Programme for Schools; PE: physical exercise; RCT: randomised controlled trial; SPIY: Skills for Preventing Injury in Youth.

\section{Characteristics of excluded studies [ordered by study ID]}

\section{Study Reason for exclusion}




\begin{tabular}{|c|c|}
\hline Study & Reason for exclusion \\
\hline Anonymous 1986 & Did not report study design of interest. \\
\hline Arbogast 2014 & Did not report intervention of interest. \\
\hline Aronson 1986 & Did not report intervention of interest. \\
\hline Asher 1995 & Did not report intervention of interest. \\
\hline Avolio 1992 & Did not report study design of interest. \\
\hline Banfield 2010 & Did not report intervention of interest. \\
\hline Banfield 2011 & Did not report intervention of interest. \\
\hline Bass 1991 & Did not report intervention of interest. \\
\hline Bennett 1999 & Did not report intervention of interest. \\
\hline Berfenstam 1995 & Did not report intervention of interest. \\
\hline Bergman 1982 & Did not report intervention of interest. \\
\hline Bernardo 1992 & Did not report intervention of interest. \\
\hline Birkland 1993 & Did not report intervention of interest. \\
\hline Bjerre 1998 & Did not report intervention of interest. \\
\hline Bohman 2004 & Did not report intervention of interest. \\
\hline Bondurant 2009 & Did not report intervention of interest. \\
\hline Bouvette 1990 & Did not report intervention of interest. \\
\hline Buckley 2013 & Did not report study design of interest. \\
\hline Bulska 2008 & Did not report intervention of interest. \\
\hline Burgus 2007 & Did not report intervention of interest. \\
\hline Cao 2014 & Did not report study design of interest. \\
\hline Cao 2015 & Did not report intervention of interest. \\
\hline Cardon 2002 & Did not report intervention of interest. \\
\hline Carrabba 2012 & Did not report study design of interest. \\
\hline Carruth 2010 & Did not report intervention of interest. \\
\hline CDC 1991 & Did not report intervention of interest. \\
\hline Chapman 2010 & Did not report study design of interest. \\
\hline Chapman 2011 & Did not report intervention of interest. \\
\hline
\end{tabular}




\begin{tabular}{|c|c|}
\hline Study & Reason for exclusion \\
\hline Chiarelli 1995 & Did not report study design of interest. \\
\hline Christophersen 1989 & Did not report study design of interest. \\
\hline Clapham 2010 & Did not report study design of interest. \\
\hline Coggan 2000 & Did not report intervention of interest. \\
\hline Coles 2007 & Did not report intervention of interest. \\
\hline Collard 2009 & Did not report study design of interest. \\
\hline Collins 1995 & Did not report study design of interest. \\
\hline Cook 2003 & Did not report intervention of interest. \\
\hline Crespo 1974 & Did not report intervention of interest. \\
\hline Danin 1978 & Did not report intervention of interest. \\
\hline Day 2001 & Did not report intervention of interest. \\
\hline Duff 2002 & Did not report intervention of interest. \\
\hline Eckelt 1985 & Did not report study design of interest. \\
\hline Eichel 2001 & Did not report study design of interest. \\
\hline El-Otiefy 2010 & Did not report study design of interest. \\
\hline El-Sayed 2010 & Did not report study design of interest. \\
\hline Ellis 2009 & Did not report intervention of interest. \\
\hline Englander 1993 & Did not report study design of interest. \\
\hline Floerchinger-Franks 2000 & Did not report intervention of interest. \\
\hline Franco-Diaz 1974 & Did not report intervention of interest. \\
\hline Frank 1992 & Did not report study design of interest. \\
\hline Frederick 2006 & Did not report study design of interest. \\
\hline Gallagher 1982 & Did not report intervention of interest. \\
\hline Gallagher 1987 & Did not report study design of interest. \\
\hline García 2005 & Did not report study design of interest. \\
\hline Ghosh 2000 & Did not report study design of interest. \\
\hline Gielen 1996 & Did not report intervention of interest. \\
\hline Gittelman 2007 & Did not report intervention of interest. \\
\hline
\end{tabular}




\begin{tabular}{|c|c|}
\hline Study & Reason for exclusion \\
\hline Gong 2001 & Did not report intervention of interest. \\
\hline Grigorovich 1985 & Did not report study design of interest. \\
\hline Guo 2010 & Did not report study design of interest. \\
\hline Guyer 1989 & Did not report intervention of interest. \\
\hline Hall-Long 2001 & Did not report study design of interest. \\
\hline Hamilton 2010 & Did not report intervention of interest. \\
\hline Harré 2000 & Did not report intervention of interest. \\
\hline Hazinski 1995 & Did not report participants of interest. \\
\hline Heck 2001 & Did not report study design of interest. \\
\hline Heinle 1995 & Did not report study design of interest. \\
\hline Hidalgo-Solorzano 2008 & Did not report intervention of interest. \\
\hline Hobbie 1991 & Did not report intervention of interest. \\
\hline Hunter 1991 & Did not report study design of interest. \\
\hline Jones 1981 & Did not report intervention of interest. \\
\hline Josse 2006 & Did not report intervention of interest. \\
\hline Kamsiuk 1987 & Did not report intervention of interest. \\
\hline Karataeva 1982 & Did not report study design of interest. \\
\hline Kennedy 2009 & Did not report intervention of interest. \\
\hline Klas 2013 & Did not report study design of interest. \\
\hline Knapp 1965 & Did not report intervention of interest. \\
\hline Korn 2009 & Did not report intervention of interest. \\
\hline Lachapelle 2013 & Did not report intervention of interest. \\
\hline Lamb 2006 & Did not report intervention of interest. \\
\hline Lang-Runtz 1983 & Did not report intervention of interest. \\
\hline Langley 1996 & Did not report intervention of interest. \\
\hline Laraque 1995 & Did not report intervention of interest. \\
\hline Lazaros 2009 & Did not report study design of interest. \\
\hline Lazaros 2012 & Did not report intervention of interest. \\
\hline
\end{tabular}




\begin{tabular}{|c|c|}
\hline Study & Reason for exclusion \\
\hline Liller 2002 & Did not report study design of interest. \\
\hline Lim 2009 & Did not report outcomes of interest. \\
\hline Lindqvist 2012 & Did not report intervention of interest. \\
\hline Linker 2005 & Did not report study design of interest. \\
\hline Lowden 2001 & Did not report study design of interest. \\
\hline Luria 2000 & Did not report intervention of interest. \\
\hline MacKay 1982 & Did not report intervention of interest. \\
\hline Maddocks 1981 & Did not report intervention of interest. \\
\hline Manno 2011 & Did not report study design of interest. \\
\hline Manuele 2005 & Did not report intervention of interest. \\
\hline Martinez-Lopez 1974 & Did not report intervention of interest. \\
\hline Martino-McAllister 2001 & Did not report intervention of interest. \\
\hline Mason 2007 & Did not report intervention of interest. \\
\hline May 2005 & Did not report study design of interest. \\
\hline Mayshark 1976 & Did not report intervention of interest. \\
\hline McConnell 1996 & Did not report intervention of interest. \\
\hline McLoughlin 1982 & Did not report intervention of interest. \\
\hline Mears 2012 & Did not report study design of interest. \\
\hline Melenovich 2008 & Did not report intervention of interest. \\
\hline Mello 2007 & Did not report intervention of interest. \\
\hline Messonnier 1999 & Did not report intervention of interest. \\
\hline Miara 2003 & Did not report study design of interest. \\
\hline Mickalide 1994 & Did not report intervention of interest. \\
\hline Mickalide 1995 & Did not report intervention of interest. \\
\hline Miles 2012 & Did not report study design of interest. \\
\hline Mondozzi 2001 & Did not report study design of interest. \\
\hline Monneuse 2008 & Did not report study design of interest. \\
\hline Mori 1986 & Did not report participants of interest. \\
\hline
\end{tabular}




\begin{tabular}{|c|c|}
\hline Study & Reason for exclusion \\
\hline Morriss 2000a & Did not report study design of interest. \\
\hline Morriss 2000b & Did not report study design of interest. \\
\hline Nauta 2013 & Did not report intervention of interest. \\
\hline Nelmarie 2004 & Did not report study design of interest. \\
\hline Neuwelt 1989 & Did not report intervention of interest. \\
\hline Nishioka, 2011 & Did not report intervention of interest. \\
\hline O'Hare 1997 & Did not report intervention of interest. \\
\hline O'Neill 2013 & Did not report study design of interest. \\
\hline Olsen 2010 & Did not report study design of interest. \\
\hline Orzel 1996 & Did not report study design of interest. \\
\hline Oxford Evaluation Team 2003 & Did not report intervention of interest. \\
\hline Page 2001 & Did not report study design of interest. \\
\hline Patel 2013 & Did not report intervention of interest. \\
\hline Paulson 1981 & Did not report intervention of interest. \\
\hline Persaud 1997 & Did not report study design of interest. \\
\hline Peterson 1984a & Did not report intervention of interest. \\
\hline Peterson 1984b & Did not report intervention of interest. \\
\hline Picanol 1992 & Did not report intervention of interest. \\
\hline Pless 1987 & Did not report study design of interest. \\
\hline Posner 2005 & Did not report intervention of interest. \\
\hline Pressley 2005 & Did not report intervention of interest. \\
\hline Pusin 1985 & Did not report intervention of interest. \\
\hline Reed 1990 & Did not report intervention of interest. \\
\hline Reed 2000 & Did not report intervention of interest. \\
\hline Reed 2002 & Did not report study design of interest. \\
\hline Reichelderfer 1977 & Did not report intervention of interest. \\
\hline Reinberg 1995 & Did not report intervention of interest. \\
\hline Repath 1970 & Did not report intervention of interest. \\
\hline
\end{tabular}




\begin{tabular}{|c|c|}
\hline Study & Reason for exclusion \\
\hline Rey 1993 & Did not report intervention of interest. \\
\hline Rieman 2012 & Did not report study design of interest. \\
\hline Rieman 2013 & Did not report study design of interest. \\
\hline Rigau-Perez 1986 & Did not report intervention of interest. \\
\hline Rimmer 2010 & Did not report study design of interest. \\
\hline Rimmer 2011 & Did not report study design of interest. \\
\hline Rivara 1991 & Did not report intervention of interest. \\
\hline Rivara 1998 & Did not report intervention of interest. \\
\hline Roper 2007 & Did not report intervention of interest. \\
\hline Ryan 1971 & Did not report intervention of interest. \\
\hline Salvarani 2009 & Did not report intervention of interest. \\
\hline San Agustin 1973 & Did not report intervention of interest. \\
\hline Schaplowsky 1973 & Did not report intervention of interest. \\
\hline Schlesinger 1997 & Did not report intervention of interest. \\
\hline Schriever 2012 & Did not report intervention of interest. \\
\hline Schulkind 1983 & Did not report intervention of interest. \\
\hline Scott-Moncrieff 1989 & Did not report intervention of interest. \\
\hline Self 2007 & Did not report study design of interest. \\
\hline Shani 1998 & Did not report study design of interest. \\
\hline Shani 2003 & Did not report study design of interest. \\
\hline Sibert 1983 & Did not report intervention of interest. \\
\hline Sidky 1996 & Did not report intervention of interest. \\
\hline Simko 1978 & Did not report intervention of interest. \\
\hline Sims 2003 & Did not report intervention of interest. \\
\hline Sinha 2011 & Did not report study design of interest. \\
\hline Sloan 1990 & Did not report study design of interest. \\
\hline Smith 1994 & Did not report intervention of interest. \\
\hline Sorensen 1976 & Did not report intervention of interest. \\
\hline
\end{tabular}




\begin{tabular}{|c|c|}
\hline Study & Reason for exclusion \\
\hline Sullivan 2010 & Did not report study design of interest. \\
\hline Summers 2011 & Did not report intervention of interest. \\
\hline Tamburro 2002 & Did not report study design of interest. \\
\hline Tellnes 2006 & Did not report intervention of interest. \\
\hline Torres 2006 & Did not report intervention of interest. \\
\hline Towner 1997 & Did not report intervention of interest. \\
\hline Utley 2010 & Did not report intervention of interest. \\
\hline Valenzuela 2009 & Did not report intervention of interest. \\
\hline Van Schagen 1994 & Did not report intervention of interest. \\
\hline Van Schagen 1997 & Did not report study design of interest. \\
\hline Varas 1988 & Did not report study design of interest. \\
\hline Vassilyadi 2009 & Did not report study design of interest. \\
\hline Vicas-Kunse 1992 & Did not report study design of interest. \\
\hline Victor 1988 & Did not report study design of interest. \\
\hline Walls 2006 & Did not report intervention of interest. \\
\hline Ward 2010 & Did not report study design of interest. \\
\hline Watts 1992 & Did not report study design of interest. \\
\hline West 1996 & Did not report intervention of interest. \\
\hline Wigglesworth 1987 & Did not report study design of interest. \\
\hline
\end{tabular}

\section{DATA AND ANALYSES}

\section{Comparison 1. Medically attended or non-medically attended injury rates}

\begin{tabular}{lllll}
\hline Outcome or subgroup title & No. of studies & $\begin{array}{l}\text { No. of partici- } \\
\text { pants }\end{array}$ & Statistical method & Effect size \\
\hline $\begin{array}{l}1 \text { Injury rates at follow-up, adjusted for base- } \\
\text { line injury rates in non-randomised studies }\end{array}$ & 3 & 2073 & $\begin{array}{l}\text { Rate Ratio (Random, } \\
95 \% \mathrm{Cl})\end{array}$ & $0.73[0.49,1.08]$ \\
\hline
\end{tabular}


Analysis 1.1. Comparison 1 Medically attended or non-medically attended injury rates, Outcome 1 Injury rates at follow-up, adjusted for baseline injury rates in non-randomised studies.

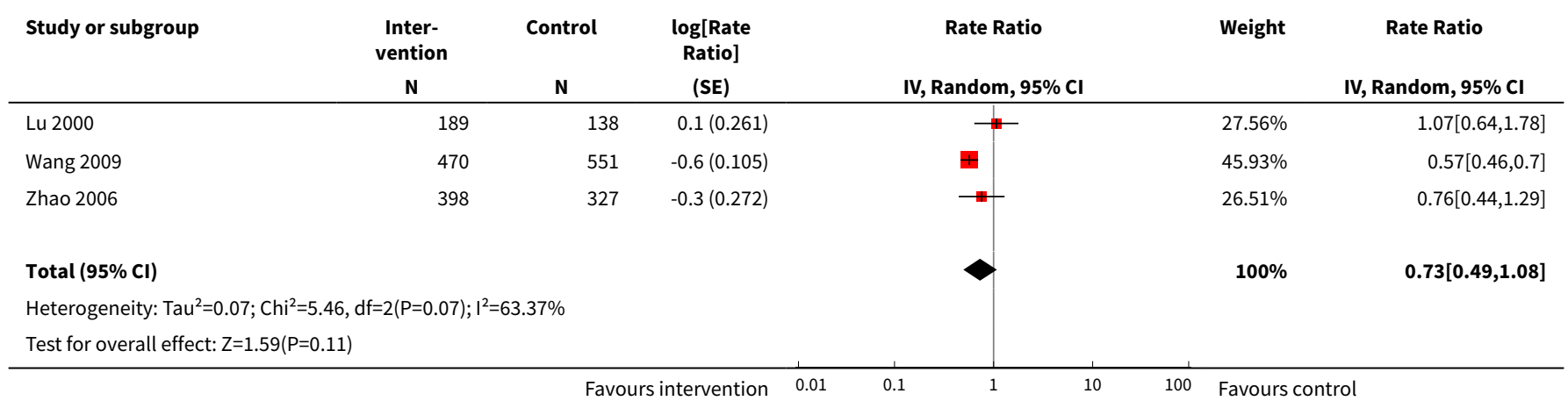




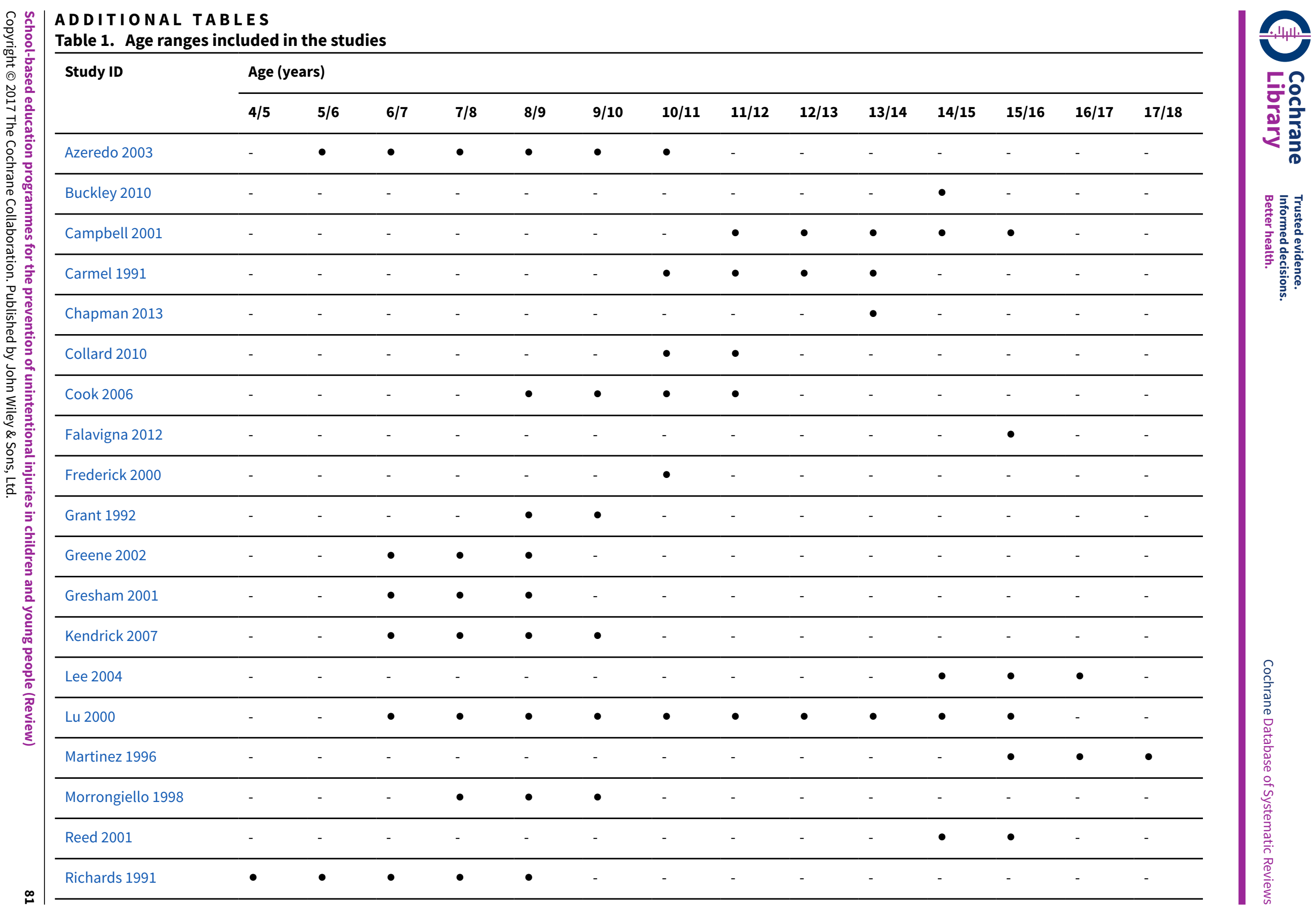




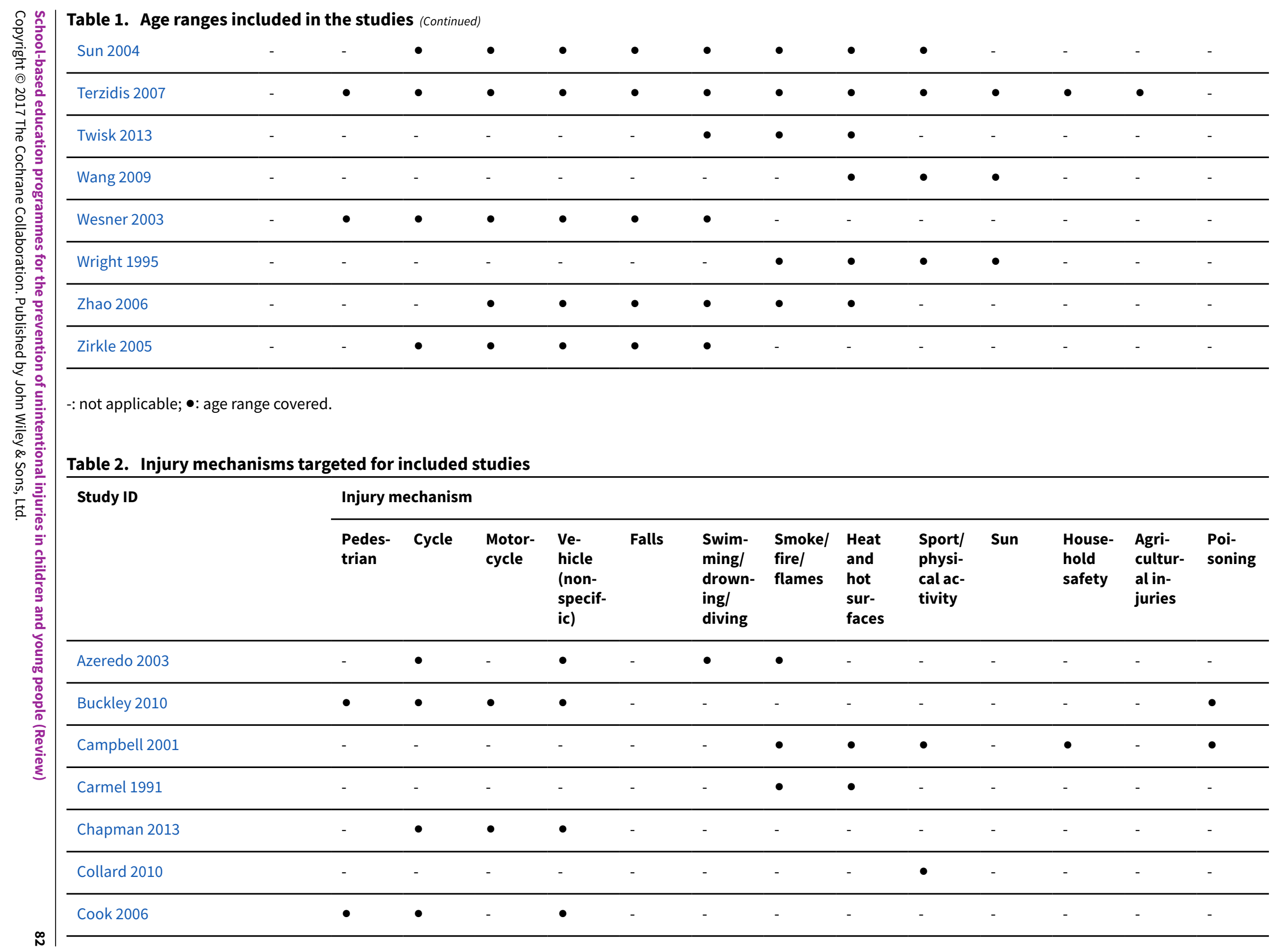




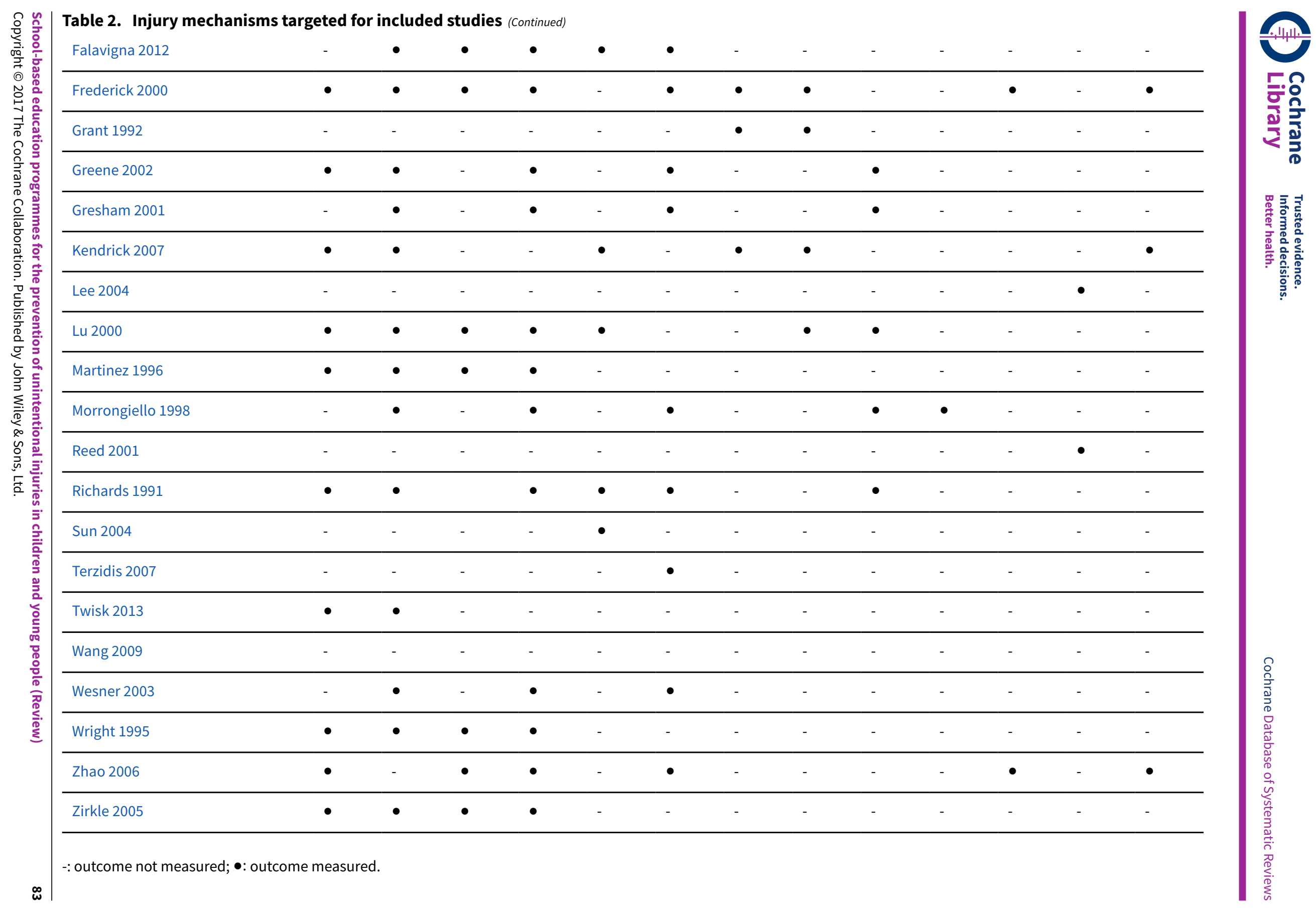




\section{AP PE N D I C E S}

\section{Appendix 1. Search strategies 1}

\section{Cochrane Injuries Group's Specialised Register (August 2013)}

\#1 ((student* or pupil $^{\star}$ or peer?group ${ }^{\star}$ or peergroup ${ }^{\star}$ or peer $^{\star}$ curricul $^{\star}$ or teach* or mentor $\left.^{\star}\right)$ ) AND (INREGISTER) [REFERENCE] [STANDARD] \#2 ((educat* or school* or highschool* or high?school* or pre?school* or preschool* or kindergarten ${ }^{\star}$ ) AND (young* or adolesc $^{\star}$ or teen $^{\star}$ or minor ${ }^{\star}$ or boy ${ }^{\star}$ or girl ${ }^{\star}$ or youth ${ }^{\star}$ or male* or female* or child* or toddler* or infant ${ }^{\star}$ or junior $\left.{ }^{\star}\right)$ ) AND (INREGISTER) [REFERENCE] [STANDARD]

\#3 \#1 OR \#2 [REFERENCE] [STANDARD]

\#4 ((safety or health or accident* or risk ${ }^{\star}$ or behavio*) AND (reduc* or prevent* or train* or instruct* or demonstrat* or educat* or aware* or teach* or inform* or chang* or counsel ${ }^{\star}$ or learn*)) AND ( INREGISTER) [REFERENCE] [STANDARD]

\#5 (injur* AND (prevent* or control* or reduc $\left.{ }^{\star}\right)$ ) AND ( INREGISTER) [REFERENCE] [STANDARD]

\#6 ((injur* or wound*)) AND ( INREGISTER) [REFERENCE] [STANDARD]

\#7 \#5 OR \#6 [REFERENCE] [STANDARD]

\#8 \#3 AND \#4 AND \#7 [REFERENCE] [STANDARD]

\section{Cochrane Injuries Group's Specialised Register (all years to 16-September-2016)}

$\# 1$ (((injury or injuries) and (prevention or safety))):TI,AB,KY AND SR-INJ:CC

\#2("health and safety"):TI,AB,KY AND SR-INJ:CC

\#3(injury and prevention):SO AND SR-INJ:CC

\#4 (\#1 OR \#2 OR \#3)

\#5((infant ${ }^{\star}$ or child ${ }^{\star}$ or kids or adolesc ${ }^{\star}$ or student ${ }^{\star}$ or pupils or teen* or young or youngsters or youth or youths or pediatric ${ }^{\star}$ or paediatric ${ }^{\star}$ ) and (kindergarten or * school $^{*}$ or classroom or college* or curricul ${ }^{*}$ or teachers or education)) AND SR-INJ:CC

\#6((child* or adolesc* or pediatric* or paediatric*)):SO AND SR-INJ:CC

\#7\#5 OR \#6

\#8\#4 AND \#7

Cochrane Central Register of Controlled Trials (The Cochrane Library, Issue 7, 2013)

\#1MeSH descriptor: [Schools] explode all trees

\#2MeSH descriptor: [Students] explode all trees

\#3MeSH descriptor: [Education] this term only

\#4MeSH descriptor: [Curriculum] this term only

\#5MeSH descriptor: [Teaching] this term only

\#6student ${ }^{\star}$ or pupil ${ }^{\star}$ or peer?group or peergroup or peer or curricul ${ }^{\star}$ or teach ${ }^{\star}$ or mentor $^{\star}$ :ti,ab,kw (Word variations have been searched) \#7(young ${ }^{\star}$ or adolesc ${ }^{\star}$ or teen* or minor ${ }^{\star}$ or boy ${ }^{\star}$ or girl ${ }^{\star}$ or youth ${ }^{\star}$ or male* or female* or child* or toddler ${ }^{\star}$ or infant $^{\star}$ or junior $^{\star}$ ) next/3 (educat ${ }^{\star}$ or school $^{\star}$ or highschool ${ }^{\star}$ or preschool ${ }^{\star}$ or pre?schoo ${ }^{\star}$ or kindergarten ${ }^{\star}$ or high?school*):ti,ab,kw (Word variations have been searched)

$\# 8 \# 1$ or \#2 or \#3 or \#4 or \#5 or \#6 or \#7

\#9((safety or health or accident ${ }^{\star}$ or risk ${ }^{\star}$ or behavio*) next/1 (reduc ${ }^{\star}$ or prevent ${ }^{\star}$ or train ${ }^{\star}$ or instruct ${ }^{\star}$ or demonstrat ${ }^{\star}$ or educat ${ }^{\star}$ or aware* or teach* or inform $^{\star}$ or chang $^{\star}$ or counsel $^{\star}$ or learn $\left.{ }^{\star}\right)$ ):ti,ab,kw (Word variations have been searched)

$\# 10 \mathrm{MeSH}$ descriptor: [School Health Services] this term only

$\# 11 \mathrm{MeSH}$ descriptor: [Health Education] this term only

\#12MeSH descriptor: [Accident Prevention] this term only

\#13MeSH descriptor: [Health Promotion] this term only

\#14MeSH descriptor: [Risk Reduction Behavior] this term only

$\# 15 \mathrm{MeSH}$ descriptor: [Health Knowledge, Attitudes, Practice] this term only

$\# 16 \# 9$ or \#10 or \#11 or \#12 or \#13 or \#14 or \#15

\#17\#8 and \#16

\#18MeSH descriptor: [Wounds and Injuries] explode all trees and with qualifiers: [Prevention \& control - PC]

\#19injur ${ }^{\star}$ next/3 (prevent ${ }^{\star}$ or control ${ }^{\star}$ or reduc ${ }^{\star}$ ):ti,ab,kw (Word variations have been searched)

$\# 20 \# 18$ or \#19

$\# 21 \# 17$ and \#2

[Appended 16-September-2016 (The Cochrane Library, Issue 8, 2016)]

\#22 ((prevent* ${ }^{\star}$ or reduc $\left.{ }^{\star}\right)$ near/3 (injury or injuries)) or "health and safety"

\#23 (young or youth or youths or adolesc ${ }^{\star}$ or teen ${ }^{\star}$ or minors or boy ${ }^{\star}$ or girl ${ }^{\star}$ or child* or toddler ${ }^{\star}$ or infant ${ }^{\star}$ or junior $^{\star}$ or student ${ }^{\star}$ )

\#24 (school or classroom or curric*)

$\# 25$ (\#22 and \#23 and \#24)

\#26 \#25 not \#21 [difference set]

$\# 27$ (\#10 or \#11 or \#12 or \#13 or \#14 or \#15) [Intervention (MeSH) only]

\#28 (\#27 and \#20)

School-based education programmes for the prevention of unintentional injuries in children and young people (Review) 
\#29 (\#28 not \#21)

\#30 student ${ }^{\star}$ or pupil* or peer-group or peergroup or peer* or curricul* or teach* or mentor ${ }^{\star}$ [amends syntax in line \#6: peer-group rather than peer?group]

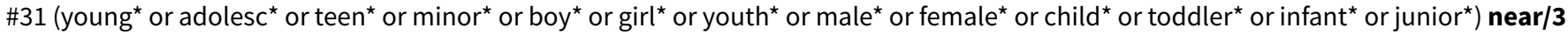
(educat ${ }^{\star}$ or school* or highschool $^{\star}$ or preschool ${ }^{\star}$ or pre-school ${ }^{\star}$ or kindergarten ${ }^{\star}$ or high-school ${ }^{\star}$ ) [amends syntax (proximity operator) in line \#7, near/3]

\#32 (\#1 or \#2 or \#3 or \#4 or \#5 or \#30 or \#31) [amended line \#8]

\#33 ((safety or health or accident ${ }^{\star}$ or risk ${ }^{\star}$ or behavio ${ }^{\star}$ ) near/1 (reduc ${ }^{\star}$ or prevent ${ }^{\star}$ or train ${ }^{\star}$ or instruct ${ }^{\star}$ or demonstrat $^{\star}$ or educat $^{\star}$ or aware $^{\star}$ or teach* or inform $^{\star}$ or chang* or counsel $^{\star}$ or learn $\left.{ }^{\star}\right)$ [ [amends syntax (proximity operator) in line \#9, near/1]

\#34 (\#33 or \#10 or \#11 or \#12 or \#13 or \#14 or \#15) [amended line \#16]

$\# 35 \# 32$ and \#34 and \#20 [amended line 21]

\#36 \#25 or \#35 [appended/updated search, 16-Sept-2016]

\#37 \#36 not \#21 [difference set: 2016 search vs 2013 search]

Health Economic Evaluation Database (HEED) (29th August 2013)

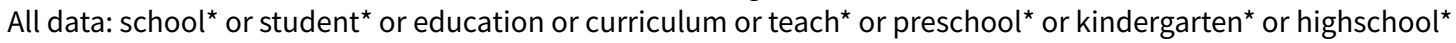

AND

All data: 'school health services' or 'health education' or 'accident prevention' or 'health promotion' or 'risk reduction'

AND

All data: wounds or injuries

Ovid MEDLINE(R), Ovid MEDLINE(R) In-Process \& Other Non-Indexed Citations, Ovid MEDLINE(R) Daily and Ovid OLDMEDLINE(R) (1946 to 29 August 2013)

1. exp Schools/

2. Students/

3. *Education/

4. *Curriculum/

5. *Teaching/

6. (student ${ }^{\star}$ or pupil ${ }^{\star}$ or peer?group ${ }^{\star}$ or peergroup ${ }^{\star}$ or peer $^{\star}$ curricul $^{\star}$ or teach* or mentor $\left.^{\star}\right)$.ab,ti.

7. ((young or adolesc $^{\star}$ or teen ${ }^{\star}$ or minor ${ }^{\star}$ or boy ${ }^{\star}$ or girl ${ }^{\star}$ or youth ${ }^{\star}$ or male ${ }^{\star}$ or female ${ }^{\star}$ or child or toddler $^{\star}$ or infant ${ }^{\star}$ or junior $^{\star}$ ) adj3

(educat ${ }^{\star}$ or school ${ }^{\star}$ or highschool ${ }^{\star}$ or high?school* or pre?school* or preschool ${ }^{\star}$ or kindergarten $\left.{ }^{\star}\right)$ ).mp.

8. or/1-7

9. * School Health Services/

10. *Health Education/

11. *Accident prevention/

12. *Health promotion/

13. * Risk reduction behavior/

14. *Health Knowledge, Attitudes, Practice/

15. ((safety or health or accident* or risk ${ }^{\star}$ or behavio*) adj1 (reduc ${ }^{\star}$ or prevent* or train* or instruct* or demonstrat* or educat* or aware* or teach ${ }^{\star}$ or inform* or chang ${ }^{\star}$ or counsel ${ }^{\star}$ or learn*)).ab,ti.

16.9 or 10 or 11 or 12 or 13 or 14 or 15

17. 8 and 16

18. exp "Wounds and Injuries"/pc [Prevention \& Control]

19. (injur ${ }^{\star}$ adj3 (prevent ${ }^{\star}$ or control ${ }^{\star}$ or reduc $\left.{ }^{\star}\right)$ ).ab,ti.

20. 18 or 19

21.17 and 20

\section{[Appended 16-September 2016]}

23. ((young or youth or youths or youngster ${ }^{\star}$ or kids or adolesc ${ }^{\star}$ or teen ${ }^{\star}$ or minors or boy ${ }^{\star}$ or girl ${ }^{\star}$ or child* or toddler ${ }^{\star}$ or infant $^{\star}$ or junior ${ }^{\star}$ or student ${ }^{\star}$ or pupils) and (school or college or classroom or nursery or kindergarten or curric $\left.{ }^{\star}\right)$ ).mp.

24. (injuries or prevention \& control).fs.

25. Accident Prevention/

26. (prevent* adj2 (injury or injuries)).ti,kf.

27. ((injur ${ }^{\star}$ or safety) and (awareness or education or evaluation or initiative or intervention or program)).ti,kf.

28. ((education* adj1 awareness) or (prevent* and program*)).ti,kf.

29. (accident* or safety or injury or injuries).mp.

30. (risk and education).ti.

31. (23 and ( 24 or 25$)$ and ( 26 or 27$)$ )

32. ( 23 and 28 and 29 )

33. (23 and 29 and 30$)$

34. or/31-33

35. (34 not 22$)$

36. $\left(2013^{\star}\right.$ or $2014^{\star}$ or $2015^{\star}$ or $\left.2016^{\star}\right) \cdot y r$,ed. 
37. (22 and 36$)$

38. (35 or 37$)$

Embase + Embase Classic (Ovid) (1947 to 2013 August 28)

1. exp Schools/

2. Students/

3. *Education/

4. *Curriculum/

5. *Teaching/

6. (student ${ }^{\star}$ or pupil ${ }^{\star}$ or peer?group ${ }^{\star}$ or peergroup ${ }^{\star}$ or peer $^{\star}$ curricul $^{\star}$ or teach* or mentor $\left.^{\star}\right)$. ab,ti.

7. ((young or adolesc $^{\star}$ or teen ${ }^{\star}$ or minor ${ }^{\star}$ or boy ${ }^{\star}$ or girl ${ }^{\star}$ or youth ${ }^{\star}$ or male or female $^{\star}$ or child or toddler $^{\star}$ or infant $^{\star}$ or junior $^{\star}$ ) adj3 (educat ${ }^{\star}$ or school ${ }^{\star}$ or highschool ${ }^{\star}$ or high?school ${ }^{\star}$ or pre? school ${ }^{\star}$ or preschool ${ }^{\star}$ or kindergarten ${ }^{\star}$ )).mp.

8. or/1-7

9. * School Health Services/

10. *Health Education/

11. *Accident prevention/

12. *Health promotion/

13. * Risk reduction behavior/

14. *Health Knowledge, Attitudes, Practice/

15. ((safety or health or accident ${ }^{\star}$ or risk ${ }^{\star}$ or behavio ${ }^{\star}$ ) adj1 (reduc ${ }^{\star}$ or prevent ${ }^{\star}$ or train ${ }^{\star}$ or instruct* or demonstrat $^{\star}$ or educat $^{\star}$ or aware* or teach ${ }^{\star}$ or inform ${ }^{\star}$ or chang ${ }^{\star}$ or counsel $^{\star}$ or learn $\left.\left.^{\star}\right)\right) \cdot$ ab,ti.

16.9 or 10 or 11 or 12 or 13 or 14 or 15

17. 8 and 16

18. exp "Wounds and Injuries"/pc [Prevention \& Control] [MEDLINE syntax]

19. (injur ${ }^{\star}$ adj3 (prevent ${ }^{\star}$ or control $^{\star}$ or reduc $\left.^{\star}\right)$ ).ab,ti.

20. 18 or 19

21. 17 and 20

[Appended 16-September-2016]

22. $\left(2013^{\star}\right.$ or $2014^{\star}$ or $2015^{\star}$ or $\left.2016^{\star}\right)$.em,yr.

23. 21 and 22

24. limit 23 to embase

25. ((injury or injuries) adj3 (prevent* ${ }^{\star}$ or control ${ }^{\star}$ or reduc $\left.\left.{ }^{\star}\right)\right)$. ab,ti,kw.

26. Accident Prevention/

27. exp injury/pc [Prevention]

28. childhood injury/pc [Prevention]

29. Accident/ and Prevention/

30. or/25-29

31. 17 and 30

32. 31 not 21

33. limit 32 to embase

34. (prevent ${ }^{\star}$ and (program* or intervention) and school*).ti. and (injury or injuries).mp.

35. ((injury or injuries) and risk and educat $\left.{ }^{\star}\right)$.ti,kw.

36. ((young or youth or youths or youngster ${ }^{\star}$ or kids or adolesc* or teen* or minors or boy ${ }^{\star}$ or girl ${ }^{\star}$ or child* or toddler ${ }^{\star}$ or infant $^{\star}$ or junior ${ }^{\star}$ or pupils or curricul $\left.{ }^{\star}\right)$ and (school* or classroom or nursery or kindergarten)).mp.

37. (prevent ${ }^{\star}$ adj2 (injury or injuries)).ti,kw.

38. ((injury or injuries or safety) and (awareness or education or evaluation or initiative or intervention or program)).ti,kw.

39. ((education ${ }^{\star}$ adj1 awareness) or (prevent ${ }^{\star}$ and program $\left.\left.{ }^{\star}\right)\right) . t i, k w$.

40. (accident ${ }^{\star}$ or safety or injury or injuries).mp.

41. (risk and education).ti.

42. 36 and 37 and 38

43. 36 and 39 and 40

44. 36 and 40 and 41

45.34 or 35 or 42 or 43 or 44

46. 45 not 21

47. 24 or 33 or 46

[Controlled trials filter applied]

48. Controlled Study/

49. Controlled Clinical Trial/

50. major clinical study/

51. human experiment/

52. (study or trial).ti.

53. (prevent ${ }^{\star}$ and program ${ }^{\star}$ ).ti.

School-based education programmes for the prevention of unintentional injuries in children and young people (Review) 
54. (evaluat ${ }^{\star}$ and (intervention or program ${ }^{\star}$ or $\left(\right.$ injur $^{\star}$ and prevent $\left.\left.{ }^{\star}\right)\right)$ ).ti.

55. randomisation/

56. (random* or RCT or CCT or CBA).ti,ab,kw.

57. crossover procedure/

58. (quasiexperiment ${ }^{\star}$ or quasi experiment ${ }^{\star}$ ).ti,ab,kw.

59. ((pre or post) adj (test or intervention or exposure)).ab.

60. "before and after".ab.

61. intervention study/

62. ((control or comparison or intervention or treatment or experimental or reference or study) adj2 (group or groups or school ${ }^{\star}$ or subjects or participants or pupils or students)).ti,ab,kw.

63. prospective study/

64. prospective.ti,ab,kw.

65. (prevention.fs. or Accident Prevention/) and (evaluation/ or evaluation study/)

66. or/48-65

67.47 and 66

CINAHL Plus (1939 to 29th August 2013)

S19S15 AND S18 (Limiters - Exclude MEDLINE records)

S18S16 OR S17

S17(MH "Wounds and Injuries+/PC")

S16TX (injur* N3 (prevent* or control $\left.^{\star}\right)$ )

S15S7 AND S14

S14S8 OR S9 OR S10 OR S 11 OR S12 OR S 13

S13TI ((safety or health or accident ${ }^{\star}$ or risk* or behavio*) N1 (reduc* or prevent* or train* ${ }^{\star}$ instruct* or demonstrat* or educat ${ }^{\star}$ or aware* or teach* or inform* or chang*))

S12AB ((safety or health or accident ${ }^{\star}$ or risk ${ }^{\star}$ or behavio ${ }^{\star}$ ) N1 (reduc ${ }^{\star}$ or prevent* or train $^{\star}$ or instruct ${ }^{\star}$ or demonstrat ${ }^{\star}$ or educat $^{\star}$ or aware $^{\star}$ or teach* or inform* or chang*))

S11(MH "Health Promotion")

S10(MH "Accidents/PC")

S9(MH "Health Education")

S8(MH "School Health Services")

S7S1 OR S2 OR S3 OR S4 OR S5 OR S6

S6TI (student* or pupil ${ }^{\star}$ or peer ${ }^{\star}$ or curricul ${ }^{\star}$ or teach* or mentor $\left.{ }^{\star}\right)$ or ((young* or adolesc or teen $^{\star}$ or minor $^{\star}$ or boy ${ }^{\star}$ or girl* or youth ${ }^{\star}$ or male* or female*) N3 (educat* or school $^{\star}$ or highschool* or high?school*)) OR AB (student* or pupil or peer $^{\star}$ or curricul $^{\star}$ or teach $^{\star}$ or mentor $^{\star}$ ) or ((young ${ }^{\star}$ or adolesc or teen $^{\star}$ or minor ${ }^{\star}$ or boy ${ }^{\star}$ or girl ${ }^{\star}$ or youth* or male* or female*) N3 (educat ${ }^{\star}$ or school $^{\star}$ or highschool $^{\star}$ or high?school $\left.{ }^{\star}\right)$ )

S5(MH"Teaching")

S4(MH"Curriculum")

S3(MH "Education")

S2(MH "Students+")

S1(MH "Schools+")

ISI Web of Science: Science Citation Index Expanded, Conference Proceedings Citation Index-Science, Social Sciences Citation Index, Conference Proceedings Citation Index - Social Sciences \& Humanities (29th August 2013)

$\# 9$ \#5 and \#8

\#8 \#7 AND \#6

\#7 TS= (prevent ${ }^{\star}$ OR control ${ }^{\star}$ or reduc $\left.{ }^{\star}\right)$

\#6 TS= (injur ${ }^{\star}$ or trauma ${ }^{\star}$ or wound ${ }^{\star}$ or contusion ${ }^{\star}$ or burn ${ }^{\star}$ or rupture or damag $^{\star}$ )

\#5 \#4 AND \#3

\#4 TS= ((safety or health or accident ${ }^{\star}$ or risk $^{\star}$ or behavio $\left.{ }^{\star}\right)$ NEAR (reduc ${ }^{\star}$ or prevent ${ }^{\star}$ or train ${ }^{\star}$ or instruct ${ }^{\star}$ or demonstrat $^{\star}$ or educat or $^{\star}$ aware $^{\star}$ or teach* or inform* or chang $^{\star}$ or learn $^{\star}$ or counsel $\left.{ }^{\star}\right)$ )

$\# 3$ \#2 and \#1

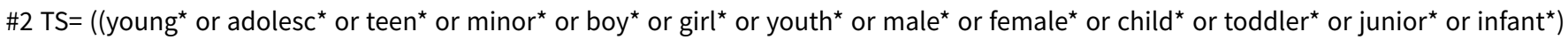
NEAR (educat ${ }^{\star}$ or school ${ }^{\star}$ or highschool ${ }^{\star}$ or high?school ${ }^{\star}$ or preschool* or pre?school ${ }^{\star}$ or kindergarten $\left.{ }^{\star}\right)$ )

$\# 1$ TS $=\left(\right.$ school $^{\star}$ or student ${ }^{\star}$ or education or curriculum or teach* ${ }^{\star}$ or mentor ${ }^{\star}$ or peergroup ${ }^{\star}$ )

ISI Web of Science Core Collection, 2016 Update.

As all of the included studies are indexed on the main biomedical databases (MEDLINE, Embase and/or PsycINFO) (with the exception of (Sun 2004) and (Zirkle 2005) (theses)) we took the decision to run a cited reference search for reports of all included studies (to date), rather than a full basic search on the Web of Science.

The authors have also conducted their own, extensive searches on a host of other social science and educational resources to compliment Cochrane MECIR conduct standard (c24). For further details of MECIR, please see: http://editorial-unit.cochrane.org/mecir

School-based education programmes for the prevention of unintentional injuries in children and young people (Review) 
ZETOC (1993 to 29th August 2013)

General: education AND safety AND "injury prevention"

\section{Appendix 2. Search strategies 2}

\section{The following searches were re-run up to 14 October 2016}

\section{LILACS}

English MeSH, keywords in Spanish and Portuguese

1. Schools/

2. Students/

3. Education/

4. Curriculum/

5. Teaching/

6. student or teach

7. ((young or adolescent or boy or girl or female or male) and (education or school)

8. or/1-7

9. School health services/

10. Health education/

11. Accident prevention/

12. Health promotion/

13. Risk reduction behavior/

14. Health knowledge, attitudes and practice/

15. ((safety or health or accident) and (education or prevention or reduction)

16. or/9-15

17. (injury and (prevention or reduction or control)

18. Violence/

19. 8 and 16 and 17 not 18

(((MH:Schools) OR (MH:students) OR (MH:education) OR (MH:curriculum) OR (MH:teaching) OR AB:(aluno\$ OR estudiante\$ OR alumno\$ OR collegial\$ OR cursante\$ OR educando\$ OR escolar\$ OR ensinar\$ OR Enseñar\$ OR adoctrinar\$ OR aleccionar\$ OR instruir\$) OR ((jovem \$ OR joven\$ OR juvenile\$ OR adolescente\$ OR garoto\$ OR menino\$ OR muchacho\$ OR niño\$ OR peque\$ OR garota\$ OR menina\$ OR muchacha\$ OR niña\$ OR zagalaor\$ OR fêmea\$ OR feminino\$ OR mujer\$ OR masculino\$ OR hombre\$ OR varon\$) AND (educação\$ OR educación\$ OR enseñanza\$ OR formación\$ OR instrucción\$ OR escola\$ OR escuela\$ OR academia\$ OR colegio\$ OR conservatorio\$ OR liceo\$))) AND ((MH:school health services) OR (MH:health education) OR (MH:accident prevention) OR (MH:health promotion) OR (MH:risk reduction behaviour) OR (MH:health knowledge, attitudes and practice) OR ((segurança\$ OR saúde\$ OR salud\$ OR sanidad\$ OR acidente \$ OR accidente\$ OR contingencia\$ OR percance\$) AND (educação\$ OR educación\$ OR enseñanza\$ OR formación\$ OR instrucción\$ OR reduccion\$ OR ensinar\$ OR Enseñar\$ OR adoctrinar\$ OR aleccionar\$ OR instruir\$ OR inibição\$ OR impedimento\$ OR obstáculo\$ OR prevención\$ OR prevenção\$))) AND ((ferimento\$ OR lesion\$ OR herida\$ OR lastimadura\$ OR daño\$ OR lisiadura) AND (prevenção\$ OR prevención\$ OR control\$ OR manejo\$ OR inibição\$ OR impedimento\$ OR obstáculo\$ OR reduccion\$ OR achicamiento\$ OR redução\$ OR diminuição\$ OR baixa\$)) AND NOT (MH:violence))

\section{PyschINFO}

1. $\exp$ Schools/

2. exp Students/

3. *Education/

4. *Curriculum/

5. *Teaching/

6. (student ${ }^{\star}$ or pupil ${ }^{\star}$ or peer?group ${ }^{\star}$ or peergroup ${ }^{\star}$ or peer $^{\star}$ or curricul ${ }^{\star}$ or teach ${ }^{\star}$ or mentor $\left.^{\star}\right)$. ab,ti.

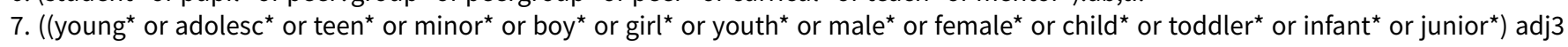
(educat ${ }^{\star}$ or school ${ }^{\star}$ or highschool ${ }^{*}$ or high?school* or pre?school* or preschool* or kindergarten*)).mp.

8. or/1-7

9. * School Health Services/

10. *Health Education/

11. *Accident prevention/

12. *Health promotion/

13. *Risk reduction behavior/

14. *Health Knoweldge, Attitudes, Practice/

15. ((safety or health or accident ${ }^{\star}$ or risk ${ }^{\star}$ or behavio*) adj1 (reduc ${ }^{\star}$ or prevent* or train $^{\star}$ or instruct ${ }^{\star}$ or demonstrat* or educat* or aware*

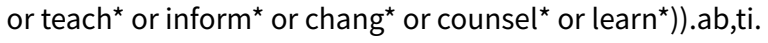

16. or/9-15

17.8 and 16

18. exp "Wounds and Injuries"/pc [Prevention \& Control]

School-based education programmes for the prevention of unintentional injuries in children and young people (Review) 
19. (injur ${ }^{\star}$ adj3 (prevent* or control $^{\star}$ or reduc $\left.\left.{ }^{\star}\right)\right) \cdot a b, t i$.

20. 18 or 19

21.17 and 20

changes to searches in June 2015 resulting from Psychinfo moving to being hosted by Proquest

18.Wounds and injuries

19. exp Accident Prevention/ or exp Prevention/

20. 18 and 19

21. (injur ${ }^{\star}$ adj3 (prevent ${ }^{\star}$ or control* or reduc $\left.\left.^{\star}\right)\right) \cdot$ ab,ti.

22. 20 or 21

23.17 and 22

\section{ERIC}

1. SU.EXACT.EXPLODE("Schools")

2. SU.EXACT.EXPLODE("Students")

3. SU.EXACT("Education")

4. SU.EXACT("Curriculum")

5. SU.EXACT("Teaching")

6. AB,TI(student ${ }^{\star}$ or pupil* or peer?group ${ }^{\star}$ or peergroup ${ }^{\star}$ or peer ${ }^{\star}$ or curricul ${ }^{\star}$ or teach $^{\star}$ or mentor ${ }^{\star}$ )

7. ((young ${ }^{\star}$ or adolesc ${ }^{\star}$ or teen ${ }^{\star}$ or minor ${ }^{\star}$ or boy ${ }^{\star}$ or girl ${ }^{\star}$ or youth ${ }^{\star}$ or male* or female or child $^{\star}$ or toddler or infant $^{\star}$ or junior $^{\star}$ ) NEAR/3 (educat ${ }^{\star}$ or school ${ }^{\star}$ or highschool* or high?school ${ }^{\star}$ or preschool ${ }^{\star}$ or pre?school ${ }^{\star}$ or kindergarten $\left.{ }^{\star}\right)$ )

8. or/1-7

9. SU.EXACT("School Health Services")

10. SU.EXACT("Health Education")

11. SU.EXACT("Accident Prevention")

12. SU.EXACT("Health Promotion")

13. AB,TI((safety or health or accident* or risk ${ }^{\star}$ or behavio $\left.{ }^{\star}\right)$ near/1 (reduc ${ }^{\star}$ or prevent ${ }^{\star}$ or train ${ }^{\star}$ or instruct or demonstrat $^{\star}$ or educat $^{\star}$ or $^{*}$ aware $^{\star}$ or teach ${ }^{\star}$ or inform ${ }^{\star}$ or chang ${ }^{\star}$ or counsel $^{\star}$ or learn $\left.{ }^{\star}\right)$ )

14. or/9-13

15. AB,TI(injur ${ }^{\star}$ near/3 (prevent ${ }^{\star}$ or control ${ }^{\star}$ or reduc $\left.{ }^{\star}\right)$ )

16. 14 and 15

17.8 and 16

Dissertation abstracts online

1. SU.EXACT.EXPLODE("Schools")

2. SU.EXACT.EXPLODE("Students")

3. SU.EXACT("Education")

4. SU.EXACT("Curriculum")

5. SU.EXACT("Teaching")

6. AB,TI(student ${ }^{\star}$ or pupil ${ }^{\star}$ or peer?group ${ }^{\star}$ or peergroup ${ }^{\star}$ or peer ${ }^{\star}$ or curricul ${ }^{\star}$ or teach $^{\star}$ or mentor ${ }^{\star}$ )

7. ((young ${ }^{\star}$ or adolesc or teen $^{\star}$ or minor ${ }^{\star}$ or boy ${ }^{\star}$ or girl ${ }^{\star}$ or youth ${ }^{\star}$ or male* or female $^{\star}$ or child ${ }^{\star}$ or toddler or infant $^{\star}$ or junior ${ }^{\star}$ ) NEAR/3 (educat ${ }^{\star}$ or school* or highschool $^{\star}$ or high?school ${ }^{\star}$ or preschool ${ }^{\star}$ or pre?school ${ }^{\star}$ or kindergarten $\left.{ }^{\star}\right)$ )

8. or/1-7

9. SU.EXACT("Health Education")

10. SU.EXACT("Accident prevention")

11. SU.EXACT("Health promotion")

12. AB,TI((safety or health or accident* or risk $^{\star}$ or behavio*) NEAR/1 (reduc or prevent $^{\star}$ or train ${ }^{\star}$ or instruct $^{\star}$ or demonstrat $^{\star}$ or educat $^{\star}$ or aware or teach $^{\star}$ or inform ${ }^{\star}$ or chang $^{\star}$ or counsel ${ }^{\star}$ or learn $\left.{ }^{\star}\right)$ )

13. or/9-12

14. 8 and 13

15. AB,TI(injur ${ }^{\star}$ NEAR/3 (prevent* or control $^{\star}$ or reduc $\left.\left.{ }^{\star}\right)\right)$

16. 14 and 15

17. Date limits $1988-2013$

14 October 2016 - This database has transferred to Dissertations and Theses so now incorporated into that search.

IBSS

1. SU.EXACT.EXPLODE("Schools")

2. SU.EXACT.EXPLODE("Students")

3. SU.EXACT("Education")

4. SU.EXACT("Curriculum")

5. SU.EXACT("Teaching")

School-based education programmes for the prevention of unintentional injuries in children and young people (Review) 
6. AB,TI(student ${ }^{\star}$ or pupil ${ }^{\star}$ or peer?group ${ }^{\star}$ or peergroup ${ }^{\star}$ or peer $^{\star}$ or curricul ${ }^{\star}$ or teach $^{\star}$ or mentor ${ }^{\star}$ )

7. ((young ${ }^{\star}$ or adolesc ${ }^{\star}$ or teen ${ }^{\star}$ or minor ${ }^{\star}$ or boy ${ }^{\star}$ or girl ${ }^{\star}$ or youth ${ }^{\star}$ or male or female $^{\star}$ or child ${ }^{\star}$ or toddler ${ }^{\star}$ or infant ${ }^{\star}$ or junior ${ }^{\star}$ ) NEAR/3 (educat ${ }^{\star}$ or school ${ }^{\star}$ or highschool ${ }^{\star}$ or high?school ${ }^{\star}$ or preschool ${ }^{\star}$ or pre?school ${ }^{\star}$ or kindergarten $\left.{ }^{\star}\right)$ )

8. or/1-7

9. SU.EXACT("Health educaton")

10. SU.EXACT("Health promotion")

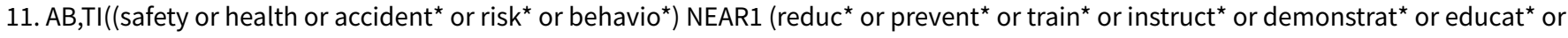
aware $^{\star}$ or teach ${ }^{\star}$ or inform ${ }^{\star}$ or chang ${ }^{\star}$ or counsel* or learn $\left.{ }^{\star}\right)$ )

12. or/9-11

13. 8 and 12

14. AB,TI(injur ${ }^{\star}$ NEAR/3 (prevent ${ }^{\star}$ or control ${ }^{\star}$ or reduc $\left.{ }^{\star}\right)$ )

15. 13 and 14

\section{Open Grey}

1. student ${ }^{\star}$ OR pupil ${ }^{\star}$ OR peer?group ${ }^{\star}$ OR peergroup ${ }^{\star}$ OR peer $^{\star}$ curricul $^{\star}$ OR teach ${ }^{\star}$ OR mentor $^{\star}$

2. young ${ }^{\star}$ OR adolesc ${ }^{\star}$ OR teen ${ }^{\star}$ OR minor ${ }^{\star}$ OR boy ${ }^{\star}$ OR girl ${ }^{\star}$ OR youth* OR male* OR female* OR child* OR toddler ${ }^{\star}$ OR infant ${ }^{\star}$ OR junior

3. "schools" OR "students" OR "education" OR "curriculum" OR "teaching"

4. 1 or 2 or 3

5. ((safety OR health OR accident* OR risk ${ }^{\star}$ OR behavio*) NEAR/1 (reduc ${ }^{\star}$ OR prevent* OR train* OR instruct ${ }^{\star}$ OR demonstrat $^{\star}$ OR educat* OR aware ${ }^{\star}$ OR teach* ${ }^{\star}$ OR inform ${ }^{\star}$ OR chang* OR counsel ${ }^{\star}$ OR learn $\left.{ }^{\star}\right)$ )

6. "school health service*" OR "health educat" ${ }^{\star}$ OR "accident prevent" ${ }^{\star}$ OR "risk reduc* behavio*" OR "health* knowledge" OR "health* attitude*" OR "health* practice*"

7.5 or 6

8. (injur ${ }^{\star}$ NEAR/3 (prevent ${ }^{\star}$ OR control ${ }^{\star}$ OR reduc $\left.{ }^{\star}\right)$ )

9. 4 and 7 and 9

Appended 14 October 2016

student $^{\star}$ AND (safety OR health OR accident* OR risk* OR behav*) AND injur*

\section{Index to Theses}

Standard search:

Title: (injur ${ }^{\star} w / 3$ (prevent* or control $^{\star}$ or reduc $\left.\left.{ }^{\star}\right)\right)$ and

Title: (reduc ${ }^{\star}$ or prevent ${ }^{\star}$ or train ${ }^{\star}$ or instruct ${ }^{\star}$ or demonstrat* or educat $^{\star}$ or aware or teach $^{\star}$ or inform ${ }^{\star}$ or chang or counsel $^{\star}$ or learn $^{\star}$ )

changes to searches in June 2015 resulting from Index to Theses moving to being hosted by Proquest

Title: (injur ${ }^{\star} w / 3\left(\right.$ prevent $^{\star}$ or control* or reduc $\left.\left.{ }^{\star}\right)\right)$ and

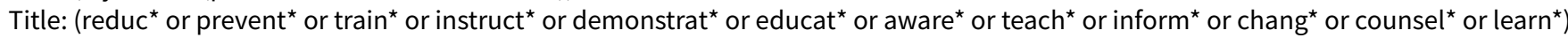

Appended 14 October 2016

Title: (injur ${ }^{\star} \mathrm{n} / 3\left(\right.$ prevent $^{\star}$ or control ${ }^{\star}$ or reduc $\left.\mathrm{c}^{\star}\right)$ ) and

Title: (reduc ${ }^{\star}$ or prevent ${ }^{\star}$ or train ${ }^{\star}$ or instruct ${ }^{\star}$ or demonstrat* or educat ${ }^{\star}$ or aware* or teach $^{\star}$ or inform ${ }^{\star}$ or chang $^{\star}$ or counsel* or learn ${ }^{\star}$ )

\section{EPPI-Centre}

1. student* or "pupil" or "peer?group*" or "peergroup" or "peer* curricul*" or "teach" " or "mentor"

2. "young*" NEAR "educat"

3. "young*" NEAR "schook"

4. "young*" NEAR "highschool*"

5. "young*" NEAR "high?school*"

6. or $/ 2-5$

7. "adolesc*" NEAR "educat*"

8. "adolesc" NEAR "school*"

9. "adolesc*" NEAR "highschool*"

10. "adolesc*" NEAR "high?school*"

11. or/7-10

12. "teen*" NEAR "educat*"

13. "teen*" NEAR "school*"

14. "teen" ${ }^{\star}$ NEAR "highschoo*"

15. "teen*" NEAR "high?school*"

16. or $/ 12-15$

17. "minor ${ }^{\star} "$ NEAR "educat*"

18. "minor*" NEAR "school*"

School-based education programmes for the prevention of unintentional injuries in children and young people (Review) 
19. "minor*" NEAR "highschool*"

20. "minor*" NEAR "high?school*"

21. or/17-20

22. "boy*" NEAR "educat"

23. "boy" "NEAR "school*"

24. "boy " NEAR "highschool ${ }^{\star "}$

25. "boy*" NEAR "high?school*"

26. or/22-25

27. "girl*" NEAR "educat*"

28. "girl*" NEAR "school*"

29. "girl" NEAR "highschool ${ }^{\star "}$

30. "girl*" NEAR "high?school*"

31. or/27-30

32. "youth*" NEAR "educat*"

33. "youth" NEAR "school*"

34. "youth*" NEAR "highschool*"

35. "youth*" NEAR "high?school*"

36. or/32-35

37. "male*" NEAR "educat ${ }^{\star \prime}$

38. "male*" NEAR "school*"

39. "male*" NEAR "highschool*"

40. "male*" NEAR "high?school*"

41. or/37-40

42. "female*" NEAR "educat ${ }^{\star} "$

43. "female*" NEAR "school ${ }^{\star \prime}$

44. "female*" NEAR "highschool*"

45. "female*" NEAR "high?school*"

46. or/42-45

47.6 or 11 or 16 or 21 or 26 or 31 or 36 or 41 or 46

48. Characteristics of the study population: children OR young people

49. 1 or 48

50.47 or 49

51 . Focus of the report: education system

52.50 or 51

53. Intervention site(s): educational institution or preschool or primary education or secondary education or tertiary education

54.52 or 53

55. Focus of the report: accidents or health promotion or injury

56. "safety*" NEAR "reduc*"

57. "safety*" NEAR "prevent*"

58. "safety*" NEAR "train*"

59. "safety" NEAR "instruct*"

60. "safety*" NEAR "demonstrat*"

61. "safety" " NEAR "educat*"

62. "safety*" NEAR "aware*"

63. "safety*" NEAR "teach"

64. "safety" ${ }^{\star}$ NEAR "inform"

65. "safety" NEAR "chang*"

66. or/56-65

67. "health" NEAR "reduc*"

68. "health" NEAR "prevent*"

69. "health*" NEAR "train*"

70. "health" NEAR "instruct ${ }^{\star "}$

71. "health*" NEAR "demonstrat*"

72. "health*" NEAR "educat*"

73. "health" NEAR "aware*"

74. "health*" NEAR "teach"

75. "health" NEAR "inform*"

76. "health*" NEAR "chang"

77. or/67-76

78. "accident ${ }^{\star} "$ NEAR "reduc ${ }^{*}$

79. "accident*" NEAR "prevent*"

80. "accident" NEAR "train"

School-based education programmes for the prevention of unintentional injuries in children and young people (Review) 
81. "accident*" NEAR "instruct*"

82. "accident ${ }^{*}$ " NEAR "demonstrat*"

83. "accident" ${ }^{\star}$ NEAR "educat ${ }^{\star "}$

84. "accident" NEAR "aware*"

85. "accident ${ }^{\star}$ NEAR "teach"

86. "accident ${ }^{\star}$ "NEAR "inform"

87. "accident*" NEAR "chang*"

88. or/78-87

89. "risk*" NEAR "reduc*"

90. "risk*" NEAR "prevent"

91. "risk" NEAR "train*"

92. "risk*" NEAR "instruct*"

93. "risk" NEAR "demonstrat ${ }^{\star} "$

94. "risk" NEAR "educat*"

95. "risk" "NEAR "aware*"

96. "risk" NEAR "teach"

97. "risk*" NEAR "inform*"

98. "risk*" NEAR "chang*"

99. or/89-98

100. "behavio*" NEAR "reduc*"

101. "behavio*" NEAR "prevent*"

102. "behavio*" NEAR "train*"

103. "behavio*" NEAR "instruct*"

104. "behavio*" NEAR "demonstrat*"

105. "behavio*" NEAR "educat*"

106. "behavio*" NEAR "aware*"

107. "behavio*" NEAR "teach*"

108. "behavio*" NEAR "inform*"

109. "behavio*" NEAR "chang*"

110. or/100-109

111.66 or 77 or 88 or 99 or 110

112. 55 or 111

113. 52 and 112

114. "injur*" NEAR "control*"

115. "injur*" NEAR "prevent ${ }^{\star "}$

116. 114 or 115

117. 113 and 116

\section{British Education Index}

1. SU.EXACT.EXPLODE("Schools")

2. SU.EXACT.EXPLODE("Students")

3. SU.EXACT("Education")

4. SU.EXACT("Curriculum")

5. SU.EXACT("Teaching")

6. AB,TI(student ${ }^{\star}$ or pupil ${ }^{\star}$ or peer?group ${ }^{\star}$ or peergroup ${ }^{\star}$ or peer $^{\star}$ or curricul ${ }^{\star}$ or teach $^{\star}$ or mentor ${ }^{\star}$ )

7. ((young or adolesc $^{\star}$ or teen ${ }^{\star}$ or minor ${ }^{\star}$ or boy ${ }^{\star}$ or girl ${ }^{\star}$ or youth ${ }^{\star}$ or male* or female $^{\star}$ or child or toddler $^{\star}$ or infant ${ }^{\star}$ or junior ${ }^{\star}$ ) NEAR/3

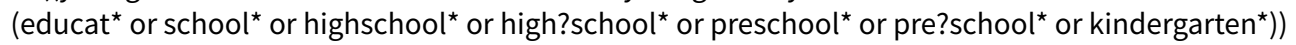

8. or/1-7

9. SU.EXACT("School Health Services")

10. SU.EXACT("Health education")

11. SU.EXACT("Accident prevention")

12. AB,TI((safety or health or accident ${ }^{\star}$ or risk ${ }^{\star}$ or behavio*) NEAR/1 (reduc ${ }^{\star}$ or prevent ${ }^{\star}$ or train ${ }^{\star}$ or instruct* or demonstrat $^{\star}$ or educat $^{\star}$ or aware* or teach $^{\star}$ or inform ${ }^{\star}$ or chang $^{\star}$ or counsel ${ }^{\star}$ or learn $\left.{ }^{\star}\right)$ )

13. 9 or 10 or 11 or 12

14. AB,TI(injur ${ }^{\star} \mathrm{NEAR} / 3$ (prevent ${ }^{\star}$ or control* or reduc $\left.^{\star}\right)$ )

15. 13 and 14

16. 8 and 15

changes to searches in June 2015 resulting from BEI moving to being hosted by EBSCO

S1 (MH "Schools+")

S2 (MH "Students+")

School-based education programmes for the prevention of unintentional injuries in children and young people (Review) 
S3 (MH "Education")

S4 (MH"Curriculum")

S5 (MH"Teaching")

S6 TI (student ${ }^{\star}$ or pupil ${ }^{\star}$ or peer ${ }^{\star}$ or curricul ${ }^{\star}$ or teach* or mentor ${ }^{\star}$ ) or ((young* or adolesc ${ }^{\star}$ or teen ${ }^{\star}$ or minor ${ }^{\star}$ or boy ${ }^{\star}$ or girl $^{\star}$ or youth ${ }^{\star}$ or male* or female*) N3 (educat* or school* or highschool* or high?school*)) OR AB (student* or pupil* or peer ${ }^{\star}$ or curricul* or teach* or

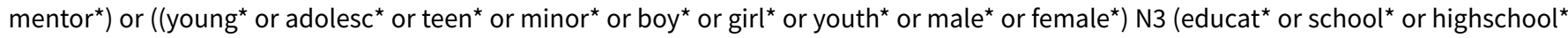
or high?school $\left.\left.{ }^{*}\right)\right)$

S7 S1 OR S2 OR S3 OR S4 OR S5 OR S6

S8 (MH "School Health Services")

S9 (MH "Health Education")

S10 (MH "Accidents/PC")

S11 (MH "Health Promotion")

S12 AB ((safety or health or accident* or risk ${ }^{\star}$ or behavio*) N1 (reduc ${ }^{\star}$ or prevent ${ }^{\star}$ or train ${ }^{\star}$ or instruct ${ }^{\star}$ or demonstrat ${ }^{\star}$ or educat ${ }^{\star}$ or aware* or teach* or inform* or chang $\left.\left.{ }^{\star}\right)\right)$

S13 TI ((safety or health or accident* or risk ${ }^{\star}$ or behavio*) N1 (reduc* or prevent ${ }^{\star}$ or train ${ }^{\star}$ or instruct* or demonstrat $^{\star}$ or educat $^{\star}$ or aware* $^{\star}$ or teach* or inform* or chang*))

S14 S8 OR S9 OR S10 OR S11 OR S12 OR S13

S15 S7 AND S14

S16 TX (injur N3 (prevent $^{\star}$ or control $\left.\left.{ }^{\star}\right)\right)$

S17 (MH "Wounds and Injuries+/PC")

S18 S16 OR S17

S19 S15 AND S18 (Limiters - Exclude MEDLINE records)

\section{ASSIA}

1. SU.EXACT.EXPLODE("Schools")

2. SU.EXACT.EXPLODE("Students")

3. SU.EXACT("Education")

4. SU.EXACT("Curriculum")

5. SU.EXACT("Teaching")

6. AB,TI(student ${ }^{\star}$ or pupil ${ }^{\star}$ or peer?group ${ }^{\star}$ or peergroup ${ }^{\star}$ or peer $^{\star}$ or curricul ${ }^{\star}$ or teach $^{\star}$ or mentor ${ }^{\star}$ )

7. ((young ${ }^{\star}$ or adolesc ${ }^{\star}$ or teen ${ }^{\star}$ or minor ${ }^{\star}$ or boy ${ }^{\star}$ or girl ${ }^{\star}$ or youth ${ }^{\star}$ or male* or female* or child ${ }^{\star}$ or toddler $^{\star}$ or infant $^{\star}$ or junior $^{\star}$ ) NEAR/3 (educat ${ }^{\star}$ or school ${ }^{\star}$ or highschool ${ }^{\star}$ or high?school ${ }^{\star}$ or preschool ${ }^{\star}$ or pre?school* or kindergarten*))

8. or/1-7

9. SU.EXACT("Health Education")

10. SU.EXACT.EXPLODE("Prevention")

11. SU.EXACT("Health promotion")

12. SU.EXACT("Risk reduction")

13. AB,TI((safety OR health OR accident* OR risk* OR behavio*) NEAR/1 (reduc* OR prevent* OR train* OR instruct* OR demonstrat* OR educat ${ }^{\star}$ OR aware ${ }^{\star}$ OR teach* OR inform* OR chang* OR counsel* or learn*))

14. or/9-13

15. AB,TI(injur ${ }^{\star}$ NEAR/3 (prevent* or control* or reduc $\left.^{\star}\right)$ )

16. 8 and 14 and 15

17. Date limits 1987-2013

Appended 14 October 2016 - date limits changed to 1987-2016

\section{CSA Sociological Abstracts}

\section{SU.EXACT.EXPLODE("Schools")}

2. SU.EXACT.EXPLODE("Students")

3. SU.EXACT("Education")

4. SU.EXACT("Curriculum")

5. SU.EXACT("Teaching")

6. $\mathrm{AB}, \mathrm{TI}\left(\right.$ student $^{\star}$ or pupil* or peer?group ${ }^{\star}$ or peergroup ${ }^{\star}$ or peer ${ }^{\star}$ or curricul* or teach $^{\star}$ or mentor ${ }^{\star}$ )

7. ((young ${ }^{\star}$ or adolesc ${ }^{\star}$ or teen ${ }^{\star}$ or minor ${ }^{\star}$ or boy ${ }^{\star}$ or girl ${ }^{\star}$ or youth ${ }^{\star}$ or male* or female* or child* or toddler $^{\star}$ or infant $^{\star}$ or junior $^{\star}$ ) NEAR/3

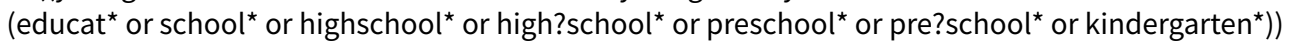

8. or/1-7

9. SU.EXACT("Health education")

10. SU.EXACT("Health behavior")

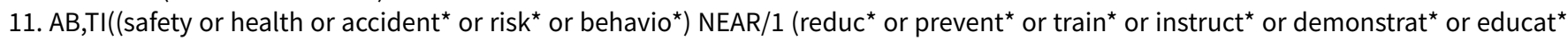
or aware* or teach* or inform* or chang* or counsel $^{\star}$ or learn $\left.{ }^{\star}\right)$ )

12. 9 or 10 or 11

13. 8 and 12 
14. AB,TI(injur ${ }^{\star}$ NEAR/3 (prevent ${ }^{\star}$ or control $^{\star}$ or reduc $\left.{ }^{\star}\right)$ )

15. 13 and 14

\section{SafetyLit}

BT schools or BT students or NT curriculum textword(s) Exact

BT health education or BT accident prevention or BT health promotion textword(s) Exact

prevent $^{\star}$ or control ${ }^{\star}$ or reduc ${ }^{\star}$ textword+synonyms

1 and 2 and 3

Date limits 1998-2013

\section{EconLit}

1. SU.EXACT("Allocative Efficiency, Cost-Benefit Analysis (D610)")

2. (SU.exact("BENEFIT COST ANALYSIS") OR SU.exact("COST BENEFIT ANALYSIS") OR SU.exact("COST BENEFIT ANALYSIS") OR SU.exact("COST BENEFIT ANALYSES") OR SU.exact("COST BENEFIT ANALYSIS 03601") OR SU.exact("COST BENEFIT ANALYSES") OR SU.exact("COST BENEFIT ANALYSIS"))

3. (SU.exact("COST EFFECTIVENESS ANALYSIS 04491") OR SU.exact("COST EFFECTIVENESS ANALYSIS"))

4. AB,TI(cost utility analysis)

5. AB,TI(cost NEAR estimate*)

6. AB,TI(cost NEAR variable*)

7. AB,TI(unit NEAR cost*)

8. or/1-7

9. SU.EXACT.EXPLODE("Schools")

10. SU.EXACT("Education")

11. SU.EXACT("Teaching")

12. AB,TI(student ${ }^{\star}$ or pupil ${ }^{\star}$ or peer?group ${ }^{\star}$ or peergroup ${ }^{\star}$ or peer ${ }^{\star}$ or curricul $^{\star}$ or teach $^{\star}$ or mentor ${ }^{\star}$ )

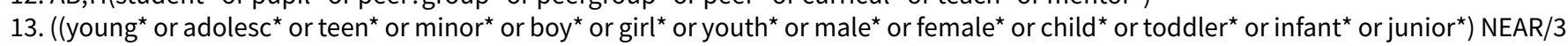
(educat ${ }^{\star}$ or school ${ }^{\star}$ or highschool ${ }^{\star}$ or high?school ${ }^{\star}$ or preschool $^{\star}$ or pre?school ${ }^{\star}$ or kindergarten $\left.{ }^{\star}\right)$ )

14. or/9-13

15. ((safety or health or accident ${ }^{\star}$ or risk* or behavio*) NEAR/1 (reduc* or prevent ${ }^{\star}$ or train* or instruct* or demonstrat $^{\star}$ or educat $^{\star}$ or $^{\star}$ aware $^{\star}$ or teach ${ }^{\star}$ or inform ${ }^{\star}$ or chang ${ }^{\star}$ or counsel ${ }^{\star}$ or learn $\left.{ }^{\star}\right)$ )

16. 8 and 14 and 15

17. SU.EXACT.EXPLODE("Injury")

18. AB,TI(injur* NEAR/3 (prevent* or control* or reduc $\left.{ }^{\star}\right)$ )

19. 17 or 18

20. AB,TI(cost* NEAR/5 (ratio* OR resource* OR unit* OR variable* OR utilit* OR effect* OR benefi* OR sav* OR injur ${ }^{\star}$ OR "quality-adjusted life year" $\left.{ }^{\star}\right)$ )

21. AB,TI(estimate ${ }^{\star}$ NEAR/3 (resource* OR cost $\left.{ }^{\star}\right)$ )

22. 19 and ( 20 or 21$)$

16 and 22

\section{TRoPHI}

1. Freetext: school $^{*}$

2. Freetext: student ${ }^{\star}$

3. Freetext: curriculum ${ }^{\star}$

4. Freetext: teaching

5. Freetext: pupil ${ }^{*}$

6. Freetext: "peer* group*"

7. Freetext: "peer curricul"

8. Freetext: teach*

9. Freetext: mentor*

10. Freetext: young*

11. Freetext: adolesc *

12. Freetext: teen ${ }^{\star}$

13. Freetext: minor ${ }^{\star}$

14. Freetext: boy ${ }^{\star}$

15. Freetext: girl ${ }^{\star}$

16. Freetext: youth*

17. Freetext: male*

18. Freetext: female ${ }^{\star}$

19. Freetext: child*

20. Freetext: toddler ${ }^{\star}$

21. Freetext: infant ${ }^{\star}$ 
22. Freetext: junior*

23. 1 OR 2 OR 3 OR 4 OR 5 OR 6 OR 7 OR 8 OR 9 OR 10 OR 11 OR 12 OR 13 OR 14 OR 15 OR 16 OR 17 OR 18 OR 19 OR 20 OR 21 OR 22

24. Freetext: "health educat*"

25. Freetext: "accident prevent ${ }^{\star "}$

26. Freetext: "health promotion"

27. Focus of the report: health promotion

28. Freetext: "safety" near "reduc*"

29. Freetext: "safety*" NEAR "prevent ${ }^{\star "}$

30. Freetext: "safety*" NEAR "train*"

31. Freetext: "safety*" NEAR "instruct"

32. Freetext: "safety*" NEAR "demonstrat*"

33. Freetext: "safety*" NEAR "educat"

34. Freetext: "safety*" NEAR "aware*"

35. Freetext: "safety*" NEAR "teach"

36. Freetext: "safety*" NEAR "inform*"

37. Freetext: "safety" NEAR "chang"

38. Freetext: "safety*" NEAR "counsel ${ }^{\star} "$

39. Freetext: "safety" "NEAR "learn*"

40. 28 OR 29 OR 30 OR 31 OR 32 OR 33 OR 34 OR 35 OR 36 OR 37 OR 38 OR 39

41. Freetext: "health*" NEAR "reduc*"

42. Freetext: "health*" NEAR "prevent ${ }^{\star "}$

43. Freetext: "health*" NEAR "train*"

44. Freetext: "health*" NEAR "instruct"

45. Freetext: "health" " NEAR "demonstrat*"

46. Freetext: "health*" NEAR "educat*"

47. Freetext: "health" NEAR "aware*"

48. Freetext: "health*" NEAR "teach"

49. Freetext: "health" NEAR "inform*"

50. Freetext: "health" NEAR "chang*"

51. Freetext: "health" "NEAR "counsel ${ }^{\star "}$

52. Freetext: "health*" NEAR "learn*"

53. Freetext: "accident ${ }^{\star} "$ NEAR "reduc ${ }^{\star} "$

54. Freetext: "accident ${ }^{\star}$ NEAR "prevent*"

55. Freetext: "accident*" NEAR "train"

56. Freetext: "accident ${ }^{\star} "$ NEAR "instruct*"

57. Freetext: "accident*" NEAR "demonstrat*"

58. Freetext: "accident ${ }^{\star} "$ NEAR "educat*"

59. Freetext: "accident*" NEAR "aware*"

60. Freetext: "accident ${ }^{\star}$ " NEAR "teach"

61. Freetext: "accident ${ }^{\star}$ NEAR "inform*"

62. Freetext: "accident*" NEAR "chang"

63. Freetext: "accident ${ }^{\star} "$ NEAR "counsel*"

64. Freetext: "accident ${ }^{\star} "$ NEAR "learn*"

65. 41 OR 42 OR 43 OR 44 OR 45 OR 46 OR 47 OR 48 OR 49 OR 50 OR 51 OR 52

66. 53 OR 54 OR 55 OR 56 OR 57 OR 58 OR 59 OR 60 OR 61 OR 62 OR 63 OR 64 OR 65

67. Freetext: "risk*" NEAR "reduc*"

68. Freetext: "risk*" NEAR "prevent*"

69. Freetext: "risk*" NEAR "train*"

70. Freetext: "risk*" NEAR "instruct*"

71. Freetext: "risk*" NEAR "demonstrat*"

72. Freetext: "risk*" NEAR "educat"

73. Freetext: "risk" NEAR "aware*"

74. Freetext: "risk" NEAR "teach"

75. Freetext: "risk" NEAR "inform"

76. Freetext: "risk*" NEAR "chang*"

77. Freetext: "risk*" NEAR "counsel*"

78. Freetext: "risk*" NEAR "learn*"

79. 67 OR 68 OR 69 OR 70 OR 71 OR 72 OR 73 OR 74 OR 75 OR 76 OR 77 OR 78

80. Freetext: "behavio*" NEAR "reduc*"

81. Freetext: "behavio*" NEAR "prevent*"

82. Freetext: "behavio*" NEAR "train*"

83. Freetext: "behavio*" NEAR "instruct*"

School-based education programmes for the prevention of unintentional injuries in children and young people (Review)

Copyright $\odot 2017$ The Cochrane Collaboration. Published by John Wiley \& Sons, Ltd. 
84. Freetext: "behavio*" NEAR "demonstrat*"

85. Freetext: "behavio*" NEAR "educat"

86. Freetext: "behavio*" NEAR "aware*"

87. Freetext: "behavio*" NEAR "teach"

88. Freetext: "behavio*" NEAR "inform*"

89. Freetext: "behavio*" NEAR "chang*"

90. Freetext: "behavio*" NEAR "counsel*"

91. Freetext: "behavio*" NEAR "learn*"

92. 80 OR 81 OR 82 OR 83 OR 84 OR 85 OR 86 OR 87 OR 88 OR 89 OR 90 OR 91

93. 24 OR 25 OR 26 OR 27 OR 40 OR 65 OR 66 OR 79 OR 92

94. 23 AND 93

95. Freetext: "injur*" NEAR "control*"

96. Freetext: "injur" NEAR "prevent ${ }^{\star "}$

97. Freetext: "injur*" NEAR "reduc ${ }^{\star "}$

98. Focus of the report: injury

99. 95 OR 96 OR 97 OR 98

100. 94 AND 99

\section{H I S T O R Y}

Protocol first published: Issue 11, 2012

Review first published: Issue 12, 2016

\begin{tabular}{lll}
\hline Date & Event & Description \\
\hline 18 July 2017 & Amended & Minor edits to search section and an author affiliation \\
\hline
\end{tabular}

\section{CONTRIBUTIONS OF AUTHORS}

EO is the guarantor and co-ordinator of the review.

EO, MW, CM and DK wrote the protocol for the review.

JMM, MC, JW and MB ran the searches for the review.

JMM, EO, JW, MW, CM, MB and JS selected articles for inclusion.

EO, JMM, JW, MB, CM, MC, MW, DK and JS extracted data and undertook quality assessment.

EO, DK and JW undertook analyses.

EO, JW and JMM wrote the report.

All review authors commented on the draft.

\section{DECLARATIONS OF INTEREST}

At the time that the review started, Elizabeth Orton was the public health representative from National Health Service (NHS) Nottingham City on the steering group for the Nottingham Injury Minimisation Programme (IMPs) that is delivered in part in the school setting. However, there were no financial incentives related to this work and her future employment is not dependent upon the continued funding of the IMPs programme by NHS Nottingham City.

Denise Kendrick: author on some studies included in the review. To avoid risk of bias of including these studies in the review, all articles retrieved from the literature searches were screened independently by Jacqueline Mhizha-Murira or Jessica Whitehead and then a second author from the team. If the screening assessments differed a third author adjudicated the decision.

Caroline Mulvaney: author on some studies included in the review. To avoid risk of bias of including these studies in the review, all articles retrieved from the literature searches were screened independently by Jacqueline Mhizha-Murira or Jessica Whitehead and then a second author from the team. If the screening assessments differed a third author adjudicated the decision. 
Michael Watson: author on some studies included in the review. To avoid risk of bias of including these studies in the review, all articles retrieved from the literature searches were screened independently by Jacqueline Mhizha-Murira or Jessica Whitehead and then a second author from the team. If the screening assessments differed a third author adjudicated the decision.

Jessica Whitehead: none known.

Jacqueline Mhizha-Murira: none known

Munish Bhuchar: none known.

Joy Staniforth: none known.

\section{SOURCES OF SUPPORT}

\section{Internal sources}

- Elizabeth Orton, UK.

Salary paid by the University of Nottingham and the East Midlands NHS Healthcare Workforce Deanery

- Denise Kendrick, UK.

Salary paid by the University of Nottingham

- Michael Watson, UK.

Salary paid by the University of Nottingham

- Caroline Mulvaney, UK.

Salary paid by the University of Nottingham

\section{External sources}

- Nottingham City PCT, UK.

Financial support of GBP17,771

- National Institute for Health Research (NIHR), UK.

This project was supported by the UK National Institute for Health Research, through Cochrane Infrastructure funding to the Cochrane Injuries Group. The views and opinions expressed are those of the authors and do not necessarily reflect those of the Systematic Reviews Programme, NIHR, National Health Service or the Department of Health.

\section{DIFFERENCES BETWEEN PROTOCOLANDREVIEW}

We clarified that included studies needed to be aimed at a preventing a range of injury mechanisms. We did this by changing the wording of the types of interventions from "Primary and secondary injury prevention education aimed at reducing a range of unintentional injuries..." to "...primary and secondary injury prevention interventions aimed at reducing a range of unintentional injury mechanisms..."

The searches were first run in 2013, and were rerun up to 2 July 2015. Between the first and second searches, three of the databases had changed hosts: PsycINFO and Index to Theses became hosted by Proquest and BEI became hosted by EBSCO and some changes to the search terms were required because of this. The final MEDLINE search strategy and the search strategies adapted for each of the databases are reported in full in Appendix 1 and Appendix 2.

\section{N D EX TERMS}

\section{Medical Subject Headings (MeSH)}

*Health Knowledge, Attitudes, Practice; *Safety; ${ }^{\star}$ School Health Services; *Schools; Accident Prevention [methods]; Accidents, Traffic [prevention \& control]; Agriculture; Athletic Injuries [prevention \& control]; Controlled Before-After Studies; Cost-Benefit Analysis; Primary Prevention [economics] [*education]; Program Evaluation; Randomized Controlled Trials as Topic; Secondary Prevention [economics] [*education]; Wounds and Injuries [epidemiology] [ ${ }^{*}$ prevention \& control]

\section{MeSH check words}

Adolescent; Child; Child, Preschool; Female; Humans; Male 